\title{
Abscopal Effects in Metastatic Cancer: Is a Predictive Approach Possible to Improve Individual Outcomes?
}

\author{
Barbara Link ${ }^{1}$, Adriana Torres Crigna ${ }^{1}$, Michael Hölzel ${ }^{2}$, Frank A. Giordano ${ }^{1}$ and Olga Golubnitschaja ${ }^{3, *}$ \\ 1 Department of Radiation Oncology, University Hospital Bonn, Rheinische Friedrich-Wilhelms-Universität \\ Bonn, 53127 Bonn, Germany; Barbara.Link@ukbonn.de (B.L.); Adriana.Torres_Crigna@ukbonn.de (A.T.C.); \\ Frank.Giordano@ukbonn.de (F.A.G.) \\ 2 Institute of Experimental Oncology, University Hospital Bonn, Rheinische Friedrich-Wilhelms-Universität \\ Bonn, 53127 Bonn, Germany; michael.hoelzel@ukbonn.de \\ 3 Predictive, Preventive, Personalised (3P) Medicine, Department of Radiation Oncology, University Hospital \\ Bonn, Rheinische Friedrich-Wilhelms-Universität Bonn, 53127 Bonn, Germany \\ * Correspondence: Olga.Golubnitschaja@ukbonn.de
}

Citation: Link, B.; Torres Crigna, A.; Hölzel, M.; Giordano, F.A.;

Golubnitschaja, O. Abscopal Effects in Metastatic Cancer: Is a Predictive Approach Possible to Improve Individual Outcomes?. J. Clin. Med. 2021, 10, 5124. https://doi.org/ $10.3390 /$ jcm10215124

Academic Editor: Prakash Kulkarni

Received: 28 September 2021

Accepted: 29 October 2021

Published: 31 October 2021

Publisher's Note: MDPI stays neutral with regard to jurisdictional claims in published maps and institutional affiliations.

Copyright: (c) 2021 by the authors. Licensee MDPI, Basel, Switzerland. This article is an open access article distributed under the terms and conditions of the Creative Commons Attribution (CC BY) license (https:// creativecommons.org/licenses/by/ $4.0 /)$.
Abstract: Patients with metastatic cancers often require radiotherapy (RT) as a palliative therapy for cancer pain. RT can, however, also induce systemic antitumor effects outside of the irradiated field (abscopal effects) in various cancer entities. The occurrence of the abscopal effect is associated with a specific immunological activation in response to RT-induced cell death, which is mainly seen under concomitant immune checkpoint blockade. Even if the number of reported apscopal effects has increased since the introduction of immune checkpoint inhibition, its occurrence is still considered rare and unpredictable. The cases reported so far may nevertheless allow for identifying first biomarkers and clinical patterns. We here review biomarkers that may be helpful to predict the occurrence of abscopal effects and hence to optimize therapy for patients with metastatic cancers.

Keywords: predictive preventive personalized medicine (3PM); molecular patterns; abscopal effects; cancers; metastatic disease; radiotherapy; biomarker panel; immunotherapy; immune checkpoint inhibitors; multi-level diagnostics; liquid biopsy; prognosis; artificial intelligence; big data analysis; personalized treatment algorithms; individual outcomes; cost-efficacy

\section{Introduction}

Radiotherapy (RT) has been widely used as an extremely effective anticancer treatment resulting in local tumor management. The targeted ionizing irradiation therapeutic effect is principally described to exert direct localized cell death through deoxyribonucleic acid (DNA) damage to promptly proliferating cells. However, preclinical studies have recognized irradiation to induce tumor recession at non-irradiated distant tumor milieus by means of tumor-specific immunity induction or immunogenic cell death (ICD) [1]. This systemic response is called the "abscopal effect" (AbE), derived from the Latin words $a b$ (position away from) and scopus (mark or target), first introduced by Mole in 1953 and later enhanced by Andrews describing of distant normal tissue effects [2,3]. In modern oncology, $\mathrm{AbE}$ is becoming increasingly important as the association between and understanding of localized irradiation and immune-mediated systemic antitumor effects are enhanced. Nevertheless, the occurrence of $\mathrm{AbE}$ is mainly described in isolated case reports.

Here, we overview the present state of clinical data concerning AbE. The aim of this review is to provide an overview of the $\mathrm{AbE}$ in different cancer entities, along with its employment in combination with chemo- and immunotherapy and identify potential predictors/biomarkers associated with RT immunogenic features for patient stratification and treatment optimization. 


\section{Historical Background}

The abscopal effect was first described and named by Mole in 1953 in a preclinical model of metastatic cancer [3]. Later his definition was broadened by Andrews to include radiation-related effects of both distant tumor and normal tissue [2,3]. Furthermore, Formenti et al. determined the abscopal response as a size shrinkage of $30 \%$ of a non-irradiated metastasis irrespective of other lesions [1]. AbE must be distinguished from bystander effects, the former being an effect that occurs at distance from the original radiation field, whereas the latter occurs as a local reaction due to radiation-induced signals from nearby irradiated cells [4].

Since its first description, AbE has been rarely observed in the clinical setting despite the millions of patients treated worldwide with local irradiation of tumor tissue in the absence of any systemic therapy. From 1969 to 2018, only 47 cases for multiple metastatic cancers including melanoma, renal cell carcinoma, lymphoma, breast cancer, and hepatocellular carcinoma following RT have been reported $[5,6]$. In Table 1, we provide case reports of AbE after RT in which no immunotherapy was utilized. We performed a literature search in PubMed up to March 2021, using as search criteria "abscopal effect" in the title and/or abstract and filtering for case reports. Results revealed nine additional AbE reports correlated with RT only.

Table 1. Abscopal effect case reports (no immunotherapy).

\begin{tabular}{|c|c|c|c|c|c|c|c|c|c|c|c|c|}
\hline Reference & Age & Gender & Histo-pathology & $\begin{array}{c}\text { Primary } \\
\text { Tumor Site }\end{array}$ & $\begin{array}{l}\text { Treatment of } \\
\text { Orimary Tumor }\end{array}$ & $\begin{array}{l}\text { Metastasis } \\
\text { Site }\end{array}$ & $\begin{array}{l}\text { Systemic } \\
\text { Treatment }\end{array}$ & RT & $\begin{array}{l}\text { Irradiation } \\
\text { Site }\end{array}$ & $\begin{array}{c}\text { Non- } \\
\text { Irradiated } \\
\text { Abscopal } \\
\text { Regression }\end{array}$ & $\begin{array}{c}\text { Time Frame } \\
\text { for } \\
\text { Abscopal } \\
\text { Response }\end{array}$ & $\begin{array}{c}\text { Reported } \\
\text { Parameters }\end{array}$ \\
\hline $\begin{array}{l}\text { Lome et al. } \\
\text { (1970) } \\
{[7]}\end{array}$ & 66 & M & $\begin{array}{l}\text { Transitional cell } \\
\text { carcinoma of } \\
\text { bladder }\end{array}$ & Bladder & RT & $\begin{array}{l}\text { Lung, } \\
\text { mediastinal } \\
\text { + retroperi- } \\
\text { toneal LNs, } \\
\text { adrenal } \\
\text { glands }\end{array}$ & $\mathrm{n} / \mathrm{a}$ & $\begin{array}{l}40 \text { Gy, } \\
4 \text { weeks }\end{array}$ & Pelvis & $\begin{array}{l}\text { Pulmonary } \\
\text { lesions }\end{array}$ & 5 months & $\begin{array}{c}\text { Blood pressure, } \\
\text { hematocrit, blood } \\
\text { urea nitrogen, }\end{array}$ \\
\hline $\begin{array}{c}\text { Ehlers et al. } \\
\text { (1973) } \\
{[8]}\end{array}$ & 35 & $\mathrm{~F}$ & $\begin{array}{l}\text { Adeno-carcinoma } \\
\text { (unknown origin) }\end{array}$ & Unknown & $\mathrm{n} / \mathrm{a}$ & $\begin{array}{l}\text { neck, axilla }+ \\
\text { medi- } \\
\text { astinum }\end{array}$ & $\mathrm{n} / \mathrm{a}$ & 40 Gy, 20 fr & $\begin{array}{l}\text { Neck/supra- } \\
\text { clavicular } \\
\text { LN }\end{array}$ & $\begin{array}{l}\text { Axilla and } \\
\text { medi- } \\
\text { astinum }\end{array}$ & 2 weeks & \\
\hline \multirow{2}{*}{$\begin{array}{c}\text { Antoniades } \\
\text { et al. (1977) } \\
{[9]}\end{array}$} & 44 & M & Lymphoma & $\begin{array}{c}\text { Left axillary } \\
\text { + bilateral } \\
\text { supra- } \\
\text { clavicular } \\
\text { LNs }\end{array}$ & RT & $\begin{array}{l}\text { Right lung, } \\
\text { abdominal } \\
\text { LN }\end{array}$ & $\mathrm{n} / \mathrm{a}$ & $30 \mathrm{~Gy}, 20 \mathrm{fr}$ & $\begin{array}{l}\text { LN above } \\
\text { diaphragm } \\
\text { (mantle } \\
\text { field) }\end{array}$ & $\begin{array}{l}\text { Abdominal } \\
\text { LN }\end{array}$ & $\mathrm{n} / \mathrm{a}$ & \multirow{2}{*}{$\begin{array}{c}\text { Blood cunt values: } \\
\text { hemoglobin, } \\
\text { hematocrit, white } \\
\text { blood cells (WBC), } \\
\text { platelets, } \\
\text { differential count } \\
\text { of neutrophils, } \\
\text { eosinophils, } \\
\text { basophils, } \\
\text { lymphocytes + } \\
\text { monocytes }\end{array}$} \\
\hline & 40 & M & $\begin{array}{l}\text { Lympho-cytic } \\
\text { lymphoma }\end{array}$ & $\begin{array}{c}\text { Right } \\
\text { axillary LN }\end{array}$ & RT & $\begin{array}{l}\text { Abdominal } \\
\text { LN }\end{array}$ & $\mathrm{n} / \mathrm{a}$ & $30 \mathrm{~Gy}, 20 \mathrm{fr}$ & $\begin{array}{l}\text { LN above } \\
\text { diaphragm } \\
\text { (mantle } \\
\text { field) }\end{array}$ & $\begin{array}{l}\text { Abdominal } \\
\text { LN }\end{array}$ & $\mathrm{n} / \mathrm{a}$ & \\
\hline $\begin{array}{l}\text { Fairlamb } \\
\text { et al. (1981) } \\
\text { [10] }\end{array}$ & 73 & F & $\begin{array}{c}\text { Renal cell } \\
\text { carcinoma (RCC) }\end{array}$ & Left kidney & Nephrec-tomy & $\begin{array}{l}\text { Left groin, } \\
\text { lung, hila, } \\
\text { pubic bone }\end{array}$ & $\mathrm{n} / \mathrm{a}$ & 40 Gy, 15 fr & Groin & Lung & 3 month & \\
\hline \multirow{9}{*}{$\begin{array}{l}\text { Rees et al. } \\
\text { (1981) } \\
\text { [11] }\end{array}$} & $\mathrm{n} / \mathrm{a}$ & $\mathrm{n} / \mathrm{a}$ & $\begin{array}{l}\text { Mixed-cellularity } \\
\text { Hodgkin } \\
\text { lymphoma }\end{array}$ & $\mathrm{n} / \mathrm{a}$ & $\mathrm{n} / \mathrm{a}$ & $\mathrm{n} / \mathrm{a}$ & $\mathrm{n} / \mathrm{a}$ & $\begin{array}{l}35 \text { Gy, } \\
28 \text { days }\end{array}$ & Mantle field & Pelvis & $\mathrm{n} / \mathrm{a}$ & \\
\hline & $\mathrm{n} / \mathrm{a}$ & $\mathrm{n} / \mathrm{a}$ & $\begin{array}{l}\text { Pre-dominant } \\
\text { Hodgkin }\end{array}$ & $\mathrm{n} / \mathrm{a}$ & $\mathrm{n} / \mathrm{a}$ & $\mathrm{n} / \mathrm{a}$ & $\mathrm{n} / \mathrm{a}$ & $\begin{array}{l}36 \text { Gy, } \\
24 \text { days }\end{array}$ & Mantle field & $\begin{array}{c}\text { Pelvis, } \\
\text { para-sortic } \\
\text { nodes }\end{array}$ & $\mathrm{n} / \mathrm{a}$ & \\
\hline & $\mathrm{n} / \mathrm{a}$ & $\mathrm{n} / \mathrm{a}$ & $\begin{array}{l}\text { Recurrenced } \\
\text { Hodgkin } \\
\text { unspecific }\end{array}$ & $\mathrm{n} / \mathrm{a}$ & $\mathrm{n} / \mathrm{a}$ & $\mathrm{n} / \mathrm{a}$ & $\mathrm{n} / \mathrm{a}$ & $\begin{array}{l}38 \mathrm{~Gy}, \\
39 \text { days }\end{array}$ & $\begin{array}{l}\text { Para-aortic } \\
\text { and pelvic } \\
\text { nodes }\end{array}$ & $\begin{array}{l}\text { Left axilla } \\
\text { LN }\end{array}$ & $\mathrm{n} / \mathrm{a}$ & \\
\hline & $\mathrm{n} / \mathrm{a}$ & $\mathrm{n} / \mathrm{a}$ & $\begin{array}{l}\text { Mixed-cellularity } \\
\text { Hodgkin } \\
\text { lymphoma }\end{array}$ & $\mathrm{n} / \mathrm{a}$ & $\mathrm{n} / \mathrm{a}$ & $\mathrm{n} / \mathrm{a}$ & $\mathrm{n} / \mathrm{a}$ & $\begin{array}{l}40 \mathrm{~Gy}, \\
29 \text { days }\end{array}$ & Mantle field & $\begin{array}{l}\text { Para-aortic } \\
\text { region }\end{array}$ & $\mathrm{n} / \mathrm{a}$ & \\
\hline & $\mathrm{n} / \mathrm{a}$ & $\mathrm{n} / \mathrm{a}$ & $\begin{array}{l}\text { Brill Symmers } \\
\text { disease }\end{array}$ & $\mathrm{n} / \mathrm{a}$ & $\mathrm{n} / \mathrm{a}$ & $\mathrm{n} / \mathrm{a}$ & $\mathrm{n} / \mathrm{a}$ & $\begin{array}{l}21 \mathrm{~Gy}, \\
15 \text { days }\end{array}$ & $\begin{array}{l}\text { Chest wall, } \\
\text { right } \\
\text { axillary }\end{array}$ & $\begin{array}{l}\text { Left axilla, } \\
\text { spleen }\end{array}$ & $\mathrm{n} / \mathrm{a}$ & \\
\hline & $\mathrm{n} / \mathrm{a}$ & $\mathrm{n} / \mathrm{a}$ & Lympho-sacroma & $\mathrm{n} / \mathrm{a}$ & $\mathrm{n} / \mathrm{a}$ & $\mathrm{n} / \mathrm{a}$ & $\mathrm{n} / \mathrm{a}$ & $\begin{array}{l}18 \text { Gy, } \\
13 \text { days }\end{array}$ & Right groin & $\begin{array}{l}\text { Right neck } \\
\text { LN }\end{array}$ & 2 month & \\
\hline & $\mathrm{n} / \mathrm{a}$ & $\mathrm{n} / \mathrm{a}$ & Lymphoma & $\mathrm{n} / \mathrm{a}$ & $\mathrm{n} / \mathrm{a}$ & $\mathrm{n} / \mathrm{a}$ & $\mathrm{n} / \mathrm{a}$ & $\begin{array}{l}35 / 20 \mathrm{~Gy}, 34 \\
\text { days }\end{array}$ & $\begin{array}{l}\text { Right breast, } \\
\text { pelvis }\end{array}$ & $\begin{array}{l}\text { Mediastinal } \\
\text { mass }\end{array}$ & $\mathrm{n} / \mathrm{a}$ & \\
\hline & $\mathrm{n} / \mathrm{a}$ & $\mathrm{n} / \mathrm{a}$ & $\begin{array}{l}\text { Reticulum cell } \\
\text { sarcoma }\end{array}$ & $\mathrm{n} / \mathrm{a}$ & $\mathrm{n} / \mathrm{a}$ & $\mathrm{n} / \mathrm{a}$ & $\mathrm{n} / \mathrm{a}$ & $\begin{array}{l}39 \mathrm{~Gy}, 43 \\
\text { days }\end{array}$ & $\begin{array}{c}\text { Para-aortic } \\
\text { and pelvic } \\
\text { nodes }\end{array}$ & Right axilla & $\mathrm{n} / \mathrm{a}$ & \\
\hline & $\mathrm{n} / \mathrm{a}$ & $\mathrm{n} / \mathrm{a}$ & $\begin{array}{l}\text { Follicular } \\
\text { lymphoma }\end{array}$ & $\mathrm{n} / \mathrm{a}$ & $\mathrm{n} / \mathrm{a}$ & $\mathrm{n} / \mathrm{a}$ & $\mathrm{n} / \mathrm{a}$ & $\begin{array}{l}30 \mathrm{~Gy}, \\
22 \text { days }\end{array}$ & $\begin{array}{l}\text { Neck, supra- } \\
\text { clavicular } \\
\text { area }\end{array}$ & $\begin{array}{l}\text { Bilateral } \\
\text { axilla }\end{array}$ & $\mathrm{n} / \mathrm{a}$ & \\
\hline
\end{tabular}


Table 1. Cont.

\begin{tabular}{|c|c|c|c|c|c|c|c|c|c|c|c|c|}
\hline Reference & Age & Gender & Histo-pathology & $\begin{array}{c}\text { Primary } \\
\text { Tumor Site }\end{array}$ & $\begin{array}{l}\text { Treatment of } \\
\text { Orimary Tumor }\end{array}$ & $\begin{array}{l}\text { Metastasis } \\
\text { Site }\end{array}$ & $\begin{array}{l}\text { Systemic } \\
\text { Treatment }\end{array}$ & RT & $\begin{array}{l}\text { Irradiation } \\
\text { Site }\end{array}$ & $\begin{array}{c}\text { Non- } \\
\text { Irradiated } \\
\text { Abscopal } \\
\text { Regression }\end{array}$ & $\begin{array}{c}\text { Time Frame } \\
\text { for } \\
\text { Abscopal } \\
\text { Response }\end{array}$ & $\begin{array}{c}\text { Reported } \\
\text { Parameters }\end{array}$ \\
\hline $\begin{array}{l}\text { Robin et al. } \\
\quad(1981) \\
\text { [12] }\end{array}$ & 59 & F & $\begin{array}{l}\text { Histiocytic } \\
\text { lymphoma }\end{array}$ & $\begin{array}{c}\text { Right } \\
\text { kidney }\end{array}$ & COPP, BACOP & Left kidney & $\mathrm{n} / \mathrm{a}$ & 20 Gy, 10 fr & $\begin{array}{c}\text { Right } \\
\text { kidney }\end{array}$ & Left kidney & $\mathrm{n} / \mathrm{a}$ & \\
\hline \multirow[b]{2}{*}{$\begin{array}{l}\text { Rees et al. } \\
\text { (1983) } \\
\text { [13] }\end{array}$} & 49 & $\mathrm{M}$ & $\begin{array}{l}\text { Adeno-carcinoma } \\
\text { (esophagus) }\end{array}$ & Esophagus & $\mathrm{n} / \mathrm{a}$ & Lung & $\mathrm{n} / \mathrm{a}$ & $40 \mathrm{~Gy}, 20 \mathrm{fr}$ & Esophagus & Lung & 14 month & \\
\hline & $\mathrm{n} / \mathrm{a}$ & $\mathrm{n} / \mathrm{a}$ & $\begin{array}{l}\text { Adeno-carcinoma } \\
\text { (lung) }\end{array}$ & $\begin{array}{l}\text { Lung (left } \\
\text { lower lobe) }\end{array}$ & $\mathrm{n} / \mathrm{a}$ & $\begin{array}{c}\text { Mediastinum, } \\
\text { subcuta- } \\
\text { neous } \\
\text { metastases } \\
\text { (forehead, } \\
\text { left } \\
\text { shoulder) }\end{array}$ & $\mathrm{n} / \mathrm{a}$ & 35 Gy, 10 fr & $\begin{array}{l}\text { Medi- } \\
\text { astinum and } \\
\text { left lower } \\
\text { lung }\end{array}$ & $\begin{array}{c}\text { Subcutaneous } \\
\text { metastases } \\
\text { (forehead, } \\
\text { left } \\
\text { shoulder) }\end{array}$ & 2 weeks & \\
\hline $\begin{array}{c}\text { MacManus } \\
\text { et al. (1994) } \\
{[114]}\end{array}$ & 58 & M & $\begin{array}{c}\text { Renal cell } \\
\text { carcinoma (RCC) }\end{array}$ & $\begin{array}{c}\text { Right } \\
\text { kidney }\end{array}$ & RT & $\begin{array}{l}\text { Left lung, } \\
\text { paratracheal } \\
\text { lymphadeno- } \\
\text { pathy }\end{array}$ & $\begin{array}{l}\text { Medroxy- } \\
\text { proges- } \\
\text { terone } \\
\text { acetate }\end{array}$ & $20 \mathrm{~Gy}, 10 \mathrm{fr}$ & $\begin{array}{l}\text { Right } \\
\text { kidney }\end{array}$ & $\begin{array}{l}\text { Lung, } \\
\text { paratracheal } \\
\text { LN }\end{array}$ & 4 month & $\begin{array}{c}\text { TNF- } \alpha, \text { TNF- } \beta \\
\text { INF- } \gamma, \text { IL-2 } \\
\text { receptor, IL-6 }\end{array}$ \\
\hline $\begin{array}{c}\text { Ohba et al. } \\
\text { (1998) } \\
\text { [15] }\end{array}$ & 76 & M & $\begin{array}{l}\text { Hepato-cellular } \\
\text { carcinoma }\end{array}$ & Liver & Resection/CT & $\begin{array}{l}\text { Second } \\
\text { thoracic } \\
\text { vertebra }\end{array}$ & Acetate & $36 \mathrm{~Gy}, \mathrm{n} / \mathrm{a}$ & $\begin{array}{l}\text { Thoracic } \\
\text { vertebral }\end{array}$ & Liver & 10 months & $\begin{array}{c}\text { Hemoglobin, } \\
\text { leucocyte, platelet } \\
\text { count, bilirubin, } \\
\text { aspartate } \\
\text { amino-transferase, } \\
\text { alanine } \\
\text { amino-transferase, } \\
\text { albumin, alkaline } \\
\text { phosphatase, AFP, } \\
\text { PIVKA-II, IL-1 } \beta, \\
\text { IL-2, IL-4, IL-6, } \\
\text { HGF, TNF- } \alpha\end{array}$ \\
\hline $\begin{array}{c}\text { Nam et al. } \\
(2005) \\
{[16]}\end{array}$ & 65 & $\mathrm{M}$ & $\begin{array}{l}\text { Hepato-cellular } \\
\text { carcinoma }\end{array}$ & Liver & $\mathrm{n} / \mathrm{a}$ & $\begin{array}{l}\text { Skull, ribs } \\
\text { (3-6th), } \\
\text { sternum }\end{array}$ & $\mathrm{n} / \mathrm{a}$ & 30 Gy, & Skull & $\begin{array}{l}\text { Liver, ribs, } \\
\text { sternum }\end{array}$ & 10 months & AST, ALT, AFP \\
\hline \multirow{2}{*}{$\begin{array}{l}\text { Wersäll et al. } \\
\qquad(2006) \\
\text { [17] }\end{array}$} & 83 & F & $\begin{array}{c}\text { Renal cell } \\
\text { carcinoma (RCC) }\end{array}$ & $\begin{array}{c}\text { Right } \\
\text { kidney }\end{array}$ & $\mathrm{n} / \mathrm{a}$ & $\begin{array}{l}\text { Lung, LN, } \\
\text { abdomen }\end{array}$ & $\mathrm{n} / \mathrm{a}$ & $\begin{array}{l}32 \mathrm{~Gy}, \\
4 \mathrm{fr}\end{array}$ & Kidney & LN, lung & 2 years & \\
\hline & 55 & F & $\begin{array}{c}\text { Renal cell } \\
\text { carcinoma (RCC) }\end{array}$ & $\begin{array}{c}\text { Right } \\
\text { kidney }\end{array}$ & $\mathrm{n} / \mathrm{a}$ & $\begin{array}{l}\mathrm{LN} \text {, aorta, } \\
\text { liver }\end{array}$ & $\mathrm{n} / \mathrm{a}$ & $\begin{array}{l}32 \mathrm{~Gy}, \\
4 \mathrm{fr}\end{array}$ & Kidney & Lung & 5 months & \\
\hline \multirow[t]{2}{*}{$\begin{array}{l}\text { Takaya et al. } \\
(2007) \\
{[18]}\end{array}$} & \multirow[t]{2}{*}{69} & \multirow[t]{2}{*}{$\mathrm{F}$} & \multirow[t]{2}{*}{ Uterine cervix } & \multirow[t]{2}{*}{ Pelvic } & \multirow[t]{2}{*}{$\mathrm{n} / \mathrm{a}$} & \multirow[t]{2}{*}{$\begin{array}{l}\text { Para-aortic } \\
\text { LN }\end{array}$} & \multirow[t]{2}{*}{$\mathrm{n} / \mathrm{a}$} & $\begin{array}{c}28.8 \mathrm{~Gy}, 16 \mathrm{fr} \\
22 \mathrm{~Gy}, 21 \mathrm{fr} \\
\end{array}$ & \multirow[t]{2}{*}{ Pelvis } & \multirow[t]{2}{*}{$\begin{array}{l}\text { Para-aortic } \\
\text { LN }\end{array}$} & \multirow[t]{2}{*}{$\mathrm{n} / \mathrm{a}$} & \multirow{2}{*}{$\begin{array}{l}\text { serum levels of } \\
\text { squamous cell } \\
\text { carcinoma (SCC) } \\
\text { antigen }\end{array}$} \\
\hline & & & & & & & & $\begin{array}{l}24 \mathrm{~Gy}, \\
4 \mathrm{fr}\end{array}$ & & & & \\
\hline $\begin{array}{c}\text { Isobe et al. } \\
\text { (2009) } \\
\text { [19] }\end{array}$ & 65 & M & $\begin{array}{l}\text { Natural killer cell } \\
\text { lymphoma }\end{array}$ & $\mathrm{n} / \mathrm{a}$ & $\mathrm{n} / \mathrm{a}$ & $\begin{array}{l}\text { Skin, sub- } \\
\text { mandibular } \\
\text { LN }\end{array}$ & $\begin{array}{l}\text { Chemo- } \\
\text { therapy }\end{array}$ & 40 Gy & Skin & $\begin{array}{l}\text { Sub- } \\
\text { mandibular } \\
\text { LN }\end{array}$ & 2 months & $\begin{array}{c}\text { WBC, } \\
\text { haemoglobin, } \\
\text { platelet count, } \\
\text { serum lactate } \\
\text { dehydrogenase, } \\
\text { IL-2, TIA-1, } \\
\text { granzyme b, CD2, } \\
\text { CD3, CD4, CD5, } \\
\text { CD7, CD8, CD16, } \\
\text { CD19, CD20, CD25, } \\
\text { CD30, CD38, CD56, } \\
\text { TCR } \alpha \beta, \text { TCR } \\
\gamma \delta .\end{array}$ \\
\hline $\begin{array}{l}\text { Lakshmanagowd } \\
\text { et al. (2009) } \\
\text { [20] }\end{array}$ & 65 & $\mathrm{~F}$ & $\begin{array}{c}\text { Chronic } \\
\text { lymphocytic } \\
\text { leukemia }\end{array}$ & Leukemia & $\mathrm{n} / \mathrm{a}$ & $\begin{array}{l}\text { Right } \\
\text { axillary LN, } \\
\text { right neck } \\
\text { LN }\end{array}$ & $\mathrm{n} / \mathrm{a}$ & $24 \mathrm{~Gy}, 12 \mathrm{fr}$ & $\begin{array}{c}\text { Right } \\
\text { axillary LN }\end{array}$ & $\begin{array}{l}\text { Right neck } \\
\text { LN }\end{array}$ & $\begin{array}{c}\text { During } \\
\text { treatment }\end{array}$ & \\
\hline $\begin{array}{l}\text { Okuma et al. } \\
\text { (2011) } \\
\text { [21] }\end{array}$ & 63 & M & $\begin{array}{l}\text { Hepato-cellular } \\
\text { carcinoma }\end{array}$ & Liver & $\mathrm{n} / \mathrm{a}$ & $\begin{array}{c}\text { Lung, } \\
\text { mediastinal } \\
\text { LN }\end{array}$ & $\mathrm{n} / \mathrm{a}$ & $\begin{array}{l}60.75 \mathrm{~Gy}, \\
27 \mathrm{fr}\end{array}$ & $\begin{array}{l}\text { Mediastinal } \\
\text { LN }\end{array}$ & Lung & 1 month & \\
\hline \multirow[b]{2}{*}{$\begin{array}{c}\text { Ishiyama } \\
\text { et al. (2012) } \\
\text { [22] }\end{array}$} & \multirow[b]{2}{*}{61} & \multirow[b]{2}{*}{ M } & \multirow[b]{2}{*}{$\begin{array}{c}\text { Renal cell } \\
\text { carcinoma (RCC) }\end{array}$} & \multirow[b]{2}{*}{ Left kidney } & \multirow[b]{2}{*}{ Nephrec-tomy } & \multirow{2}{*}{$\begin{array}{c}\text { Left adrenal } \\
\text { gland, lung, } \\
\text { multiple } \\
\text { mediastinal } \\
\text { + hilar LN, } \\
\text { bone, spine, } \\
\text { brain }\end{array}$} & \multirow{2}{*}{$\begin{array}{l}\mathrm{n} / \mathrm{a} \\
\mathrm{n} / \mathrm{a}\end{array}$} & $18 \mathrm{~Gy}$ & Brain & \multirow[b]{2}{*}{ Lung, LN } & \multirow[b]{2}{*}{1 month } & \\
\hline & & & & & & & & $\begin{array}{l}40 \mathrm{~Gy}, \\
5 \mathrm{fr}\end{array}$ & bone, spine & & & \\
\hline $\begin{array}{l}\text { Tubin et al. } \\
\text { (2012) } \\
\text { [23] }\end{array}$ & 72 & M & $\begin{array}{l}\text { Medullary thyroid } \\
\text { carcinoma }\end{array}$ & Thyroid & Thyroidec-tomy & $\begin{array}{c}\text { Left supra- } \\
\text { clavicular } \\
\text { LN, left infr- } \\
\text { aclavicular } \\
\text { LN, } \\
\text { mediastinal } \\
\text { LN levels 4R } \\
+6\end{array}$ & $\mathrm{n} / \mathrm{a}$ & $\begin{array}{l}30 \mathrm{~Gy}, \\
3 \mathrm{fr}\end{array}$ & 4R LN level & $6 \mathrm{LN}$ level & 1 month & \\
\hline \multirow{2}{*}{$\begin{array}{c}\text { Siva et al. } \\
\text { (2013) } \\
\text { [24] }\end{array}$} & \multirow[t]{2}{*}{78} & \multirow[t]{2}{*}{$\mathrm{F}$} & \multirow{2}{*}{$\begin{array}{l}\text { Non-small-cell } \\
\text { lung carcinoma } \\
\text { (NSCLC) }\end{array}$} & \multirow{2}{*}{$\begin{array}{l}\text { Lung (left } \\
\text { upper lobe + } \\
\text { right lower } \\
\text { lobe) }\end{array}$} & \multirow[t]{2}{*}{$\begin{array}{l}\text { Carboplatin, } \\
\text { paclitaxel, RT }\end{array}$} & \multirow{2}{*}{$\begin{array}{l}\text { Right } \\
\text { adrenal, } \\
\text { right } \\
\text { humeral } \\
\text { head }\end{array}$} & \multirow{2}{*}{$\begin{array}{l}\text { Chemo- } \\
\text { therapy } \\
\text { (carboplatin, } \\
\text { paclitaxel) }\end{array}$} & 60 Gy, 30 fr & $\begin{array}{l}\text { Left upper } \\
\text { lobe }\end{array}$ & $\begin{array}{l}\text { Right } \\
\text { adrenal, }\end{array}$ & 12 months & \\
\hline & & & & & & & & $\begin{array}{l}26 \mathrm{~Gy}, \\
1 \mathrm{fr}\end{array}$ & $\begin{array}{l}\text { Right lower } \\
\text { lobe }\end{array}$ & $\begin{array}{l}\text { humeral } \\
\text { head }\end{array}$ & & \\
\hline $\begin{array}{l}\text { Teulings } \\
\text { et al. (2013) } \\
{[25]}\end{array}$ & 67 & M & Melanoma & Left scapula & Resection & $\begin{array}{l}\text { Axilla }+ \\
\text { suprascapu- } \\
\text { lar region }\end{array}$ & $\begin{array}{l}\text { Chemo- } \\
\text { therapy }\end{array}$ & $\begin{array}{l}50 \mathrm{~Gy}, \\
30 \mathrm{fr}\end{array}$ & $\begin{array}{c}\text { Axilla }+ \\
\text { supra- } \\
\text { scapular } \\
\text { region } \\
\end{array}$ & $\mathrm{n} / \mathrm{a}$ & $\mathrm{n} / \mathrm{a}$ & $\begin{array}{c}\text { S100, CD8, CD68, } \\
\text { CD3, IL-4, IL-10, } \\
\text { Il-17, TNF- } \alpha,\end{array}$ \\
\hline & & & & & & $(\mathrm{LN})$, brain & & $\begin{array}{l}20 \mathrm{~Gy}, \\
4 \mathrm{fr}\end{array}$ & Whole brain & $\begin{array}{l}\text { Lung, medi- } \\
\text { astinum }\end{array}$ & 2 weeks & IFN- $\gamma$ \\
\hline
\end{tabular}


Table 1. Cont.

\begin{tabular}{|c|c|c|c|c|c|c|c|c|c|c|c|c|}
\hline Reference & Age & Gender & Histo-pathology & $\begin{array}{c}\text { Primary } \\
\text { Tumor Site }\end{array}$ & $\begin{array}{l}\text { Treatment of } \\
\text { Orimary Tumor }\end{array}$ & $\begin{array}{l}\text { Metastasis } \\
\text { Site }\end{array}$ & $\begin{array}{l}\text { Systemic } \\
\text { Treatment }\end{array}$ & RT & $\begin{array}{l}\text { Irradiation } \\
\text { Site }\end{array}$ & $\begin{array}{c}\text { Non- } \\
\text { Irradiated } \\
\text { Abscopal } \\
\text { Regression }\end{array}$ & $\begin{array}{c}\text { Time Frame } \\
\text { for } \\
\text { Abscopal } \\
\text { Response }\end{array}$ & $\begin{array}{c}\text { Reported } \\
\text { Parameters }\end{array}$ \\
\hline $\begin{array}{l}\text { Lock et al. } \\
\text { (2015) } \\
\text { [26] }\end{array}$ & 71 & M & $\begin{array}{l}\text { Hepato-cellular } \\
\text { carcinoma }\end{array}$ & Liver & RT & Lung & $\mathrm{n} / \mathrm{a}$ & $\begin{array}{l}70 \mathrm{~Gy}, \\
15 \mathrm{fr}\end{array}$ & Liver & Lung & 4 months & AFP, liver enzymes \\
\hline $\begin{array}{c}\text { Yarchoan } \\
\text { et al. (2015) } \\
\text { [27] }\end{array}$ & 60 & $\mathrm{M}$ & $\begin{array}{l}\text { Non-small-cell } \\
\text { lung carcinoma } \\
\text { (NSCLC) }\end{array}$ & $\begin{array}{l}\text { Lung (right } \\
\text { upper lobe) }\end{array}$ & $\mathrm{n} / \mathrm{a}$ & $\begin{array}{l}\text { Brain, hilar } \\
\text { LN, left } \\
\text { adrenal } \\
\text { gland, left } \\
\text { lower lung } \\
\text { lobe, liver }\end{array}$ & $\begin{array}{l}\text { Chemo- } \\
\text { therapy }\end{array}$ & Unknown & Brain & $\begin{array}{c}\text { Adrenal, } \\
\text { lung, + liver }\end{array}$ & 1 month & $\begin{array}{l}\text { History of tobacco } \\
\text { use, CK7, TTF-1, } \\
\text { CK20, EGFR }\end{array}$ \\
\hline $\begin{array}{l}\text { Desar et al. } \\
\text { (2016) } \\
\text { [28] }\end{array}$ & 19 & $\mathrm{M}$ & $\begin{array}{l}\text { Diffuse-type giant } \\
\text { cell tumor }\end{array}$ & Knee & $\begin{array}{l}\text { Imatinib, femoral } \\
\text { amputation }\end{array}$ & $\begin{array}{l}\text { Lung, } \\
\text { mediastinal } \\
\text { LN, right } \\
\text { hilar }\end{array}$ & $\begin{array}{l}\text { Tyrosine } \\
\text { kinase } \\
\text { receptor } \\
\text { inhibitor } \\
\text { (imatinib), } \\
\text { steroid }\end{array}$ & $\begin{array}{l}30 \mathrm{~Gy}, \\
10 \mathrm{fr}\end{array}$ & Right hilar & Left lung & 1 month & $\begin{array}{c}\text { Hemoglobulin, } \\
\text { leukocytes, } \\
\text { platelets, } \\
\text { neutrophils, } \\
\text { lymphocytes, } \\
\text { monocytes, } \\
\text { sodium, albumin, } \\
\text { CRP }\end{array}$ \\
\hline $\begin{array}{l}\text { Orton et al. } \\
\text { (2016) } \\
\text { [29] }\end{array}$ & 84 & $\mathrm{M}$ & $\begin{array}{l}\text { Pleomorphic soft } \\
\text { tissue sarcoma }\end{array}$ & Scalp & Resection & $\begin{array}{l}\text { Pinna of left } \\
\text { ear, parotid } \\
\text { gland, lung }\end{array}$ & $\mathrm{n} / \mathrm{a}$ & $\begin{array}{l}40 \mathrm{~Gy}, \\
8 \mathrm{fr}\end{array}$ & $\begin{array}{l}\text { Post- } \\
\text { auricular } \\
\text { lesion }\end{array}$ & Lung & 2 months & \\
\hline $\begin{array}{l}\text { Saba et al. } \\
\text { (2016) } \\
{[30]}\end{array}$ & 69 & $\mathrm{~F}$ & Multiple myeloma & $\mathrm{n} / \mathrm{a}$ & $\begin{array}{c}\text { Chemo-therapy } \\
\text { (melphalan, } \\
\text { prednisone) }\end{array}$ & $\begin{array}{c}\text { Left } \\
\text { humerus, } \\
\text { bilateral } \\
\text { clavicles, } \\
\text { right } \\
\text { scapula left } \\
\text { skull, right } \\
\text { anterior + } \\
\text { posterior } \\
\text { thigh, } \\
\text { stomach }\end{array}$ & $\begin{array}{l}\text { Chemo- } \\
\text { therapy } \\
\text { (melphalan, } \\
\text { prednisone) }\end{array}$ & $150.5 \mathrm{~Gy}$ & $\begin{array}{c}\text { Left } \\
\text { humerus, } \\
\text { bilateral } \\
\text { clavicles, } \\
\text { right } \\
\text { scapula, left } \\
\text { skull, right } \\
\text { anterior LN } \\
\text { + posterior } \\
\text { thigh, } \\
\text { stomach }\end{array}$ & $\begin{array}{l}\text { Head of left } \\
\text { triceps }\end{array}$ & 5 months & Serum IgG levels \\
\hline $\begin{array}{l}\text { Joe et al. } \\
(2017) \\
{[31]}\end{array}$ & 57 & $\mathrm{~F}$ & $\begin{array}{l}\text { Squamous } \\
\text { carcinoma of anal } \\
\text { canal (SCCA) }\end{array}$ & Anal canal & RT & $\begin{array}{l}\text { Mesorectum, } \\
\text { perirectal, } \\
\text { right } \\
\text { internal iliac } \\
\text { + obturator } \\
\text { LN, liver, } \\
\text { right liliac } \\
\text { bone }\end{array}$ & $\begin{array}{l}\text { Chemo- } \\
\text { therapy }\end{array}$ & $\begin{array}{l}54 \mathrm{~Gy}, \\
30 \mathrm{fr}\end{array}$ & $\begin{array}{l}\text { Primary } \\
\text { anal tumor, } \\
\text { affected } \\
\text { pelvic } \\
\text { lymph } \\
\text { nodes, iliac } \\
\text { bone } \\
\text { metastasis }\end{array}$ & Liver & 1 month & $\begin{array}{c}\text { SCC antigen, PD-1, } \\
\text { PD-L1, CD163, } \\
\text { CD3, CD8 } \\
\text { expression of } \\
\text { tumor-infiltrating } \\
\text { lymphocytes (TILs) }\end{array}$ \\
\hline $\begin{array}{l}\text { Lesueur } \\
\text { et al. (2017) } \\
\text { [32] }\end{array}$ & 89 & $\mathrm{M}$ & $\begin{array}{l}\text { Neuroendocrine } \\
\text { large-cell thymic } \\
\text { carcinoma }\end{array}$ & $\begin{array}{l}\text { Thymus } \\
\text { with sternal } \\
\text { extension }\end{array}$ & $\mathrm{n} / \mathrm{a}$ & $\begin{array}{l}\text { Lung, } \\
\text { pancreas, } \\
\text { right lower } \\
\text { paratracheal } \\
\text { LN }\end{array}$ & $\mathrm{n} / \mathrm{a}$ & $\begin{array}{l}29.6 \mathrm{~Gy}, \\
8 \mathrm{fr}\end{array}$ & Sternum & Lung & 4 months & $\begin{array}{c}\text { CK7, } \\
\text { synaptophysin + } \\
\text { chromogranin A+ } \\
\text { negative for CK5, } \\
\text { CK6, CK20, TTF-1, } \\
\text { S100, PSA, } \\
\text { melan-A }\end{array}$ \\
\hline \multirow[b]{3}{*}{$\begin{array}{c}\text { Azami et al. } \\
(2018) \\
{[33]}\end{array}$} & \multirow[b]{3}{*}{64} & \multirow[b]{3}{*}{$\mathrm{F}$} & \multirow[b]{3}{*}{ Breast carcinoma } & \multirow[b]{3}{*}{ Right breast } & \multirow[b]{3}{*}{ Irradiation } & \multirow{3}{*}{$\begin{array}{c}\text { Lung, bone } \\
\text { (femur, } \\
\text { lumbar } \\
\text { vertebrae + } \\
\text { sacrum), } \\
\text { LNs (lung, } \\
\text { right axilla, } \\
\text { right supra- } \\
\text { clavicular } \\
\text { area, medi- } \\
\text { astinum) }\end{array}$} & \multirow[b]{3}{*}{$\mathrm{n} / \mathrm{aa}$} & $60 \mathrm{~Gy}$ & Right breast & \multirow[b]{3}{*}{ Lung, LNs } & \multirow[b]{3}{*}{10 months } & \multirow[b]{3}{*}{$\begin{array}{l}\text { HER2, KI-67, CEA, } \\
\text { CA15-3 }\end{array}$} \\
\hline & & & & & & & & $28 \mathrm{~Gy}$ & Reft femur & & & \\
\hline & & & & & & & & $39 \mathrm{~Gy}$ & $\begin{array}{c}\text { Lumbar } \\
\text { vertebrae + } \\
\text { sacrum }\end{array}$ & & & \\
\hline $\begin{array}{l}\text { Bruton Joe } \\
\text { et al. (2018) } \\
\text { [34] }\end{array}$ & 74 & $\mathrm{M}$ & $\begin{array}{l}\text { Adeno-carcinoma } \\
\text { (esophagus) }\end{array}$ & Esophagus & Esophagec-tomy & $\begin{array}{l}\mathrm{LN} \text {, right } \\
\text { renal vessels }\end{array}$ & $\mathrm{n} / \mathrm{a}$ & $\begin{array}{l}30 \mathrm{~Gy}, \\
10 \mathrm{fr}\end{array}$ & $\begin{array}{l}\text { Primary } \\
\text { tumor, } \\
\text { closest LN }\end{array}$ & Renal vein & 12 months & Hemoglobin \\
\hline $\begin{array}{l}\text { Chantharasamee } \\
\text { et al. (2018) } \\
\text { [35] }\end{array}$ & 51 & $\mathrm{~F}$ & $\begin{array}{c}\text { Melanoma of } \\
\text { unknown primary }\end{array}$ & $\begin{array}{l}\text { Left lower } \\
\text { extremities } \\
\text { left inguinal } \\
\text { mass }\end{array}$ & $\mathrm{n} / \mathrm{a}$ & $\begin{array}{l}\text { Bilateral } \\
\text { inguinal LN, } \\
\text { multiple LN } \\
\text { throughout } \\
\text { abdominal + } \\
\text { pelvic cavity }\end{array}$ & $\begin{array}{l}\text { Chemo- } \\
\text { therapy } \\
\text { (carboplatin, } \\
\text { paclitaxel) }\end{array}$ & $\begin{array}{l}20 \mathrm{~Gy}, \\
\mathrm{NR}\end{array}$ & $\begin{array}{c}\text { Bilateral } \\
\text { inguinal LN }\end{array}$ & LNs & 6 months & $\begin{array}{l}\text { Vimentin, S100, } \\
\text { HMB-45 }\end{array}$ \\
\hline $\begin{array}{l}\text { Chino et al. } \\
\text { (2018) } \\
\text { [36] }\end{array}$ & 58 & $\mathrm{M}$ & $\begin{array}{l}\text { Non-small-cell } \\
\text { lung carcinoma } \\
\text { (NSCLC) }\end{array}$ & Lung & $\begin{array}{c}\begin{array}{c}\text { Surgery, } \\
\text { chemotherapy }\end{array}\end{array}$ & Liver & $\begin{array}{l}\text { Chemo- } \\
\text { therapy }\end{array}$ & $\begin{array}{l}60 \mathrm{~Gy}, \\
8 \mathrm{fr}\end{array}$ & Lung & Liver & 5 months & AFP \\
\hline $\begin{array}{c}\text { Chuang } \\
\text { et al. (2018) } \\
{[37]}\end{array}$ & 74 & $\mathrm{~F}$ & $\begin{array}{l}\text { Adeno-carcinoma } \\
\text { (colon) }\end{array}$ & $\begin{array}{l}\text { Colorectal } \\
\text { cancer }\end{array}$ & $\mathrm{n} / \mathrm{a}$ & $\begin{array}{l}\text { Left lung, } \\
\text { liver, brain }\end{array}$ & $\mathrm{n} / \mathrm{a}$ & $\begin{array}{l}30 \mathrm{~Gy}, \\
10 \mathrm{fr}\end{array}$ & Brain & Left lung & 2 months & $\begin{array}{c}\text { CK20, CDX2, } \\
\text { thyroid } \\
\text { transcription factor } \\
1 \text { (TTF-1), CK7 }\end{array}$ \\
\hline $\begin{array}{l}\text { Hamilton } \\
\text { et al. (2018) } \\
\text { [38] }\end{array}$ & 47 & $\mathrm{M}$ & $\begin{array}{l}\text { Non-small-cell } \\
\text { lung carcinoma } \\
\text { (NSCLC) }\end{array}$ & $\begin{array}{l}\text { lung (left } \\
\text { upper lobe) }\end{array}$ & $\mathrm{n} / \mathrm{a}$ & $\begin{array}{l}\text { Left medi- } \\
\text { astinum, } \\
\text { bilateral } \\
\text { hilar, brain }\end{array}$ & $\mathrm{n} / \mathrm{a}$ & $\begin{array}{l}25 \mathrm{~Gy}, \\
5 \mathrm{fr}\end{array}$ & Brain & $\begin{array}{l}\text { Left upper } \\
\text { lobe left me- } \\
\text { diastinum }\end{array}$ & 1 month & Previous illness \\
\hline \multirow{2}{*}{$\begin{array}{l}\text { Leung et al. } \\
\text { (2018) } \\
\text { [39] }\end{array}$} & \multirow[t]{2}{*}{65} & \multirow[t]{2}{*}{$\mathrm{F}$} & \multirow[t]{2}{*}{ Ductal carcinoma } & \multirow[t]{2}{*}{ Right breast } & \multirow[t]{2}{*}{$\mathrm{n} / \mathrm{a}$} & \multirow{2}{*}{$\begin{array}{l}\text { 8th thoracic } \\
\text { vertebra, } \\
\text { axillary LN }\end{array}$} & \multirow[t]{2}{*}{$\mathrm{n} / \mathrm{a}$} & $\begin{array}{c}225 \mathrm{~Gy} \\
15 \mathrm{fr}\end{array}$ & Breast & \multirow[t]{2}{*}{ Axillary LN } & \multirow[t]{2}{*}{12 months } & \multirow{2}{*}{$\begin{array}{l}\text { Hemoglobin } \\
\text { concentration, } \\
\text { CEA, CA-125, } \\
\text { CA15-3 }\end{array}$} \\
\hline & & & & & & & & $\begin{array}{l}50 \mathrm{~Gy}, \\
25 \mathrm{fr}\end{array}$ & $\begin{array}{c}\text { Thoracic } \\
\text { bone }\end{array}$ & & & \\
\hline $\begin{array}{c}\text { Agyeman } \\
\text { et al. (2019) } \\
\text { [40] }\end{array}$ & 56 & $\mathrm{M}$ & $\begin{array}{l}\text { Dermatofibro- } \\
\text { sarcoma } \\
\text { protuberans } \\
\text { (DFSP) }\end{array}$ & $\begin{array}{l}\text { Left lower } \\
\text { leg }\end{array}$ & Local excision & $\begin{array}{l}\text { Posterior } \\
\text { torso }\end{array}$ & $\begin{array}{l}\text { Chemo- } \\
\text { therapy } \\
\text { (imatinib } \\
\text { mesylate) }\end{array}$ & $\begin{array}{l}40 \text { Gy, } 20 \mathrm{fr} \\
\text { (Cobalt-60) }\end{array}$ & $\begin{array}{l}\text { Left lower } \\
\text { limb }\end{array}$ & $\begin{array}{l}\text { Posterior } \\
\text { torso }\end{array}$ & 5 months & $\begin{array}{l}\text { CD34, actin, } \\
\text { desmin, S100 }\end{array}$ \\
\hline
\end{tabular}


Table 1. Cont.

\begin{tabular}{|c|c|c|c|c|c|c|c|c|c|c|c|c|}
\hline Reference & Age & Gender & Histo-pathology & $\begin{array}{c}\text { Primary } \\
\text { Tumor Site }\end{array}$ & $\begin{array}{l}\text { Treatment of } \\
\text { Orimary Tumor }\end{array}$ & $\begin{array}{l}\text { Metastasis } \\
\text { Site }\end{array}$ & $\begin{array}{l}\text { Systemic } \\
\text { Treatment }\end{array}$ & RT & $\begin{array}{l}\text { Irradiation } \\
\text { Site }\end{array}$ & $\begin{array}{c}\text { Non- } \\
\text { Irradiated } \\
\text { Abscopal } \\
\text { Regression }\end{array}$ & $\begin{array}{c}\text { Time Frame } \\
\text { for } \\
\text { Abscopal } \\
\text { Response }\end{array}$ & $\begin{array}{c}\text { Reported } \\
\text { Parameters }\end{array}$ \\
\hline $\begin{array}{c}\text { Bonilla et al. } \\
\text { (2019) } \\
\text { [41] }\end{array}$ & 78 & $\mathrm{~F}$ & $\begin{array}{l}\text { Adeno-carcinoma } \\
\text { (gastric) }\end{array}$ & $\begin{array}{l}\text { Gastric } \\
\text { antrum }\end{array}$ & Gastrojejunostomy & $\begin{array}{l}\text { Retroperitoneal } \\
\text { space }\end{array}$ & & $\begin{array}{l}30 \mathrm{~Gy}, \\
10 \mathrm{fr}\end{array}$ & $\begin{array}{c}\text { Gastric mass } \\
+ \text { margin }\end{array}$ & $\begin{array}{c}\text { Retro- } \\
\text { peritoneal } \\
\text { paraaortic } \\
\text { adenopathies } \\
\text { + gastrohep- } \\
\text { atic } \\
\text { ligament }\end{array}$ & 3 months & $\begin{array}{c}\text { carbohydrate } \\
\text { antigen 19-9 (CA } \\
\text { 19-9), CA 125, ACE }\end{array}$ \\
\hline $\begin{array}{c}\text { Kim et al. } \\
(2019) \\
{[42]}\end{array}$ & 70 & $\mathrm{M}$ & Cholangiocarcinoma & $\begin{array}{l}\text { Lung (right } \\
\text { upper lobe) }\end{array}$ & Chemo-therapy & Liver & $\begin{array}{l}\text { Chemo- } \\
\text { therapy }\end{array}$ & $\begin{array}{l}48 \mathrm{~Gy}, \\
4 \mathrm{fr}\end{array}$ & $\begin{array}{l}\text { Right upper } \\
\text { lung lobe }\end{array}$ & Liver & 3 months & $\begin{array}{c}\text { Bilirubin, history } \\
\text { of tobacco use, } \\
\text { alcohol } \\
\text { consumption, CK7, } \\
\text { TTF-1, CA 19-9, } \\
\text { Napsin A, CK20, } \\
\text { anaplastic } \\
\text { lymphoma kinase } \\
\text { (ALK), PD-L1, }\end{array}$ \\
\hline $\begin{array}{l}\text { Kuroda et al. } \\
\text { (2019) } \\
\text { [43] }\end{array}$ & 76 & $\mathrm{~F}$ & $\begin{array}{l}\text { Adeno-carcinoma } \\
\text { (lung) }\end{array}$ & $\begin{array}{l}\text { Lung (right } \\
\text { upper lobe }\end{array}$ & $\begin{array}{l}\text { Right upper } \\
\text { lobectomy }\end{array}$ & $\begin{array}{c}\text { Multiple } \\
\text { mediastinal } \\
\text { + right hilar } \\
\text { LNs }\end{array}$ & $\mathrm{n} / \mathrm{a}$ & $\begin{array}{l}60 \mathrm{~Gy}, \\
30 \mathrm{fr}\end{array}$ & $\begin{array}{c}\text { Multiple } \\
\text { mediastinal } \\
\text { + right hilar } \\
\text { LNs }\end{array}$ & $\begin{array}{c}\text { New left } \\
\text { hilar + right } \\
\text { supra- } \\
\text { clavicular } \\
\text { LN, lung }\end{array}$ & 3 months & $\begin{array}{l}\text { EGFR mutation, } \\
\text { PD-L1 tumor } \\
\text { proportion score, } \\
\text { CEA, CD8+ }\end{array}$ \\
\hline $\begin{array}{l}\text { Ellerin et al. } \\
\quad(2020) \\
{[44]}\end{array}$ & 84 & $\mathrm{~F}$ & $\begin{array}{l}\text { Non-small cell } \\
\text { carcinoma (right } \\
\text { gland) }\end{array}$ & $\begin{array}{l}\text { Deep lobe of } \\
\text { right parotid } \\
\quad \text { gland }\end{array}$ & $\mathrm{n} / \mathrm{a}$ & $\begin{array}{c}\text { Left upper } \\
\text { lobe, } \\
\text { bilateral } \\
\text { pulmonary } \\
\text { masses, } \\
\text { bilateral } \\
\text { hilar, left } \\
\text { paratracheal } \\
\text { LNs in right } \\
\text { upper lobe, } \\
\text { right } \\
\text { cervical LN, } \\
\text { mediastinal } \\
\text { LN }\end{array}$ & $\mathrm{n} / \mathrm{a}$ & $\begin{array}{l}50 \mathrm{~Gy}, \\
20 \mathrm{fr}\end{array}$ & Primary site & $\begin{array}{l}\text { Lung, } \\
\text { mediastinal } \\
\text { LN }\end{array}$ & 2 weeks & $\begin{array}{c}\text { History of tobacco } \\
\text { use, previous } \\
\text { illness, Lactate } \\
\text { dehydrogenase, } \\
\text { CK7, GATA-3, } \\
\text { CK5/6, p40, } \\
\text { PD-L1, mutations } \\
\text { in NTRK1, NTRK2, } \\
\text { NTRK3 }\end{array}$ \\
\hline $\begin{array}{l}\text { Guan et al. } \\
(2020) \\
{[45]}\end{array}$ & 76 & $\mathrm{~F}$ & B3 thymoma & Thymus & Palliative RT & $\begin{array}{l}\text { Multiple } \\
\text { lung/LN } \\
\text { metastases }\end{array}$ & $\mathrm{n} / \mathrm{a}$ & $\begin{array}{l}66 \mathrm{~Gy}, \\
33 \mathrm{fr}\end{array}$ & Not clarified & $\begin{array}{c}\text { Regression } \\
\text { of thymic } \\
\text { lesion }+ \\
\text { lung } \\
\text { metastases } \\
\text { in non- } \\
\text { irradiated } \\
\text { area }\end{array}$ & 2 months & PD-L1 \\
\hline $\begin{array}{c}\text { Ohmatsu } \\
\text { et al. (2020) } \\
{[46]}\end{array}$ & 77 & $\mathrm{M}$ & $\begin{array}{l}\text { Hepato-cellular } \\
\text { carcinoma }\end{array}$ & $\begin{array}{c}\text { Liver } \\
\text { (right lobe) }\end{array}$ & $\begin{array}{c}\text { hepatic } \\
\text { segment-ectomy }\end{array}$ & $\begin{array}{c}\text { Liver, } \\
\text { inferior vena } \\
\text { cava, lung }\end{array}$ & $\mathrm{n} / \mathrm{a}$ & $\begin{array}{l}42 \mathrm{~Gy} \\
\text { (boost), } \\
14 \mathrm{fr}\end{array}$ & $\begin{array}{l}\text { Inferior } \\
\text { vena cava }\end{array}$ & Lung & 1 month & $\begin{array}{l}\text { Mediacal history, } \\
\text { AFP, }\end{array}$ \\
\hline \multirow[t]{2}{*}{$\begin{array}{c}\text { Mazzaschi } \\
\text { et al. (2021) } \\
{[47]}\end{array}$} & \multirow[t]{2}{*}{66} & \multirow[t]{2}{*}{$\mathrm{M}$} & \multirow[t]{2}{*}{$\begin{array}{l}\text { High-grade } \\
\text { squamous cell } \\
\text { carcinoma }\end{array}$} & \multirow[t]{2}{*}{$\begin{array}{c}\text { Lateral } \\
\text { pharyngeal } \\
\text { wall }\end{array}$} & \multirow[t]{2}{*}{ Chemo-therapy, RT } & \multirow[t]{2}{*}{$\begin{array}{c}\text { Multiple } \\
\text { pathological } \\
\text { left cervical } \\
\text { LNs left } \\
\text { humerus }\end{array}$} & \multirow[t]{2}{*}{$\begin{array}{l}\text { Chemo- } \\
\text { therapy } \\
\text { (docetaxel, } \\
\text { cisplatin, 5- } \\
\text { fluorouracil) }\end{array}$} & $70 \mathrm{~Gy}$ & $\begin{array}{c}\text { Oropharynx, } \\
\text { rhino- } \\
\text { pharynx, } \\
\text { hypo-- } \\
\text { pharynx, } \\
\text { larynx, } \\
\text { bilateral } \\
\text { jugular- } \\
\text { digastric } \\
\text { LNs }\end{array}$ & \multirow[t]{2}{*}{ Humerus } & \multirow[t]{2}{*}{2 months } & \multirow[t]{2}{*}{$\begin{array}{c}\text { p53 } \\
\text { hype-expressed }\end{array}$} \\
\hline & & & & & & & & 40 Gy & $\begin{array}{c}\text { Cervical + V } \\
\text { level LNs }\end{array}$ & & & \\
\hline $\begin{array}{c}\text { Tomita et al. } \\
\text { (2021) } \\
\text { [48] }\end{array}$ & 88 & $\mathrm{~F}$ & Adeno-carcinoma & Uterus & $\begin{array}{l}\text { Radical } \\
\text { hysterectomy with } \\
\text { bilateral } \\
\text { salphingooph- } \\
\text { erectomy }\end{array}$ & $\begin{array}{l}\text { Lung, } \\
\text { recurrent } \\
\text { primary }\end{array}$ & $\mathrm{n} / \mathrm{a}$ & $65 \mathrm{~Gy}, 26 \mathrm{fr}$ & $\begin{array}{l}\text { Recurrent } \\
\text { primary }\end{array}$ & $\begin{array}{l}\text { Multiple } \\
\text { lung } \\
\text { metastases }\end{array}$ & 5 months & $\begin{array}{l}\text { Medical history, } \\
\text { CA-125 }\end{array}$ \\
\hline
\end{tabular}

Abbreviations: M: male; F: female; n/a: not available; RT: radiotherapy; LN: lymph nodes; WBC: white blood cells; fr: fractions; RCC: renal cell carcinoma; TNF- $\alpha$ : tumor necrosis factor alpha; IFN- $\gamma$ : interferon gamma; IL: interleukin; CT: computed tomography; AFP: $\alpha$ fetoprotein; HGF: hepatocyte growth factor; AST: aspartate aminotransferase;ALT: alanine aminotransferase; SCC: squamous cell carcinoma; TIA-1: TIA1 Cytotoxic Granule Associated RNA Binding Protein; TCR: T-cell receptor; NSCLC: non-small-cell lung carcinoma; CK: cytokeratin; TTF-1: thyroid transcription factor 1; EGFR: epidermal growth factor receptor; CRP: C-reactive protein; SCCA: squamous carcinoma of anal canal; PD-1: programmed cell death protein 1; PD-L1: PD-1 receptor-ligand 1; TIL: tumor-infiltrating lymphocyte; PSA: Prostate-specific antigen; HER2: human epidermal growth factor receptor 2; CEA: carcinoembryonic antigen; CA15-3: cancer antigen 15-3; CA-125: cancer antigen 125; CA 19-9: carbohydrate antigen 19-9; ALK: anaplastic lymphoma kinase; DFSP: Dermatofibrosarcoma protuberans.

The reported AbEs occurred independently from the patient age, treatment dose, fractionation, modality and characteristic of the target lesion. The cases varied widely in ethnicity and age (19-89 years), as well as in the applied radiation total doses (0.45-70 Gy) and doses per fraction (fr) (0.15-26 Gy). Most patients were treated with RT delivered in conventional fractionation ( $\leq 3 \mathrm{~Gy}$ ), whilst only 14 cases received higher fraction doses. Approximately half of the reported cases were treated with RT for their primary site. AbE was observed ranging from two weeks up to several months (1-24 months) after receiving RT [5]. 
Postow et al. reported for the first time a case of $\mathrm{AbE}$ in a female patient that received systemic immunotherapy five years post primary tumor and lung metastasis treatment. Ipilimumab as immunotherapy against cytotoxic T-lymphocyte-associated protein 4 (CTLA4) was administered to treat metastatic thoracic lesions, along with additional palliative RT. Thereby, five months following irradiation, non-targeted hilar and splenic metastatic lesions had regressed leading to minimal stable disease, and suggesting a correlation between $\mathrm{AbE}$ and the immune checkpoint blockade (ICB) [49]. With the introduction of the immune checkpoint inhibitor ipilimumab in clinical practice, the number of AbE related publications considerably increased. Adjepong et al. along with Dagoglu et al. thoroughly reviewed a total of 47 cases of $\mathrm{AbE}$ in patients with melanoma, lymphoma, renal cell carcinoma, pancreatic cancer, breast cancer, and prostate cancer, among others, treated with radiation in addition to immunotherapy in just six years between 2012 and 2018 [6,50].

In Table 2 we provide case reports of AbE after RT in which immunotherapy was utilized. Our PubMed search identified 60 additional cases of AbE since 2018. Most of these cases (14 cases) were observed in renal cell carcinoma (RCC). Ten cases occur in lung cancer, eight of them in non-small cell lung cancer (NSCLC).

Table 2. Abscopal effect case reports with immunotherapy.

\begin{tabular}{|c|c|c|c|c|c|c|c|c|c|c|c|c|c|}
\hline Reference & Age & Gender & $\begin{array}{c}\text { Histo- } \\
\text { Pathology }\end{array}$ & $\begin{array}{c}\text { Primary } \\
\text { Tumor Site }\end{array}$ & $\begin{array}{l}\text { Treatment of } \\
\text { Primary } \\
\text { Tumor }\end{array}$ & $\begin{array}{l}\text { Metastasis } \\
\text { Site }\end{array}$ & $\begin{array}{c}\text { Systemic } \\
\text { Treatment }\end{array}$ & RT & $\begin{array}{l}\text { Irradiation } \\
\text { Site }\end{array}$ & $\begin{array}{c}\text { Non- } \\
\text { Irradiated } \\
\text { Abscopal } \\
\text { Regression }\end{array}$ & $\begin{array}{c}\text { Time } \\
\text { Frame for } \\
\text { Abscopal } \\
\text { Response }\end{array}$ & $\begin{array}{l}\text { Immuno- } \\
\text { Therapy }\end{array}$ & $\begin{array}{l}\text { Reported } \\
\text { Parameters }\end{array}$ \\
\hline $\begin{array}{c}\text { Postow } \\
\text { et al. (2012) } \\
{[49]}\end{array}$ & 33 & F & Melanoma & $\begin{array}{l}\text { Upper } \\
\text { back }\end{array}$ & Excision & $\begin{array}{l}\text { Lung, right } \\
\text { hilar LN, } \\
\text { paraspinal } \\
\text { region, spleen }\end{array}$ & $\begin{array}{l}\text { Chemo- } \\
\text { therapy, } \\
\text { immuno- } \\
\text { therapy }\end{array}$ & $\begin{array}{l}28.5 \mathrm{~Gy}, \\
3 \mathrm{fr}\end{array}$ & $\begin{array}{l}\text { Paraspinal } \\
\text { region }\end{array}$ & $\begin{array}{l}\text { Right hilar } \\
\text { LN, spleen }\end{array}$ & 4 months & $\begin{array}{l}\text { Ipilimumab } \\
\text { (CTLA-4) }\end{array}$ & $\begin{array}{c}\text { BRAF } \\
\text { mutation, } \\
\text { NY-ESO-1 } \\
\text { expression, } \\
\text { CD4+ } \\
\text { ICOShigh, } \\
\text { CD14+' } \\
\text { HLA-DR low, } \\
\text { CD8+, CD4+ T } \\
\text { cells, seromic } \\
\text { analysis }\end{array}$ \\
\hline $\begin{array}{l}\text { Hiniker } \\
\text { et al. (2012) } \\
\text { [51] }\end{array}$ & 57 & M & Melanoma & $\begin{array}{l}\text { Left } \\
\text { posterior } \\
\text { arm }\end{array}$ & Excision & $\begin{array}{l}\text { Left axillary, } \\
\text { liver, left } \\
\text { upper arm }\end{array}$ & $\begin{array}{l}\text { Immuno- } \\
\text { therapy }\end{array}$ & $\begin{array}{l}54 \mathrm{~Gy}, \\
3 \mathrm{fr}\end{array}$ & Liver & $\begin{array}{c}\text { All } \\
\text { metastases }\end{array}$ & 6 months & $\begin{array}{l}\text { Ipilimumab } \\
\text { (CTLA-4) }\end{array}$ & \\
\hline \multirow{2}{*}{$\begin{array}{c}\text { Golden } \\
\text { et al. (2013) } \\
\text { [52] }\end{array}$} & \multirow[t]{2}{*}{64} & \multirow[t]{2}{*}{ M } & \multirow{2}{*}{$\begin{array}{l}\text { Adeno- } \\
\text { carcinoma } \\
\text { (lung) }\end{array}$} & \multirow[t]{2}{*}{ Lung } & \multirow{2}{*}{$\begin{array}{l}\text { Chemo- } \\
\text { therapy } \\
\text { (pemetrexed, } \\
\text { carboplatin, } \\
\text { gemcitabine, } \\
\text { vinorelbine) }\end{array}$} & \multirow{2}{*}{$\begin{array}{l}\text { Left + right } \\
\text { supra- } \\
\text { clavicular LN, } \\
\text { right upper } \\
\text { lobe, left } \\
\text { lower lobe, } \\
\text { bilateral hilar, } \\
\text { mediastinal } \\
\text { adenopathy, } \\
\text { liver, sacrum }\end{array}$} & \multirow{2}{*}{$\begin{array}{l}\text { Chemo- } \\
\text { therapy } \\
\text { (pemetrexed, } \\
\text { carboplatin, } \\
\text { gemcitabine, } \\
\text { vinorelbine), } \\
\text { immuno- } \\
\text { therapy }\end{array}$} & $\begin{array}{l}59.4 \mathrm{~Gy} \text {, } \\
33 \mathrm{fr}\end{array}$ & $\begin{array}{l}\text { Right lung, } \\
\text { right supra- } \\
\text { clavicular, } \\
\text { right hilar, } \\
\text { mediasti- } \\
\text { nal } \\
\text { adenopa- } \\
\text { thy }\end{array}$ & & 2 months & \multirow{2}{*}{$\begin{array}{l}\text { Ipilimumab } \\
\text { (CTLA-4) }\end{array}$} & \multirow{2}{*}{$\begin{array}{c}\text { Absolute } \\
\text { lymphocyte } \\
\text { counts (ALCs), } \\
\text { absolute } \\
\text { eosinophil } \\
\text { counts (AECs), } \\
\text { metabolic } \\
\text { activity LN, } \\
\text { CD8 cytotoxic } \\
\text { T cells, TIA-1 } \\
\text { (cytotoxic } \\
\text { granules), } \\
\text { FoxP3+ } \\
\text { (Tregs), CK7, } \\
\text { TTF-1, CK20, } \\
\text { CDX2, CEA } \\
\text { level }\end{array}$} \\
\hline & & & & & & & & $\begin{array}{l}30 \mathrm{~Gy}, \\
5 \mathrm{fr}\end{array}$ & Liver & $\begin{array}{l}\text { Left lung, } \\
\text { right lung, } \\
\text { hilar } \\
\text { adenopa- } \\
\text { thy }\end{array}$ & 3 months & & \\
\hline \multirow{2}{*}{$\begin{array}{c}\text { Stamell } \\
\text { et al. (2013) } \\
{[53]}\end{array}$} & \multirow[t]{2}{*}{67} & \multirow[t]{2}{*}{ M } & \multirow[t]{2}{*}{ Melanoma } & \multirow[t]{2}{*}{ Head } & \multirow[t]{2}{*}{ RT } & \multirow{2}{*}{$\begin{array}{l}\text { Forehead, } \\
\text { scalp, neck, } \\
\text { nodal, brain }\end{array}$} & \multirow{2}{*}{$\begin{array}{l}\text { Chemo- } \\
\text { therapy, } \\
\text { immuno- } \\
\text { therapy }\end{array}$} & $\begin{array}{l}24 \mathrm{~Gy}, \\
3 \mathrm{fr}\end{array}$ & $\begin{array}{l}\text { Primary } \\
\text { tumor }\end{array}$ & $\begin{array}{c}\text { Skin } \\
\text { metastasis }\end{array}$ & \multirow[t]{2}{*}{8 months } & & \multirow{2}{*}{$\begin{array}{c}\text { Melanoma } \\
\text { antigen A3 } \\
\text { (MEGA3), PAS } \\
\text { domain } \\
\text { containing 1 } \\
\text { (PASD1) level } \\
\text { of serum }\end{array}$} \\
\hline & & & & & & & & SRS & Brain & $\begin{array}{l}\text { Complete } \\
\text { remission }\end{array}$ & & $\begin{array}{l}\text { Ipilimumab } \\
\text { (CTLA-4) }\end{array}$ & \\
\hline
\end{tabular}


Table 2. Cont.

\begin{tabular}{|c|c|c|c|c|c|c|c|c|c|c|c|c|c|}
\hline Reference & Age & Gender & $\begin{array}{c}\text { Histo- } \\
\text { Pathology }\end{array}$ & $\begin{array}{c}\text { Primary } \\
\text { Tumor Site }\end{array}$ & $\begin{array}{l}\text { Treatment of } \\
\text { Primary } \\
\text { Tumor }\end{array}$ & $\begin{array}{l}\text { Metastasis } \\
\text { Site }\end{array}$ & $\begin{array}{l}\text { Systemic } \\
\text { Treatment }\end{array}$ & RT & $\begin{array}{l}\text { Irradiation } \\
\text { Site }\end{array}$ & $\begin{array}{c}\text { Non- } \\
\text { Irradiated } \\
\text { Abscopal } \\
\text { Regression }\end{array}$ & $\begin{array}{c}\text { Time } \\
\text { Frame for } \\
\text { Abscopal } \\
\text { Response }\end{array}$ & $\begin{array}{l}\text { Immuno- } \\
\text { Therapy }\end{array}$ & $\begin{array}{l}\text { Reported } \\
\text { Parameters }\end{array}$ \\
\hline \multirow{11}{*}{$\begin{array}{c}\text { Grimaldi } \\
\text { et al. (2014) } \\
{[54]}\end{array}$} & $\mathrm{n} / \mathrm{a}$ & $\mathrm{n} / \mathrm{a}$ & Melanoma & $\mathrm{n} / \mathrm{a}$ & $\mathrm{n} / \mathrm{a}$ & $\mathrm{n} / \mathrm{a}$ & \multirow{11}{*}{$\begin{array}{l}\text { Immuno- } \\
\text { therapy }\end{array}$} & $\begin{array}{l}30 \mathrm{~Gy}, \\
10 \mathrm{fr}\end{array}$ & Brain & Liver & $\mathrm{n} / \mathrm{a}$ & \multirow{11}{*}{$\begin{array}{l}\text { Ipilimumab } \\
\text { (CTLA-4) }\end{array}$} & \\
\hline & $n / a$ & $\mathrm{n} / \mathrm{a}$ & Melanoma & $\mathrm{n} / \mathrm{a}$ & $\mathrm{n} / \mathrm{a}$ & $\mathrm{n} / \mathrm{a}$ & & $\begin{array}{l}30 \mathrm{~Gy}, \\
10 \mathrm{fr}\end{array}$ & Brain & $\begin{array}{l}\text { Pelvic } \\
\text { relapse }\end{array}$ & $\mathrm{n} / \mathrm{a}$ & & \\
\hline & $n / a$ & $\mathrm{n} / \mathrm{a}$ & Melanoma & $n / a$ & $\mathrm{n} / \mathrm{a}$ & $\mathrm{n} / \mathrm{a}$ & & $\begin{array}{l}50 \mathrm{~Gy}, \\
25 \mathrm{fr}\end{array}$ & $\begin{array}{l}\text { Chest wall, } \\
\text { right axilla }\end{array}$ & $\begin{array}{c}\text { Liver, } \\
\text { cutaneous } \\
\text { metastases }\end{array}$ & $\mathrm{n} / \mathrm{a}$ & & \\
\hline & $n / a$ & $\mathrm{n} / \mathrm{a}$ & Melanoma & $\mathrm{n} / \mathrm{a}$ & $\mathrm{n} / \mathrm{a}$ & $\mathrm{n} / \mathrm{a}$ & & $\begin{array}{l}20 \mathrm{~Gy}, \\
5 \mathrm{fr}\end{array}$ & $\begin{array}{l}\text { Right } \\
\text { inguinal } \\
\text { lymph } \\
\text { node }\end{array}$ & $\begin{array}{c}\text { Gastric, } \\
\text { cutaneous, } \\
\text { lung, } \\
\text { lymph } \\
\text { nodal + } \\
\text { retroperi- } \\
\text { toneal } \\
\text { abdominal } \\
\text { metastases }\end{array}$ & $\mathrm{n} / \mathrm{a}$ & & \\
\hline & $\mathrm{n} / \mathrm{a}$ & $\mathrm{n} / \mathrm{a}$ & Melanoma & $n / a$ & $\mathrm{n} / \mathrm{a}$ & $\mathrm{n} / \mathrm{a}$ & & $\begin{array}{l}30 \mathrm{~Gy}, \\
10 \mathrm{fr}\end{array}$ & $\begin{array}{c}\text { Brain } \\
\text { (WBRT) }\end{array}$ & $\begin{array}{c}\text { Liver, } \\
\text { bilateral } \\
\text { axillary }+ \\
\text { right } \\
\text { ovaric } \\
\text { metastases }\end{array}$ & $\mathrm{n} / \mathrm{a}$ & & \\
\hline & $\mathrm{n} / \mathrm{a}$ & $\mathrm{n} / \mathrm{a}$ & Melanoma & $\mathrm{n} / \mathrm{a}$ & $\mathrm{n} / \mathrm{a}$ & $\mathrm{n} / \mathrm{a}$ & & $\begin{array}{l}30 \mathrm{~Gy}, \\
10 \mathrm{fr}\end{array}$ & $\begin{array}{c}\text { Brain } \\
\text { (WBRT) }\end{array}$ & $\begin{array}{c}\text { Lung, } \\
\text { cutaneous, } \\
\text { lymph } \\
\text { nodal }+ \\
\text { abdominal } \\
\text { metastases }\end{array}$ & $\mathrm{n} / \mathrm{a}$ & & \\
\hline & $\mathrm{n} / \mathrm{a}$ & $\mathrm{n} / \mathrm{a}$ & Melanoma & $\mathrm{n} / \mathrm{a}$ & $\mathrm{n} / \mathrm{a}$ & $\mathrm{n} / \mathrm{a}$ & & $\begin{array}{l}30 \mathrm{~Gy}, \\
10 \mathrm{fr}\end{array}$ & $\begin{array}{l}\text { Right chest } \\
\text { wall }\end{array}$ & $\begin{array}{c}\text { Lymph } \\
\text { nodal, } \\
\text { cutaneous } \\
\text { + chest wall } \\
\text { metastases }\end{array}$ & $\mathrm{n} / \mathrm{a}$ & & \\
\hline & $\mathrm{n} / \mathrm{a}$ & $\mathrm{n} / \mathrm{a}$ & Melanoma & $\mathrm{n} / \mathrm{a}$ & $\mathrm{n} / \mathrm{a}$ & $\mathrm{n} / \mathrm{a}$ & & $\begin{array}{l}30 \mathrm{~Gy}, \\
10 \mathrm{fr}\end{array}$ & $\begin{array}{l}\text { Vertebral } \\
\text { metastasis }\end{array}$ & $\begin{array}{c}\text { Lung } \\
\text { metastases }\end{array}$ & $\mathrm{n} / \mathrm{a}$ & & \\
\hline & $\mathrm{n} / \mathrm{a}$ & $\mathrm{n} / \mathrm{a}$ & Melanoma & $n / a$ & $\mathrm{n} / \mathrm{a}$ & $\mathrm{n} / \mathrm{a}$ & & $\begin{array}{l}24 \mathrm{~Gy}, \\
1 \mathrm{fr}\end{array}$ & Brain (SRT) & $\begin{array}{l}\text { Cutaneous } \\
\text { metastases }\end{array}$ & $\mathrm{n} / \mathrm{a}$ & & \\
\hline & $\mathrm{n} / \mathrm{a}$ & $\mathrm{n} / \mathrm{a}$ & Melanoma & $\mathrm{n} / \mathrm{a}$ & $\mathrm{n} / \mathrm{a}$ & $\mathrm{n} / \mathrm{a}$ & & $\begin{array}{l}20 \mathrm{~Gy}, \\
1 \mathrm{fr}\end{array}$ & Brain (SRT) & $\begin{array}{c}\text { Liver } \\
\text { metastases }\end{array}$ & $\mathrm{n} / \mathrm{a}$ & & \\
\hline & $\mathrm{n} / \mathrm{a}$ & $\mathrm{n} / \mathrm{a}$ & Melanoma & $\mathrm{n} / \mathrm{a}$ & $\mathrm{n} / \mathrm{a}$ & $\mathrm{n} / \mathrm{a}$ & & $\begin{array}{l}24 \mathrm{~Gy}, \\
1 \mathrm{fr}\end{array}$ & Brain (SRT) & $\begin{array}{c}\text { Lung } \\
\text { metastases }\end{array}$ & $\mathrm{n} / \mathrm{a}$ & & \\
\hline $\begin{array}{c}\text { Thallinger } \\
\text { et al. (2014) } \\
\text { [55] }\end{array}$ & 44 & M & Melanoma & $\mathrm{n} / \mathrm{a}$ & $\mathrm{n} / \mathrm{a}$ & $\begin{array}{l}\text { Liver, lung, } \\
\text { right kidney, } \\
\text { right adrenal } \\
\text { gland, LN, } \\
\text { bone, brain }\end{array}$ & $\begin{array}{l}\text { Chemo- } \\
\text { therapy, } \\
\text { immuno- } \\
\text { therapy }\end{array}$ & $\begin{array}{l}30 \mathrm{~Gy}, \\
10 \mathrm{fr}\end{array}$ & Brain & $\begin{array}{l}\text { Kidney, } \\
\text { lunge, liver }\end{array}$ & 2 months & $\begin{array}{c}\text { Ipilimumab } \\
\text { (CTLA-4) }\end{array}$ & $\begin{array}{c}\text { S100, HMB45, } \\
\text { Melan A, } \\
\text { BRAF, NRAS + } \\
\text { c-KIT } \\
\text { mutations }\end{array}$ \\
\hline $\begin{array}{c}\text { Okwan- } \\
\text { Duodu } \\
\text { et al. }(2015) \\
{[56]}\end{array}$ & 50 & F & Melanoma & $\begin{array}{c}\text { Right } \\
\text { lower back }\end{array}$ & Excision & $\begin{array}{c}\text { Right groin, } \\
\text { right occipital } \\
\text { area, right } \\
\text { suboccipital } \\
\text { node, sub- } \\
\text { centimeter } \\
\text { right } \\
\text { pulmonary } \\
\text { node, brain, } \\
\text { multiple } \\
\text { retroperi- } \\
\text { toneal, } \\
\text { subcutaneous, } \\
\text { aortocaval, left } \\
\text { periaortic }+ \\
\text { peripancreatic } \\
\text { LNs }\end{array}$ & $\begin{array}{l}\text { Immuno- } \\
\text { therapy }\end{array}$ & $\begin{array}{l}\text { Whole- } \\
\text { brain } \\
\text { RT }\end{array}$ & Brain & $\begin{array}{c}\text { Pulmonary, } \\
\text { retroperi- } \\
\text { toneal, } \\
\text { mesenteric } \\
\text { nodes. }\end{array}$ & 5 months & $\begin{array}{c}\text { IL-2 } \\
\text { therapy }\end{array}$ & \\
\hline $\begin{array}{c}\text { Michot } \\
\text { et al. (2016) } \\
\text { [57] }\end{array}$ & 33 & M & $\begin{array}{c}\text { Classical } \\
\text { Hodgkin } \\
\text { disease }\end{array}$ & $\begin{array}{c}\text { Nodal } \\
\text { supra- } \\
\text { diaphrag- } \\
\text { matic } \\
\text { area }\end{array}$ & $\begin{array}{l}\text { Chemo- } \\
\text { therapy } \\
\text { (doxorubicin } \\
\text { (Adriamycin), } \\
\text { bleomycin, } \\
\text { vinblastine, } \\
\text { dacarbazine) }\end{array}$ & $\begin{array}{c}\text { Mediastinal } \\
\text { right hilar + } \\
\text { coeliac areas } \\
\text { LN, supra- } \\
\text { diaphragmatic } \\
\text { + subdiaphrag- } \\
\text { matic LN, } \\
\text { mediastinal } \\
\text { lym- } \\
\text { phadenopathy }\end{array}$ & $\begin{array}{l}\text { Chemo- } \\
\text { therapy } \\
\text { (doxorubicin } \\
\text { (Adriamycin), } \\
\text { bleomycin, } \\
\text { vinblastine, } \\
\text { dacarbazine), } \\
\text { immuno- } \\
\text { therapy }\end{array}$ & $30 \mathrm{~Gy}, 10 \mathrm{fr}$ & $\begin{array}{l}\text { Right hilar } \\
\text { mediasti- } \\
\text { nal } \\
\text { LN }\end{array}$ & $\mathrm{n} / \mathrm{a}$ & $\mathrm{n} / \mathrm{a}$ & $\begin{array}{l}\text { Pembrolizumab } \\
\text { (PD-1) }\end{array}$ & \\
\hline $\begin{array}{c}\text { Cong et al. } \\
\text { (2017) } \\
{[58]}\end{array}$ & 64 & F & $\begin{array}{l}\text { Non-small- } \\
\text { cell lung } \\
\text { carcinoma } \\
\text { (NSCLC) }\end{array}$ & Left lung & $\begin{array}{l}\text { Chemo- } \\
\text { therapy } \\
\text { (cisplatin, } \\
\text { pemetrexed) }\end{array}$ & $\begin{array}{c}\text { Para- } \\
\text { mediastinal } \\
\text { tumor, lingual } \\
\text { segment } \\
\text { tumor }\end{array}$ & $\begin{array}{l}\text { Chemo- } \\
\text { therpay, } \\
\text { immuno- } \\
\text { therapy, EGFR } \\
\text { inhibitor }\end{array}$ & $\begin{array}{c}37.5 \mathrm{~Gy}, 5 \\
\text { fr }\end{array}$ & $\begin{array}{l}\text { Para- } \\
\text { mediastinal } \\
\text { tumor }\end{array}$ & Lung & 10 months & $\begin{array}{c}\text { Endritic } \\
\text { cells + } \\
\text { cytokine- } \\
\text { induced } \\
\text { killers } \\
\text { (DC-CIK) } \\
\text { im- } \\
\text { munother- } \\
\text { apy }\end{array}$ & $\begin{array}{c}\text { EGFR } \\
\text { mutation }\end{array}$ \\
\hline $\begin{array}{c}\text { Komatsu } \\
\text { et al. (2017) } \\
\text { [59] }\end{array}$ & 60 & M & $\begin{array}{l}\text { Adeno- } \\
\text { carcinoma } \\
\text { (lung) }\end{array}$ & $\begin{array}{l}\text { Lung (right } \\
\text { upper } \\
\text { lobe) }\end{array}$ & Lobectomy & $\begin{array}{c}\text { Liver } \\
\text { metastasis, in- } \\
\text { trapulmonary } \\
\text { metastasis }\end{array}$ & $\begin{array}{l}\text { Chemo-radio- } \\
\text { therapy, } \\
\text { immuno- } \\
\text { therapy }\end{array}$ & $\begin{array}{l}40 \mathrm{~Gy}, \\
20 \mathrm{fr}\end{array}$ & Liver & Lung & 3 weeks & $\begin{array}{c}\text { Nivolumab } \\
\text { (PD-1) }\end{array}$ & \\
\hline
\end{tabular}


Table 2. Cont.

\begin{tabular}{|c|c|c|c|c|c|c|c|c|c|c|c|c|c|}
\hline Reference & Age & Gender & $\begin{array}{c}\text { Histo- } \\
\text { Pathology }\end{array}$ & $\begin{array}{c}\text { Primary } \\
\text { Tumor Site }\end{array}$ & $\begin{array}{l}\text { Treatment of } \\
\text { Primary } \\
\text { Tumor }\end{array}$ & $\begin{array}{l}\text { Metastasis } \\
\text { Site }\end{array}$ & $\begin{array}{l}\text { Systemic } \\
\text { Treatment }\end{array}$ & RT & $\begin{array}{l}\text { Irradiation } \\
\text { Site }\end{array}$ & $\begin{array}{c}\text { Non- } \\
\text { Irradiated } \\
\text { Abscopal } \\
\text { Regression }\end{array}$ & $\begin{array}{c}\text { Time } \\
\text { Frame for } \\
\text { Abscopal } \\
\text { Response }\end{array}$ & $\begin{array}{l}\text { Immuno- } \\
\text { Therapy }\end{array}$ & $\begin{array}{c}\text { Reported } \\
\text { Parameters }\end{array}$ \\
\hline $\begin{array}{l}\text { Sato et al. } \\
\text { (2017) } \\
\text { [60] }\end{array}$ & 54 & M & $\begin{array}{l}\text { Adeno- } \\
\text { carcinoma } \\
\text { (gastric } \\
\text { cancer) }\end{array}$ & Colon & $\begin{array}{c}\text { Distal } \\
\text { gastrectomy }\end{array}$ & $\begin{array}{l}\text { Peritoneal } \\
\text { tumor }\end{array}$ & $\begin{array}{c}\text { Chemo- } \\
\text { therapy (TS-1, } \\
\text { paclitaxel), } \\
\text { immun- } \\
\text { otherapy }\end{array}$ & $\begin{array}{l}48 \mathrm{~Gy}, \\
24 \mathrm{fr}\end{array}$ & Colon & $\begin{array}{l}\text { Peritoneal } \\
\text { tumor }\end{array}$ & 2 months & $\begin{array}{l}\text { T-cell } \\
\text { immuno- } \\
\text { therapy, } \\
\text { dendritic } \\
\text { cell (DC) } \\
\text { therapy }\end{array}$ & CEA, CA19-9 \\
\hline $\begin{array}{c}\text { Sharabi } \\
\text { et al. (2017) } \\
\text { [61] }\end{array}$ & 48 & F & $\begin{array}{l}\text { Neuro- } \\
\text { endocrine } \\
\text { cervical } \\
\text { carcinoma }\end{array}$ & $\begin{array}{l}\text { Uterine, } \\
\text { cervix }\end{array}$ & $\begin{array}{l}\text { Chemo- } \\
\text { therapy, } \\
\text { RT }\end{array}$ & $\begin{array}{l}\text { Liver, pelvic, } \\
\text { retro- } \\
\text { peritoneal + } \\
\text { pelvic LN }\end{array}$ & $\begin{array}{l}\text { Chemo- } \\
\text { therapy } \\
\text { (cisplatin, } \\
\text { etoposide), } \\
\text { immuno- } \\
\text { therapy }\end{array}$ & $\begin{array}{l}20 \mathrm{~Gy}, \\
4 \mathrm{fr}\end{array}$ & $\begin{array}{c}\text { Abdominal } \\
\text { mass }\end{array}$ & $\begin{array}{l}\text { Hepatic } \\
\text { lesion, } \\
\text { pelvic } \\
\text { mass, } \\
\text { pelvic + } \\
\text { retroperi- } \\
\text { toneal } \\
\text { LN }\end{array}$ & 4 month & $\begin{array}{c}\text { Nivolumab } \\
\text { (PD-1) }\end{array}$ & $\begin{array}{c}\text { Pan- } \\
\text { cytokeratin, } \\
\text { synapto- } \\
\text { physin, CD99, } \\
\text { EMA, p16, } \\
\text { circulating } \\
\text { tumor DNA } \\
\text { (ctDNA), NGS } \\
\text { mutation } \\
\text { analysis, } \\
\text { tumor } \\
\text { mutational } \\
\text { burden, } \\
\text { PD-L1, } \\
\text { microsatellite } \\
\text { instability } \\
\text { (MSI-H) } \\
\text { status, CA-125 }\end{array}$ \\
\hline $\begin{array}{c}\text { Shi et al. } \\
\text { (2017) } \\
\text { [62] }\end{array}$ & 67 & F & $\begin{array}{l}\text { Pancreatic } \\
\text { cancer }\end{array}$ & Pancreas & $\begin{array}{l}\text { Chemo- } \\
\text { therapy } \\
\text { (gemcitabine, } \\
\text { paclitaxel } \\
\text { albumin) }\end{array}$ & $\begin{array}{l}\text { Liver, right } \\
\text { pleura } \\
\text { metastasis }\end{array}$ & $\begin{array}{c}\text { Chemo- } \\
\text { therapy } \\
\text { (gemcitabine, } \\
\text { paclitaxel } \\
\text { albumin), } \\
\text { tyrosine } \\
\text { kinase } \\
\text { inhibitor, } \\
\text { immuno- } \\
\text { therapy }\end{array}$ & $\begin{array}{l}45 \mathrm{~Gy}, \\
15 \mathrm{fr}\end{array}$ & Pancreas & Metasases & 1 month & GM-CSF & CA19-9 \\
\hline $\begin{array}{c}\text { Xie et al. } \\
(2017) \\
{[63]}\end{array}$ & 54 & M & $\begin{array}{l}\text { Renal cell } \\
\text { carcinoma } \\
\text { (RCC) }\end{array}$ & Left kidney & Nephrectomy & $\begin{array}{l}\text { Multiple } \\
\text { mediastinal, } \\
\text { retro- } \\
\text { peritoneal, } \\
\text { bilateral } \\
\text { cervical, } \\
\text { pelvis LN }\end{array}$ & $\begin{array}{l}\text { Tyrosine } \\
\text { kinase } \\
\text { inhibitors } \\
\text { (sunitinib) }\end{array}$ & $\begin{array}{l}32 \mathrm{~Gy}, \\
4 \mathrm{fr}\end{array}$ & $\begin{array}{l}\text { Left medi- } \\
\text { astinal } \\
\text { LN }\end{array}$ & $\begin{array}{c}\text { All } \\
\text { metastasis }\end{array}$ & 2 months & $\begin{array}{l}\text { Pembrolizumab } \\
\text { (PD-1) }\end{array}$ & $\begin{array}{c}\text { Circulating } \\
\text { tumor DNA } \\
\text { (ctDNA) }\end{array}$ \\
\hline $\begin{array}{c}\text { Britschgi } \\
\text { et al. (2018) } \\
\text { [64] }\end{array}$ & 47 & M & $\begin{array}{l}\text { Non-small- } \\
\text { cell lung } \\
\text { carcinoma } \\
\text { (NSCLC) }\end{array}$ & Lung & $\begin{array}{l}\text { Chemo- } \\
\text { therapy } \\
\text { cetuximab, RT, } \\
\text { resection }\end{array}$ & $\begin{array}{l}\text { Rretro- } \\
\text { peritoneal + } \\
\text { abdominal } \\
\text { lymph node }\end{array}$ & $\begin{array}{c}\text { Chemo- } \\
\text { therapy } \\
\text { (pemetrexed), } \\
\text { immuno- } \\
\text { therapy }\end{array}$ & $\begin{array}{l}18 \mathrm{~Gy}, \\
3 \mathrm{fr}\end{array}$ & $\begin{array}{l}2 \text { retro- } \\
\text { peritoneal } \\
\text { LNs }\end{array}$ & $\begin{array}{l}\text { Unirradiated } \\
\text { LNs }\end{array}$ & 10 weeks & $\underset{(\text { PD-1) }}{\text { Nivolumab }}$ & $\begin{array}{l}\text { History of } \\
\text { tobacco use }\end{array}$ \\
\hline \multirow[t]{2}{*}{$\begin{array}{l}\text { Gutkin } \\
\text { et al. (2018) } \\
\text { [65] }\end{array}$} & \multirow[t]{2}{*}{57} & \multirow[t]{2}{*}{ M } & \multirow[t]{2}{*}{ Melanoma } & \multirow[t]{2}{*}{$\begin{array}{l}\text { Left } \\
\text { posterior } \\
\text { arm }\end{array}$} & \multirow[t]{2}{*}{$\begin{array}{c}\text { Excision } \\
\text { (priamry, LN) }\end{array}$} & \multirow[t]{2}{*}{$\begin{array}{l}\text { Liver. left } \\
\text { upper arm }\end{array}$} & \multirow[t]{2}{*}{$\begin{array}{l}\text { Immuno- } \\
\text { therapy }\end{array}$} & $\begin{array}{l}50 \mathrm{~Gy}, \\
20 \mathrm{fr}\end{array}$ & $\begin{array}{c}\text { Left } \\
\text { posterior } \\
\text { arm }\end{array}$ & & & $\begin{array}{l}\text { IFN } \\
\text { therapy, ip- }\end{array}$ & $\begin{array}{l}\text { BRAF } \\
\text { mutation, }\end{array}$ \\
\hline & & & & & & & & $\begin{array}{l}54 \mathrm{~Gy}, \\
3 \mathrm{fr}\end{array}$ & $\begin{array}{c}2 \text { liver } \\
\text { metastases }\end{array}$ & $\begin{array}{l}\text { Complete } \\
\text { response }\end{array}$ & 1 year & & \\
\hline \multirow{2}{*}{$\begin{array}{c}\text { Matsushita } \\
\text { et al. (2018) } \\
\text { [66] }\end{array}$} & 62 & M & $\begin{array}{l}\text { Renal cell } \\
\text { carcinoma } \\
\text { (RCC) }\end{array}$ & $\begin{array}{c}\text { Right } \\
\text { kidney }\end{array}$ & Nephrectomy & $\begin{array}{l}\text { Right adrenal } \\
\text { gland, lumbar } \\
\text { vertebrae (L4) }\end{array}$ & $\begin{array}{l}\text { Tyrosine } \\
\text { kinase } \\
\text { inhibitors } \\
\text { (sunitinib, } \\
\text { axitinib), } \\
\text { immuno- } \\
\text { therapy }\end{array}$ & $\begin{array}{l}36 \mathrm{~Gy}, \\
12 \mathrm{fr}\end{array}$ & $\begin{array}{c}\text { Lumbar } \\
\text { vertebrae } \\
\text { (L4) }\end{array}$ & $\begin{array}{l}\text { Right } \\
\text { adrenal }\end{array}$ & 1.5 months & $\begin{array}{c}\text { Nivolumab } \\
(\text { PD-1) }\end{array}$ & \\
\hline & 71 & M & $\begin{array}{l}\text { Renal cell } \\
\text { carcinoma } \\
\text { (RCC) }\end{array}$ & $\begin{array}{c}\text { Right } \\
\text { kidney }\end{array}$ & Nephrectomy & $\begin{array}{c}\text { Left parotid } \\
\text { gland, soft } \\
\text { tissues, lung, } \\
\text { pancreas, right } \\
\text { iliopsoas } \\
\text { muscle }\end{array}$ & $\begin{array}{c}\text { Interferon- } \alpha \\
\text { therapy, } \\
\text { tyrosine } \\
\text { kinase } \\
\text { inhibitors } \\
\text { (sunitinib, } \\
\text { axitinib), } \\
\text { immuno- } \\
\text { therapy }\end{array}$ & $\begin{array}{l}66 \mathrm{~Gy}, \\
33 \mathrm{fr}\end{array}$ & $\begin{array}{l}\text { Right } \\
\text { iliopsoas } \\
\text { muscle }\end{array}$ & $\begin{array}{l}\text { Lung, } \\
\text { pancreas }\end{array}$ & 1.5 months & $\begin{array}{c}\text { Nivolumab } \\
(\text { PD-1) }\end{array}$ & Tumor burden \\
\hline $\begin{array}{c}\text { Rodriguez- } \\
\text { Ruiz et al. } \\
(2018) \\
{[67]}\end{array}$ & 68 & M & $\begin{array}{l}\text { Castration- } \\
\text { resistant } \\
\text { prostate } \\
\text { carcinoma }\end{array}$ & Prostate & $\begin{array}{c}\text { Surgery, } \\
\text { chemotherapy }\end{array}$ & $\begin{array}{c}\text { Mediastinal + } \\
\text { inguinal LN, } \\
\text { liver, bone, } \\
\text { lung }\end{array}$ & $\begin{array}{l}\text { Chemo- } \\
\text { therapy, } \\
\text { immuno- } \\
\text { therapy }\end{array}$ & $\begin{array}{l}24 \mathrm{~Gy}, \\
3 \mathrm{fr}\end{array}$ & $\begin{array}{l}\text { Prostate, } \\
\text { inguinal } \\
\text { LNs }\end{array}$ & $\begin{array}{l}\text { Mediastinal } \\
\text { + retroperi- } \\
\text { toneal } \\
\text { lesions }\end{array}$ & 6 months & $\begin{array}{l}\text { Poly ICLC, } \\
\text { DC vaccine }\end{array}$ & $\begin{array}{l}\text { PSA serum } \\
\text { concentration }\end{array}$ \\
\hline \multirow{2}{*}{$\begin{array}{c}\text { Tsui et al. } \\
\text { (2018) } \\
\text { [68] }\end{array}$} & \multirow[t]{2}{*}{65} & \multirow[t]{2}{*}{ F } & \multirow[t]{2}{*}{ Melanoma } & \multirow{2}{*}{$\begin{array}{c}\text { Maxillary } \\
\text { gingiva + } \\
\text { hard palate }\end{array}$} & \multirow[t]{2}{*}{ Resection } & \multirow{2}{*}{$\begin{array}{l}\text { Floor of } \\
\text { mouth, right } \\
\text { neck, lung, } \\
\text { cervical LN }\end{array}$} & \multirow[t]{2}{*}{$\begin{array}{l}\text { Immuno- } \\
\text { therapy }\end{array}$} & $\begin{array}{l}50 \mathrm{~Gy}, \\
20 \mathrm{fr}\end{array}$ & $\begin{array}{c}\text { Primary } \\
\text { tumor }\end{array}$ & & & \multirow[t]{2}{*}{$\begin{array}{c}\text { Pembrolizumab } \\
\text { (PD-1) }\end{array}$} & \\
\hline & & & & & & & & $\begin{array}{l}24 \mathrm{~Gy}, \\
3 \mathrm{fr}\end{array}$ & Neck & $\begin{array}{l}\text { Lung, } \\
\text { mouth }\end{array}$ & 1 month & & \\
\hline $\begin{array}{c}\text { van Gysen } \\
\text { et al. (2018) } \\
\text { [69] }\end{array}$ & 66 & F & $\begin{array}{l}\text { Renal cell } \\
\text { carcinoma } \\
\text { (RCC) }\end{array}$ & $\begin{array}{l}\text { Kidney } \\
\text { (right) }\end{array}$ & $\begin{array}{l}\text { Nephrectomy, } \\
\text { TKI, immuno- } \\
\text { therapy }\end{array}$ & $\begin{array}{c}\text { Abdominal } \\
\text { mass. } \\
\text { retroperi- } \\
\text { toneal + } \\
\text { peritoneal } \\
\text { LNs, lung }\end{array}$ & $\begin{array}{l}\text { Tyrosine } \\
\text { kinase } \\
\text { inhibitors } \\
\text { (sunitinib, } \\
\text { axitinib) }\end{array}$ & $\begin{array}{l}36 \mathrm{~Gy}, \\
12 \mathrm{fr}\end{array}$ & $\begin{array}{c}\text { Abdominal } \\
\text { mass }\end{array}$ & Lung & 1 month & $\underset{\text { Nivolumab }}{\text { (PD-1) }}$ & \\
\hline \multirow[b]{2}{*}{$\begin{array}{l}\text { Wight et al. } \\
\text { (2018) } \\
{[70]}\end{array}$} & \multirow[b]{2}{*}{24} & \multirow[b]{2}{*}{ M } & \multirow[b]{2}{*}{$\begin{array}{l}\text { Hodgkin } \\
\text { lymphoma }\end{array}$} & \multirow[t]{2}{*}{$\begin{array}{c}\text { Left } \\
\text { axillary LN }\end{array}$} & \multirow{2}{*}{$\begin{array}{l}\text { BEAM } \\
\text { conditioning } \\
\text { (carmustine, } \\
\text { etoposide, } \\
\text { cytarabine, } \\
\text { melphalan) }\end{array}$} & \multirow{2}{*}{$\begin{array}{l}\text { lung, } \\
\text { widespread } \\
\text { lymph- } \\
\text { adenopathy }\end{array}$} & \multirow{2}{*}{$\begin{array}{l}\text { BEAM } \\
\text { conditioning } \\
\text { (carmustine, } \\
\text { etoposide, } \\
\text { cytarabine, } \\
\text { melphalan), } \\
\text { immuno- } \\
\text { therapy }\end{array}$} & $20 \mathrm{~Gy}$ & $\begin{array}{c}\text { Right } \\
\text { axillary LN }\end{array}$ & & & & \\
\hline & & & & & & & & $36 \mathrm{~Gy}$ & $\begin{array}{l}\text { Infra- } \\
\text { diaphrag- } \\
\text { matic } \\
\text { sites }\end{array}$ & $\begin{array}{c}\text { Left } \\
\text { pulmonary } \\
\text { hilar, left } \\
\text { parotid, } \\
\text { right } \\
\text { cervical } \\
\text { nodal areas }\end{array}$ & 1.5 month & $\underset{(\text { PD-1) }}{\text { Nivolumab }}$ & \\
\hline
\end{tabular}


Table 2. Cont.

\begin{tabular}{|c|c|c|c|c|c|c|c|c|c|c|c|c|c|}
\hline Reference & Age & Gender & $\begin{array}{c}\text { Histo- } \\
\text { Pathology }\end{array}$ & $\begin{array}{c}\text { Primary } \\
\text { Tumor Site }\end{array}$ & $\begin{array}{c}\text { Treatment of } \\
\text { Primary } \\
\text { Tumor }\end{array}$ & $\begin{array}{l}\text { Metastasis } \\
\text { Site }\end{array}$ & $\begin{array}{l}\text { Systemic } \\
\text { Treatment }\end{array}$ & RT & $\begin{array}{l}\text { Irradiation } \\
\text { Site }\end{array}$ & $\begin{array}{c}\text { Non- } \\
\text { Irradiated } \\
\text { Abscopal } \\
\text { Regression }\end{array}$ & $\begin{array}{c}\text { Time } \\
\text { Frame for } \\
\text { Abscopal } \\
\text { Response }\end{array}$ & $\begin{array}{l}\text { Immuno- } \\
\text { Therapy }\end{array}$ & $\begin{array}{l}\text { Reported } \\
\text { Parameters }\end{array}$ \\
\hline \multirow{3}{*}{$\begin{array}{l}\text { Xu et al. } \\
\text { (2018) } \\
\text { [71] }\end{array}$} & \multirow[b]{2}{*}{69} & \multirow[b]{2}{*}{ M } & \multirow[b]{2}{*}{$\begin{array}{l}\text { Merkel cell } \\
\text { carcinoma }\end{array}$} & \multirow[b]{2}{*}{$\begin{array}{c}\text { Right } \\
\text { upper back }\end{array}$} & \multirow[b]{2}{*}{$\begin{array}{c}\text { Surgical } \\
\text { excision, RT }\end{array}$} & \multirow[b]{2}{*}{$\begin{array}{c}\text { LNs, } \\
\text { peripancreatic } \\
\text { abdominal } \\
\text { mass, left } \\
\text { adrenal } \\
\text { nodule }\end{array}$} & \multirow[b]{2}{*}{$\begin{array}{l}\text { Immuno- } \\
\text { therapy }\end{array}$} & $\begin{array}{l}50 \mathrm{~Gy}, \\
25 \mathrm{fr}\end{array}$ & $\begin{array}{l}\text { Right } \\
\text { axilla, } \\
\text { posterior } \\
\text { chest wall }\end{array}$ & & & \multirow[b]{2}{*}{$\begin{array}{l}\text { Pembrolizumab } \\
\text { (PD-1) }\end{array}$} & \multirow{3}{*}{ СK20 } \\
\hline & & & & & & & & $\begin{array}{l}8 \mathrm{~Gy}, \\
1 \mathrm{fr}\end{array}$ & $\begin{array}{c}\text { Peripan- } \\
\text { creatic } \\
\text { abdominal } \\
\text { mass, left } \\
\text { adrenal } \\
\text { nodule, } \\
\text { omental } \\
\text { nodule, } \\
\text { enlarged } \\
\text { para-aortic } \\
\text { LNs }\end{array}$ & $\begin{array}{l}\text { Hypermetabolic } \\
\text { malig- } \\
\text { nancy }\end{array}$ & 12 months & & \\
\hline & 72 & M & $\begin{array}{l}\text { Merkel cell } \\
\text { carcinoma }\end{array}$ & Left thigh & $\begin{array}{l}\text { Surgical } \\
\text { excision }\end{array}$ & $\begin{array}{c}\text { Left inguinal } \\
\text { adenopathy, } \\
\text { bilateral } \\
\text { inguinal LNs, } \\
\text { supra- } \\
\text { clavicular, } \\
\text { mediastinal, } \\
\text { hilar, upper } \\
\text { abdominal } \\
\text { nodal }\end{array}$ & $\begin{array}{l}\text { Immuno- } \\
\text { therapy }\end{array}$ & $\begin{array}{l}8 \mathrm{~Gy}, \\
1 \mathrm{fr}\end{array}$ & $\begin{array}{l}\text { Mediastinal } \\
\text { + right } \\
\text { hilar LN }\end{array}$ & $\begin{array}{c}\text { Upraclavicular } \\
+ \\
\text { abdominal } \\
\text { LN, medi- } \\
\text { astinum, } \\
\text { bilateral } \\
\text { hila, left } \\
\text { inguinal } \\
\text { region }\end{array}$ & 4 months & $\begin{array}{l}\text { Pembrolizumab } \\
\text { (PD-1) }\end{array}$ & \\
\hline $\begin{array}{l}\text { Zhao et al. } \\
\text { (2018) } \\
\text { [72] }\end{array}$ & 65 & M & $\begin{array}{l}\text { Squamous } \\
\text { cell } \\
\text { carcinoma } \\
\text { (SCC) }\end{array}$ & $\begin{array}{l}\text { Esoph- } \\
\text { agus }\end{array}$ & $\begin{array}{l}\text { Esophagec- } \\
\text { tomy }\end{array}$ & $\begin{array}{l}\text { LNs (left retro- } \\
\text { peritoneal, } \\
\text { pelvic) }\end{array}$ & $\begin{array}{l}\text { Chemo- } \\
\text { therapy } \\
\text { (cisplatin, } \\
\text { docetaxel), } \\
\text { immuno- } \\
\text { therapy }\end{array}$ & $\begin{array}{l}42 \mathrm{~Gy}, \\
6 \mathrm{fr}\end{array}$ & $\begin{array}{l}\text { LNs (left } \\
\text { retro- } \\
\text { peritoneal) }\end{array}$ & $\begin{array}{c}\text { Non } \\
\text {-irradiated } \\
\text { LN (pelvic) }\end{array}$ & 2 months & $\begin{array}{l}\text { Pembrolizumab } \\
\quad \text { (PD-1) }\end{array}$ & $\begin{array}{l}\text { ctDNA, } \\
\text { mutant allele } \\
\text { frequency } \\
\text { (MAF) }\end{array}$ \\
\hline $\begin{array}{l}\text { Abbas et al. } \\
\quad(2019) \\
{[73]}\end{array}$ & 69 & M & $\begin{array}{l}\text { Urothelial } \\
\text { carcinoma }\end{array}$ & Bladder & $\begin{array}{l}\text { Chemo- } \\
\text { therapy } \\
\text { (gemcitabine, } \\
\text { carboplatin) }\end{array}$ & $\begin{array}{c}\text { Left internal } \\
\quad \text { iliac, } \\
\text { para-aortic LN }\end{array}$ & $\begin{array}{l}\text { Chemo- } \\
\text { therapy, } \\
\text { immuno- } \\
\text { therapy }\end{array}$ & $\begin{array}{l}30 \mathrm{~Gy}, \\
12 \mathrm{fr}\end{array}$ & $\begin{array}{l}\text { Bladder } \\
\text { left iliac } \\
\text { LN }\end{array}$ & All sites & 4 months & $\begin{array}{c}\text { Nivolumab } \\
\text { (PD-1) }\end{array}$ & $\begin{array}{l}\text { History of } \\
\text { tobacco use, } \\
\text { PD-L1 }\end{array}$ \\
\hline $\begin{array}{l}\text { Bitran et al. } \\
\quad(2019) \\
{[74]}\end{array}$ & 62 & F & $\begin{array}{l}\text { Adeno- } \\
\text { carcinoma } \\
\text { (lung) }\end{array}$ & Lung (left) & $\begin{array}{c}\text { Chemo- } \\
\text { therapy } \\
\text { (carboplatin, } \\
\text { pemetrexed) }\end{array}$ & Left adrenal & $\begin{array}{c}\text { Chemo- } \\
\text { therapy } \\
\text { (carboplatin, } \\
\text { pemetrexed), } \\
\text { immuno- } \\
\text { therapy }\end{array}$ & $\begin{array}{l}27 \mathrm{~Gy}, \\
9 \mathrm{fr}\end{array}$ & Left lung & $\begin{array}{l}\text { Left } \\
\text { adrenal }\end{array}$ & 7 months & $\begin{array}{c}\text { Nivolumab } \\
\text { (PD-1) }\end{array}$ & $\begin{array}{l}\text { Epidermal } \\
\text { growth factor } \\
\text { receptor } \\
\text { (EGFR), } \\
\text { anaplastic } \\
\text { lymphoma } \\
\text { kinase (ALK), } \\
\text { hemoglobin } \\
\end{array}$ \\
\hline \multirow{2}{*}{$\begin{array}{l}\text { Choi et al. } \\
(2019) \\
{[75]}\end{array}$} & \multirow[t]{2}{*}{67} & \multirow[t]{2}{*}{ M } & \multirow{2}{*}{$\begin{array}{l}\text { Squamous } \\
\text { cell } \\
\text { carcinoma } \\
\text { (SCC) }\end{array}$} & \multirow[t]{2}{*}{ Lower lip } & \multirow[t]{2}{*}{ Resection } & \multirow{2}{*}{$\begin{array}{l}\text { Hilar nodes, } \\
\text { liver, } \\
\text { peritoneum, } \\
\text { right parotid, } \\
\text { right neck, } \\
\text { mediastinum, } \\
\text { left hilum, } \\
\text { posterior neck } \\
\text { subcutaneous } \\
\text { tissue, lung, } \\
\text { left adrenal }\end{array}$} & \multirow{2}{*}{$\begin{array}{l}\text { Immuno- } \\
\text { therapy, } \\
\text { cobimetinib }\end{array}$} & $\begin{array}{c}\text { Post- } \\
\text { operative }\end{array}$ & $\begin{array}{l}\text { Resection } \\
\text { margin }\end{array}$ & & & \multirow[t]{2}{*}{$\begin{array}{l}\text { Atezolizumab } \\
\text { (PDL1) }\end{array}$} & \\
\hline & & & & & & & & $\begin{array}{l}45 \mathrm{~Gy}, \\
5 \mathrm{fr}\end{array}$ & $\begin{array}{l}\text { Right sub- } \\
\text { mandibular } \\
\text { + neck } \\
\text { nodes }\end{array}$ & $\begin{array}{l}\text { Abdomen, } \\
\text { chest }\end{array}$ & $\begin{array}{c}13 \\
\text { months }\end{array}$ & & \\
\hline $\begin{array}{c}\text { D'Andrea } \\
\text { et al. (2019) } \\
\text { [76] }\end{array}$ & 42 & F & Melanoma & $\begin{array}{c}\text { Right } \\
\text { upper skin } \\
\text { of back }\end{array}$ & $\begin{array}{l}\text { Surgical } \\
\text { excision }\end{array}$ & $\begin{array}{l}\text { Upper-right } \\
\text { retro pectoral } \\
\text { region of chest } \\
\text { wall, right } \\
\text { ovary, brain } \\
\text { axilla }\end{array}$ & $\begin{array}{l}\text { Immuno- } \\
\text { therapy }\end{array}$ & $\begin{array}{l}30 \mathrm{~Gy}, \\
15 \mathrm{fr}\end{array}$ & $\begin{array}{l}\text { Whole } \\
\text { brain }\end{array}$ & $\begin{array}{l}\text { Chest, } \\
\text { axilla }\end{array}$ & 3 weeks & $\begin{array}{l}\text { MAPK } \\
\text { kinase } \\
\text { (MEK) } \\
\text { inhibitor }\end{array}$ & $\begin{array}{c}\text { BRAF } \\
\text { mutation, RBI } \\
\text { mutation, } \\
\text { ERCC1, } \\
\text { MLH1, MSH2, } \\
\text { MSH6, PMS2, } \\
\text { TUBB3, PDL-1, } \\
\text { TrK A/B/C, } \\
\text { MGMT } \\
\text { expression }\end{array}$ \\
\hline \multirow{3}{*}{$\begin{array}{c}\text { Garelli } \\
\text { et al. (2019) } \\
\text { [77] }\end{array}$} & 54 & M & $\begin{array}{l}\text { Pulmonary } \\
\text { large cell } \\
\text { neuro- } \\
\text { endocrine } \\
\text { carcinoma }\end{array}$ & $\begin{array}{l}\text { Lung (right } \\
\text { upper } \\
\text { lobe) }\end{array}$ & $\begin{array}{c}\text { Four cycles of } \\
\text { chemotherapy } \\
\text { (pemetrexed, } \\
\text { cisplatin, } \\
\text { bevacizumab) }\end{array}$ & $\begin{array}{l}\text { Bilateral } \\
\text { adrenal } \\
\text { metastases }\end{array}$ & $\begin{array}{l}\text { Chemo- } \\
\text { therapy, } \\
\text { immuno- } \\
\text { therapy }\end{array}$ & $\begin{array}{l}30 \mathrm{~Gy}, \\
10 \mathrm{fr}\end{array}$ & $\begin{array}{c}\text { Second + } \\
\text { third } \\
\text { thoracic } \\
\text { vertebrae }\end{array}$ & $\begin{array}{c}\text { Partial } \\
\text { regression } \\
\text { of lung } \\
\text { tumor }+ \\
\text { adrenal } \\
\text { metastases }\end{array}$ & 4 months & $\begin{array}{c}\text { Nivolumab } \\
\quad \text { (PD-1) }\end{array}$ & \multirow{3}{*}{$\begin{array}{l}\text { PD-L1, EGFR, } \\
\text { or ALK } \\
\text { mutations }\end{array}$} \\
\hline & 64 & M & $\begin{array}{l}\text { Adeno- } \\
\text { carcinoma } \\
\text { (lung) }\end{array}$ & $\begin{array}{l}\text { Lung (left } \\
\text { upper } \\
\text { lobe) }\end{array}$ & $\begin{array}{l}\text { Nabpaclitaxel/ } \\
\text { carboplatin } \\
\text { with } \\
\text { atezolizumab }\end{array}$ & $\begin{array}{l}\text { Contralateral } \\
\text { LN, brain, } \\
\text { ocular }\end{array}$ & $\begin{array}{l}\text { Chemo- } \\
\text { therapy, } \\
\text { immuno- } \\
\text { therapy }\end{array}$ & $\begin{array}{l}30 \mathrm{~Gy}, \\
10 \mathrm{fr}\end{array}$ & Brain & $\begin{array}{c}\text { Complete } \\
\text { remission } \\
\text { of lung + } \\
\text { mediasti- } \\
\text { nal tumor } \\
\text { masses }\end{array}$ & 4 months & $\begin{array}{c}\text { Atezolizumab } \\
\text { (PDL1) }\end{array}$ & \\
\hline & 70 & M & $\begin{array}{l}\text { Adeno- } \\
\text { carcinoma } \\
\text { (lung) }\end{array}$ & $\begin{array}{l}\begin{array}{l}\text { Lung } \\
\text { (middle } \\
\text { lob) }\end{array} \\
\text {. }\end{array}$ & $\mathrm{n} / \mathrm{a}$ & LN, brain & $\begin{array}{l}\text { Immuno- } \\
\text { therapy }\end{array}$ & $\begin{array}{l}30 \mathrm{~Gy}, \\
10 \mathrm{fr}\end{array}$ & Brain & $\begin{array}{l}\text { Partial } \\
\text { regression } \\
\text { of lung } \\
\text { tumor }\end{array}$ & 2 weeks & $\begin{array}{l}\text { Pembrolizumab } \\
\quad \text { (PD-1) }\end{array}$ & \\
\hline $\begin{array}{c}\text { Gounder } \\
\text { et al. (2019) } \\
\text { [78] }\end{array}$ & 25 & F & Chordoma & Sacrum & $\mathrm{n} / \mathrm{a}$ & Lung & $\begin{array}{c}\text { EZH2 } \\
\text { inhibitor } \\
\text { (tazemetostat) }\end{array}$ & $\begin{array}{l}70 \mathrm{~Gy}, \\
35 \mathrm{fr}\end{array}$ & Sacrum & Lung & 4 months & $\underset{\text { Nivolumab }}{\text { (PD-1) }}$ & $\begin{array}{l}\text { Next- } \\
\text { generation } \\
\text { sequencing, } \\
\text { tumor } \\
\text { mutation } \\
\text { burden }\end{array}$ \\
\hline
\end{tabular}


Table 2. Cont.

\begin{tabular}{|c|c|c|c|c|c|c|c|c|c|c|c|c|c|}
\hline Reference & Age & Gender & $\begin{array}{c}\text { Histo- } \\
\text { Pathology }\end{array}$ & $\begin{array}{c}\text { Primary } \\
\text { Tumor Site }\end{array}$ & $\begin{array}{c}\text { Treatment of } \\
\text { Primary } \\
\text { Tumor }\end{array}$ & $\begin{array}{l}\text { Metastasis } \\
\text { Site }\end{array}$ & $\begin{array}{l}\text { Systemic } \\
\text { Treatment }\end{array}$ & RT & $\begin{array}{l}\text { Irradiation } \\
\text { Site }\end{array}$ & $\begin{array}{c}\text { Non- } \\
\text { Irradiated } \\
\text { Abscopal } \\
\text { Regression }\end{array}$ & $\begin{array}{c}\text { Time } \\
\text { Frame for } \\
\text { Abscopal } \\
\text { Response }\end{array}$ & $\begin{array}{l}\text { Immuno- } \\
\text { Therapy }\end{array}$ & $\begin{array}{l}\text { Reported } \\
\text { Parameters }\end{array}$ \\
\hline $\begin{array}{c}\text { Grimaux } \\
\text { et al. (2019) } \\
{[79]}\end{array}$ & 78 & M & $\begin{array}{c}\text { Renal cell } \\
\text { carcinoma } \\
\text { (RCC) }\end{array}$ & Kidney & $\begin{array}{l}\text { Immuno- } \\
\text { therapy }\end{array}$ & $\begin{array}{l}\text { Pulmonary + } \\
\text { costal } \\
\text { metastasis, } \\
\text { cutaneous, } \\
\text { oral + genital } \\
\text { blisters, }\end{array}$ & $\begin{array}{l}\text { Immuno- } \\
\text { therapy }\end{array}$ & $\begin{array}{l}30 \mathrm{~Gy}, \\
10 \mathrm{fr}\end{array}$ & $\begin{array}{c}\text { Costal } \\
\text { metastases }\end{array}$ & Lung & 1 month & $\begin{array}{c}\text { Nivolumab } \\
\text { (PD-1) }\end{array}$ & \\
\hline \multirow{2}{*}{$\begin{array}{c}\text { Ishiyamal } \\
\text { et al. (2019) } \\
\text { [80] }\end{array}$} & \multirow{2}{*}{68} & \multirow{2}{*}{ F } & \multirow{2}{*}{$\begin{array}{l}\text { Renal } \\
\text { pelvic } \\
\text { cancer }\end{array}$} & \multirow{2}{*}{ Left kidney } & \multirow{2}{*}{$\begin{array}{c}\text { Nephroureter } \\
\text { ectomy + } \\
\text { regional LN } \\
\text { dissection, } \\
\text { chemotherapy } \\
\text { (cisplatin + } \\
\text { gemcitabine) }\end{array}$} & \multirow{2}{*}{$\begin{array}{l}\text { Bladder, } \\
\text { paraaortic LN, } \\
\text { left subclavian } \\
\text { LN, right renal } \\
\text { hilum LN, left } \\
\text { back (local } \\
\text { recurrence in } \\
\text { surrounding } \\
\text { muscles) }\end{array}$} & $\begin{array}{l}\text { Chemo- } \\
\text { therapy }\end{array}$ & \multirow{2}{*}{$\begin{array}{l}30 \mathrm{~Gy}, \\
10 \mathrm{fr}\end{array}$} & \multirow{2}{*}{ Left back } & $\begin{array}{c}\text { Reductiomn } \\
2 \\
\text { paraaortic } \\
\text { LNs, right } \\
\text { renal hilar } \\
\text { LN }\end{array}$ & 2 months & \multirow{2}{*}{$\begin{array}{l}\text { Pembrolizumab } \\
\quad \text { (PD-1) }\end{array}$} & \\
\hline & & & & & & & $\begin{array}{l}\text { Immuno- } \\
\text { therapy }\end{array}$ & & & $\begin{array}{c}2 \text { non- } \\
\text { irradiated } \\
\text { lesions } \\
\text { stable } \\
\text { (paraaortic } \\
\text { LN, right } \\
\text { renal } \\
\text { hilum LN) }\end{array}$ & 21 months & & \\
\hline $\begin{array}{l}\text { Lin et al. } \\
\text { (2019) } \\
{[81]}\end{array}$ & 71 & M & $\begin{array}{l}\text { Adeno- } \\
\text { carcinoma } \\
\text { (lung) }\end{array}$ & $\begin{array}{l}\text { Lung (right } \\
\text { lobe) }\end{array}$ & $\begin{array}{l}\text { Chemo- } \\
\text { therapy }\end{array}$ & $\begin{array}{l}\text { Brain, right } \\
\text { lower lung, } \\
\text { left lower lobe }\end{array}$ & $\begin{array}{l}\text { Chemo- } \\
\text { therapy, } \\
\text { immuno- } \\
\text { therapy }\end{array}$ & $\begin{array}{l}48 \mathrm{~Gy}, \\
8 \mathrm{fr}\end{array}$ & Brain & $\begin{array}{l}\text { Lung, LNs } \\
\text { (medi- } \\
\text { astinum) }\end{array}$ & 4 months & $\begin{array}{l}\text { Atezolizumab } \\
\text { (PDL1) }\end{array}$ & \\
\hline \multirow{3}{*}{$\begin{array}{l}\text { Liu et al. } \\
\text { (2019) } \\
\text { [82] }\end{array}$} & 52 & $\mathrm{~F}$ & $\begin{array}{l}\text { Intra- } \\
\text { hepatic } \\
\text { cholangio- } \\
\text { carcinoma }\end{array}$ & Liver & RT & $\begin{array}{l}\text { LN in hepatic } \\
\text { hilar + retro- } \\
\text { peritoneum }\end{array}$ & $\begin{array}{l}\text { Aapatinib + } \\
\text { lenvatinib }\end{array}$ & $\begin{array}{l}55 \mathrm{~Gy}, \\
5 \mathrm{fr}\end{array}$ & $\begin{array}{l}\text { Right } \\
\text { hepatic } \\
\text { lobe }\end{array}$ & $\begin{array}{c}\text { LN in } \\
\text { hepatic } \\
\text { hilar + } \\
\text { retroperi- } \\
\text { toneum }\end{array}$ & 1 month & $\begin{array}{c}\text { Nivolumab } \\
\text { (PD-1) }\end{array}$ & \multirow{3}{*}{$\begin{array}{l}\text { Whole-exome } \\
\text { sequencing, } \\
\text { tumor } \\
\text { mutation } \\
\text { burden, } \\
\text { PD-L1, ERBB2, } \\
\text { HBV infection }\end{array}$} \\
\hline & 59 & M & $\begin{array}{l}\text { Intra- } \\
\text { hepatic } \\
\text { cholangio- } \\
\text { carcinoma }\end{array}$ & Liver & $\begin{array}{l}\text { Resection of } \\
\text { middle } \\
\text { hepatic lobe }\end{array}$ & $\begin{array}{c}\text { Left }+ \text { right } \\
\text { lobes, hepatic } \\
\text { hilar + } \\
\text { retroperi- } \\
\text { toneal } \\
\text { LN } \\
\end{array}$ & Lapatinib & $\begin{array}{l}52 \mathrm{~Gy}, \\
4 \mathrm{fr}\end{array}$ & $\begin{array}{l}\text { Right } \\
\text { hepatic } \\
\text { lobe }\end{array}$ & $\begin{array}{c}\text { Hepatic } \\
\text { hilar + } \\
\text { retroperi- } \\
\text { toneal } \\
\text { LN }\end{array}$ & $\begin{array}{c}2 \text { to } \\
5 \text { months }\end{array}$ & $\begin{array}{l}\text { Pembrol } \\
\text { izumab } \\
\text { (PD-1) }\end{array}$ & \\
\hline & 51 & M & $\begin{array}{l}\text { Intra- } \\
\text { hepatic } \\
\text { cholangio- } \\
\text { carcinoma }\end{array}$ & Liver & $\begin{array}{l}\text { Resection in } \\
\text { left hepatic } \\
\text { lobe }\end{array}$ & $\begin{array}{c}\text { Right lobe } \\
\text { hepatic hilar + } \\
\text { retro- } \\
\text { peritoneal } \\
\text { lymph node }\end{array}$ & $\begin{array}{l}\text { Chemo- } \\
\text { therapy, } \\
\text { endostatin }\end{array}$ & $\begin{array}{l}52 \mathrm{~Gy}, \\
4 \mathrm{fr}\end{array}$ & $\begin{array}{l}\text { Left } \\
\text { hepatic } \\
\text { lobe, left } \\
\text { retroperi- } \\
\text { toneal } \\
\text { LN }\end{array}$ & $\begin{array}{l}\text { Intrahepatic } \\
\text { LN }\end{array}$ & 1 month & $\begin{array}{l}\text { Pembrolizumab } \\
\quad \text { (PD-1) }\end{array}$ & \\
\hline $\begin{array}{c}\text { Moran } \\
\text { et al. (2019) } \\
\text { [83] }\end{array}$ & 71 & M & Melanoma & Unknown & $\mathrm{n} / \mathrm{a}$ & $\begin{array}{l}\text { Lung, pelvis, } \\
\text { omental mass, } \\
\text { bilateral hilar } \\
\text { nodes }\end{array}$ & $\begin{array}{l}\text { Immuno- } \\
\text { therapy }\end{array}$ & $\begin{array}{l}50 \mathrm{~Gy}, \\
5 \mathrm{fr}\end{array}$ & left lung & Pelvis & 1 month & $\begin{array}{l}\text { Ipilimumab } \\
\text { (CTLA-4), } \\
\text { Nivolumab } \\
\text { (PD-1) }\end{array}$ & $\begin{array}{c}\text { S100, Melan A, } \\
\text { TTF1, P63, } \\
\text { CK7/20, } \\
\text { BRAF } \\
\text { mutations }\end{array}$ \\
\hline \multirow{3}{*}{$\begin{array}{l}\text { Qin et al. } \\
(2019) \\
{[84]}\end{array}$} & 21 & M & $\begin{array}{l}\text { Nodular } \\
\text { sclerosing } \\
\text { Hodgkin's } \\
\text { lymphoma }\end{array}$ & $\mathrm{n} / \mathrm{a}$ & $\begin{array}{l}\text { Different } \\
\text { chemotherapy } \\
\text { regimes }\end{array}$ & $\begin{array}{l}\text { Multiple sites } \\
\text { of adenopathy, } \\
\text { osseous } \\
\text { lesions }\end{array}$ & $\begin{array}{l}\text { Chemo- } \\
\text { therapy, stell } \\
\text { cell trans- } \\
\text { plantation, } \\
\text { immuno- } \\
\text { therapy }\end{array}$ & $\begin{array}{l}20 \mathrm{~Gy}, \\
5 \mathrm{fr}\end{array}$ & $\begin{array}{l}\text { L2, left iliac } \\
\text { crest }\end{array}$ & $\begin{array}{l}\text { Complete } \\
\text { response }\end{array}$ & 4 months & \multirow{2}{*}{$\begin{array}{c}\text { Nivolumab } \\
\quad(\text { PD-1) }\end{array}$} & \multirow{3}{*}{$\begin{array}{c}\text { PD-L1 } \\
\text { expression, } \\
\text { gene } \\
\text { mutations, } \\
\text { tumor } \\
\text { mutation } \\
\text { burden, } \\
\text { hemoglobin, } \\
\text { alkaline } \\
\text { phosphatase, } \\
\text { telomere FISH }\end{array}$} \\
\hline & 34 & M & $\begin{array}{l}\text { Nodular } \\
\text { sclerosing } \\
\text { Hodgkin's } \\
\text { lymphoma }\end{array}$ & $\mathrm{n} / \mathrm{a}$ & $\begin{array}{l}\text { Chemo- } \\
\text { therapy } \\
\text { (ICE) }\end{array}$ & $\begin{array}{l}\text { Preaortic + } \\
\text { pelvic LNs }\end{array}$ & $\begin{array}{l}\text { Chemo- } \\
\text { therapy (ICE), } \\
\text { stell cell trans- } \\
\text { plantation, } \\
\text { immuno- } \\
\text { therapy }\end{array}$ & $\begin{array}{l}36 \mathrm{~Gy}, \\
20 \mathrm{fr}\end{array}$ & Pelvic LNs & $\begin{array}{l}\text { Complete } \\
\text { response }\end{array}$ & 1 year & & \\
\hline & 23 & M & $\begin{array}{l}\text { Nodular } \\
\text { sclerosing } \\
\text { Hodgkin's } \\
\text { lymphoma }\end{array}$ & $\mathrm{n} / \mathrm{a}$ & $\begin{array}{c}\text { ABVD } \\
\text { chemotherapy }\end{array}$ & $\begin{array}{l}\text { Mediastinum, } \\
\text { multiple LNs }\end{array}$ & $\begin{array}{l}\text { ABVD chemo- } \\
\text { therapy, } \\
\text { immuno- } \\
\text { therapy }\end{array}$ & $\begin{array}{l}40 \mathrm{~Gy}, \\
20 \mathrm{fr}\end{array}$ & $\begin{array}{c}\text { Cervical + } \\
\text { mediasti- } \\
\text { nal } \\
\text { LNs }\end{array}$ & $\begin{array}{l}\text { Complete } \\
\text { response }\end{array}$ & 5 months & $\begin{array}{c}\text { Nivolumab } \\
\text { (PD-1) }\end{array}$ & \\
\hline \multirow{2}{*}{$\begin{array}{l}\text { Shinde } \\
\text { et al. (2019) } \\
\text { [85] }\end{array}$} & \multirow[t]{2}{*}{75} & \multirow[t]{2}{*}{ M } & \multirow{2}{*}{$\begin{array}{c}\text { Head + } \\
\text { neck } \\
\text { squamous } \\
\text { cell } \\
\text { carcinoma }\end{array}$} & \multirow{2}{*}{$\begin{array}{l}\text { Left neck, } \\
\text { hypo- } \\
\text { pharynx + } \\
\text { orophar- } \\
\text { ynx }\end{array}$} & \multirow[t]{2}{*}{$\begin{array}{l}\text { Immuno- } \\
\text { therapy }\end{array}$} & \multirow[t]{2}{*}{ Left lung } & \multirow[t]{2}{*}{ Immunotherapy } & $\begin{array}{c}14.8 \mathrm{~Gy}, \\
4 \mathrm{fr}\end{array}$ & Neck & \multirow[t]{2}{*}{ Lung } & \multirow[t]{2}{*}{2 weeks } & \multirow{2}{*}{$\begin{array}{l}\text { Ipilimumab } \\
\text { (CTLA-4), } \\
\text { Nivolumab } \\
\text { (PD-1) }\end{array}$} & \multirow[t]{2}{*}{$\begin{array}{l}\text { History of } \\
\text { tobacco use }\end{array}$} \\
\hline & & & & & & & & $\begin{array}{l}13.2 \mathrm{~Gy} \\
4 \mathrm{fr}\end{array}$ & Margin & & & & \\
\hline \multirow[b]{2}{*}{$\begin{array}{c}\text { Suzuki } \\
\text { et al. (2019) } \\
{[86]}\end{array}$} & \multirow[b]{2}{*}{30} & \multirow[b]{2}{*}{ F } & \multirow[b]{2}{*}{$\begin{array}{l}\text { Renal cell } \\
\text { carcinoma } \\
\text { (RCC) }\end{array}$} & \multirow[b]{2}{*}{ Left kidney } & \multirow[b]{2}{*}{ Nephrectomy } & \multirow{2}{*}{$\begin{array}{l}\text { Lung, right } \\
\text { ovarian, pelvic } \\
\text { + lumber } \\
\text { vertebrae, } \\
\text { hilar LN, } \\
\text { mediastinal } \\
\text { LNs, liver, left } \\
\text { iliac bone }\end{array}$} & & $\begin{array}{l}60 \mathrm{~Gy}, \\
30 \mathrm{fr}\end{array}$ & $\begin{array}{l}\text { Mediastinal } \\
\text { LNs }\end{array}$ & & & & \\
\hline & & & & & & & $\begin{array}{l}\text { Sunitinib, } \\
\text { axitinib }\end{array}$ & $\begin{array}{l}35 \mathrm{~Gy}, \\
5 \mathrm{fr} \\
\text { (brachy- } \\
\text { therapy) }\end{array}$ & $\begin{array}{l}\text { Left iliac } \\
\text { lesion left } \\
\text { internal } \\
\text { iliac LN }\end{array}$ & $\begin{array}{c}\text { Lumbar } \\
\text { vertebrae } \\
\text { (L4) }\end{array}$ & 3 months & $\begin{array}{c}\text { Nivolumab } \\
\quad \text { (PD-1) }\end{array}$ & LDH levels \\
\hline
\end{tabular}


Table 2. Cont.

\begin{tabular}{|c|c|c|c|c|c|c|c|c|c|c|c|c|c|}
\hline Reference & Age & Gender & $\begin{array}{c}\text { Histo- } \\
\text { Pathology }\end{array}$ & $\begin{array}{c}\text { Primary } \\
\text { Tumor Site }\end{array}$ & $\begin{array}{l}\text { Treatment of } \\
\text { Primary } \\
\text { Tumor }\end{array}$ & $\begin{array}{l}\text { Metastasis } \\
\text { Site }\end{array}$ & $\begin{array}{l}\text { Systemic } \\
\text { Treatment }\end{array}$ & RT & $\begin{array}{l}\text { Irradiation } \\
\text { Site }\end{array}$ & $\begin{array}{c}\text { Non- } \\
\text { Irradiated } \\
\text { Abscopal } \\
\text { Regression }\end{array}$ & $\begin{array}{l}\text { Time } \\
\text { Frame for } \\
\text { Abscopal } \\
\text { Response }\end{array}$ & $\begin{array}{l}\text { Immuno- } \\
\text { Therapy }\end{array}$ & $\begin{array}{c}\text { Reported } \\
\text { Parameters }\end{array}$ \\
\hline \multirow{18}{*}{$\begin{array}{c}\text { Trommer } \\
\text { et al. (2019) } \\
\text { [87] }\end{array}$} & \multirow[t]{2}{*}{$\mathrm{n} / \mathrm{a}$} & \multirow[t]{2}{*}{$\mathrm{n} / \mathrm{a}$} & \multirow[t]{2}{*}{ Melanoma } & \multirow[t]{2}{*}{ Left thigh } & \multirow[t]{2}{*}{ Resection } & \multirow{2}{*}{$\begin{array}{c}\text { Lung, } \\
\text { paraaortal LN, } \\
\text { brain }\end{array}$} & \multirow[t]{2}{*}{$\begin{array}{l}\text { Immuno- } \\
\text { therapy }\end{array}$} & $\begin{array}{l}20 \mathrm{~Gy}, \\
1 \mathrm{fr}\end{array}$ & Brain & & & \multirow{2}{*}{$\begin{array}{c}\text { Pembrolizu } \\
\text { mab } \\
\text { (PD-1) }\end{array}$} & \\
\hline & & & & & & & & $\begin{array}{l}50 \mathrm{~Gy}, \\
2 \mathrm{fr}\end{array}$ & Brain & Lung & 1 month & & \\
\hline & \multirow{3}{*}{$\mathrm{n} / \mathrm{a}$} & \multirow{3}{*}{$\mathrm{n} / \mathrm{a}$} & \multirow{3}{*}{ Melanoma } & \multirow{3}{*}{ Left knee } & \multirow{3}{*}{ Resection } & \multirow{3}{*}{$\begin{array}{l}\text { Perirenal } \\
\text { region, brain }\end{array}$} & \multirow{3}{*}{$\begin{array}{l}\text { Immuno- } \\
\text { therapy }\end{array}$} & $\begin{array}{l}40 \mathrm{~Gy}, \\
2 \mathrm{fr}\end{array}$ & $\begin{array}{l}\text { Whole } \\
\text { brain }\end{array}$ & & & \multirow{3}{*}{$\begin{array}{c}\text { Pembrolizu } \\
\text { mab } \\
\text { (PD-1) }\end{array}$} & \\
\hline & & & & & & & & $\begin{array}{l}54 \mathrm{~Gy}, \\
3 \mathrm{fr}\end{array}$ & $\begin{array}{c}\text { Popliteal } \\
\text { fossa }+ \\
\text { lower left } \\
\text { leg, brain }\end{array}$ & $\begin{array}{l}\text { Perirenal } \\
\text { region }\end{array}$ & 1.5 month & & \\
\hline & & & & & & & & $\begin{array}{l}20 \mathrm{~Gy}, \\
1 \mathrm{fr}\end{array}$ & Brain & & & & \\
\hline & \multirow{3}{*}{$\mathrm{n} / \mathrm{a}$} & \multirow{3}{*}{$\mathrm{n} / \mathrm{a}$} & \multirow{3}{*}{ Melanoma } & \multirow{3}{*}{$\mathrm{n} / \mathrm{a}$} & \multirow{3}{*}{$\mathrm{n} / \mathrm{a}$} & \multirow{3}{*}{ Lung, brain } & \multirow{3}{*}{$\begin{array}{l}\text { Immuno- } \\
\text { therapy }\end{array}$} & $\begin{array}{l}20 \mathrm{~Gy}, \\
1 \mathrm{fr}\end{array}$ & Brain & & & \multirow{3}{*}{$\begin{array}{c}\text { Pembrolizu } \\
\text { mab } \\
\text { (PD-1) }\end{array}$} & \\
\hline & & & & & & & & $\begin{array}{l}20 \mathrm{~Gy}, \\
1 \mathrm{fr}\end{array}$ & Brain & & & & \\
\hline & & & & & & & & $\begin{array}{c}20 \mathrm{~Gy}, \\
1 \mathrm{fr}\end{array}$ & Brain & Lung & 5 weeks & & \\
\hline & \multirow[t]{3}{*}{$\mathrm{n} / \mathrm{a}$} & \multirow[t]{3}{*}{$\mathrm{n} / \mathrm{a}$} & \multirow{3}{*}{$\begin{array}{l}\text { Non-small } \\
\text { cell lung } \\
\text { carcinoma } \\
\text { (NSCLC) }\end{array}$} & \multirow[t]{3}{*}{ Lung } & \multirow[t]{3}{*}{$\mathrm{n} / \mathrm{a}$} & $\begin{array}{c}\text { Suprarenal } \\
\text { glands, brain, } \\
\text { right femur os }\end{array}$ & $\begin{array}{l}\text { Immuno- } \\
\text { therapy }\end{array}$ & $\begin{array}{r}27 \mathrm{~Gy}, \\
3 \mathrm{fr} ; \\
20 \mathrm{~Gy} \\
\end{array}$ & Brain & & & $\begin{array}{c}\text { Nivolumab } \\
\text { (PD-1) }\end{array}$ & \\
\hline & & & & & & $\begin{array}{l}\text { sacrum left os. } \\
\text { ischiadicum }\end{array}$ & & $\begin{array}{l}30 \mathrm{~Gy}, \\
3 \mathrm{fr}\end{array}$ & $\begin{array}{l}\text { Right } \\
\text { femur }\end{array}$ & $\begin{array}{l}\text { Suprarenal } \\
\text { glands }\end{array}$ & 1 month & & \\
\hline & & & & & & & & $\begin{array}{l}30 \mathrm{~Gy}, \\
3 \mathrm{fr}\end{array}$ & $\begin{array}{c}\text { Os. } \\
\text { sacrum, } \\
\text { left os. is- } \\
\text { chiadicum }\end{array}$ & & & & \\
\hline & $\mathrm{n} / \mathrm{a}$ & $\mathrm{n} / \mathrm{a}$ & $\begin{array}{l}\text { Non-small } \\
\text { cell lung } \\
\text { carcinoma } \\
\text { (NSCLC) }\end{array}$ & Lung & $\mathrm{n} / \mathrm{a}$ & $\begin{array}{c}\text { Cervival + left } \\
\text { super- } \\
\text { vlavicular, } \\
\text { mediastinal } \\
\text { Ln, left hilar, } \\
\text { axillar LN, } \\
\text { intracarinal } \\
\text { LN }\end{array}$ & $\begin{array}{l}\text { Immuno- } \\
\text { therapy }\end{array}$ & $\begin{array}{l}54 \mathrm{~Gy}, \\
2 \mathrm{fr}\end{array}$ & $\begin{array}{l}\text { Cervival + } \\
\text { left super- } \\
\text { vlavicular }\end{array}$ & axillar LN & 6 months & $\begin{array}{l}\text { Nivolumab } \\
\quad \text { (PD-1) }\end{array}$ & \\
\hline & $\mathrm{n} / \mathrm{a}$ & $\mathrm{n} / \mathrm{a}$ & $\begin{array}{l}\text { Non-small } \\
\text { cell lung } \\
\text { carcinoma } \\
\text { (NSCLC) }\end{array}$ & Lung & $\mathrm{n} / \mathrm{a}$ & $\begin{array}{l}\text { Supra- + infra- } \\
\text { clavicular } \\
\text { lymph } \\
\text { drainage area, }\end{array}$ & $\begin{array}{l}\text { Immuno- } \\
\text { therapy }\end{array}$ & $\begin{array}{l}50.4 \mathrm{~Gy}, \\
1.8 \mathrm{fr}\end{array}$ & $\begin{array}{c}\text { Supra- } \\
\text { infra- } \\
\text { clavicular } \\
\text { lymph } \\
\text { drainage } \\
\text { area }\end{array}$ & & & $\begin{array}{c}\text { Nivolumab } \\
\quad \text { (PD-1) }\end{array}$ & \\
\hline & & & & & & $\begin{array}{l}\text { 3rd right rib, } \\
\text { right iliac } \\
\text { sacral joint, } \\
\text { left inguinal, } \\
\text { lung }\end{array}$ & & $\begin{array}{l}30 \mathrm{~Gy}, \\
3 \mathrm{fr}\end{array}$ & $\begin{array}{c}\text { 3rd right } \\
\text { rib, right } \\
\text { iliac sacral } \\
\text { joint, left } \\
\text { inguinal }\end{array}$ & & & & \\
\hline & & & & & & & & $\begin{array}{l}20 \mathrm{~Gy}, \\
1 \mathrm{fr}\end{array}$ & $\begin{array}{c}\text { Left } \\
\text { occipital }\end{array}$ & Lung & 7 weeks & & \\
\hline & $\mathrm{n} / \mathrm{a}$ & $\mathrm{n} / \mathrm{a}$ & $\begin{array}{l}\text { Renal cell } \\
\text { carcinoma }\end{array}$ & Kidney & $\mathrm{n} / \mathrm{a}$ & $\begin{array}{l}\text { Left os. ilium, } \\
\text { left + right hip, }\end{array}$ & Immuno- & $\begin{array}{l}36 \mathrm{~Gy}, \\
3 \mathrm{fr}\end{array}$ & $\begin{array}{l}\text { Left os. } \\
\text { ilium }\end{array}$ & $\begin{array}{l}\text { mediastinal } \\
\text { LN }\end{array}$ & 2 months & Nivolumab & \\
\hline & & & (RCC) & & & $\begin{array}{l}\text { right os. pubis, } \\
\text { thoracic } \\
\text { vertebra, } \\
\text { lumbar }\end{array}$ & & $\begin{array}{l}30 \mathrm{~Gy}, \\
3 \mathrm{fr}\end{array}$ & $\begin{array}{l}\text { Left + right } \\
\text { hip, right } \\
\text { os. pubis }\end{array}$ & & & & \\
\hline & & & & & & $\begin{array}{c}\text { vertebra, } \\
\text { mediastinal } \\
\text { LN, hilar, } \\
\text { pleural }\end{array}$ & & $\begin{array}{l}30 \mathrm{~Gy}, \\
3 \mathrm{fr}\end{array}$ & $\begin{array}{l}\text { Thoracic } \\
\text { vertebra, } \\
\text { lumbar } \\
\text { vertebra }\end{array}$ & & & & \\
\hline $\begin{array}{c}\text { Yaguchi } \\
\text { et al. (2019) } \\
\text { [88] }\end{array}$ & 63 & M & $\begin{array}{c}\text { Pulmonary } \\
\text { pleo- } \\
\text { morphic } \\
\text { carcinoma }\end{array}$ & $\begin{array}{l}\text { Lung (right } \\
\text { upper } \\
\text { lobe) }\end{array}$ & $\begin{array}{l}\text { Chemo- } \\
\text { therapy } \\
\text { (carboplatin, } \\
\text { paclitaxel) }\end{array}$ & $\begin{array}{c}\text { Brain, bone + } \\
\text { pleural } \\
\text { metastases }\end{array}$ & $\begin{array}{c}\text { Chemo- } \\
\text { therapy } \\
\text { (carboplatin, } \\
\text { paclitaxel), } \\
\text { immuno- } \\
\text { therapy }\end{array}$ & 30 Gy, NR & $\begin{array}{l}\text { Right hip } \\
\text { joint over } \\
\text { right femur }\end{array}$ & $\begin{array}{c}\text { Pleura, } \\
\text { brain }+ \\
\text { bone }\end{array}$ & & $\begin{array}{c}\text { Nivolumab } \\
\text { (PD-1) }\end{array}$ & $\begin{array}{c}\text { History of } \\
\text { tobacco use, } \\
\text { PD-L1 } \\
\text { expression of } \\
\text { tumor, EGFR } \\
\text { mutation, } \\
\text { ALK }\end{array}$ \\
\hline Forner et al. & & & $\begin{array}{c}\text { Head + } \\
\text { neck }\end{array}$ & $\begin{array}{l}\text { Left frontal } \\
\text { sinus + }\end{array}$ & $\begin{array}{c}\text { Resection, } \\
\text { chemotherapy }\end{array}$ & $\begin{array}{l}\text { Right lower } \\
\text { lobe, left }\end{array}$ & $\begin{array}{l}\text { Chemo- } \\
\text { therapy }\end{array}$ & $\begin{array}{l}66 \mathrm{~Gy}, \\
33 \mathrm{fr}\end{array}$ & & & & & \\
\hline $\begin{array}{c}(2020) \\
{[89]}\end{array}$ & 57 & $\mathrm{M}$ & $\begin{array}{l}\text { squamous } \\
\text { cell } \\
\text { carcinoma }\end{array}$ & $\begin{array}{l}\text { ethmoid } \\
\text { sinuses }\end{array}$ & & $\begin{array}{c}\text { cervical LNs, } \\
\text { subcarinal LN, } \\
\text { extraconal } \\
\text { intraorbital } \\
\text { lesion }\end{array}$ & (cisplatin) & $\begin{array}{l}30 \mathrm{~Gy}, \\
5 \mathrm{fr}\end{array}$ & $\begin{array}{l}\text { Intraorbital } \\
\text { mass }\end{array}$ & $\begin{array}{c}\text { Thorax } \\
\text { metastases, } \\
\text { lung }\end{array}$ & 1 month & $\begin{array}{c}\text { Nivolumab } \\
\quad(\text { PD-1) }\end{array}$ & $\begin{array}{l}\text { Medical } \\
\text { history }\end{array}$ \\
\hline $\begin{array}{c}\text { Hori et al. } \\
(2020) \\
{[90]}\end{array}$ & 40 & F & $\begin{array}{l}\text { Renal cell } \\
\text { carcinoma } \\
\text { (RCC) }\end{array}$ & Left kidney & Nephrectomy & $\begin{array}{l}\text { Lung, right } \\
\text { supra- } \\
\text { clavicular + } \\
\text { para-aortic LN }\end{array}$ & $\begin{array}{l}\text { Interferon- } \alpha \text {, } \\
\text { axitinib, } \\
\text { everolimus, } \\
\text { pazopanib }\end{array}$ & $\begin{array}{l}30 \text { or } 40 \mathrm{~Gy}, \\
10 \mathrm{fr}\end{array}$ & $\begin{array}{c}\text { Right } \\
\text { supra- } \\
\text { clavicular + } \\
\text { para-aortic } \\
\text { LN }\end{array}$ & Lung & 6 months & $\begin{array}{c}\text { Nivolumab } \\
\text { (PD-1) }\end{array}$ & $\begin{array}{l}\text { HLA class1, } \\
\text { CD8, PD-L1 } \\
\text { expression of } \\
\text { tumor }\end{array}$ \\
\hline $\begin{array}{c}\text { Igarashi } \\
\text { et al. (2020) } \\
{[91]}\end{array}$ & 74 & $\mathrm{M}$ & Melanoma & Maxilla & $\begin{array}{l}\text { Maxillary } \\
\text { resection }\end{array}$ & $\begin{array}{l}\text { Cervical LNs, } \\
\text { brain, spleen, } \\
\text { liver }\end{array}$ & $\begin{array}{l}\text { Immuno- } \\
\text { therapy }\end{array}$ & $\begin{array}{l}30 \mathrm{~Gy}, \\
10 \mathrm{fr}\end{array}$ & $\begin{array}{l}\text { Whole } \\
\text { brain }\end{array}$ & $\begin{array}{l}\text { Liver, } \\
\text { spleen }\end{array}$ & 2 months & $\underset{(P D-1)}{\text { Nivolumab }}$ & $\begin{array}{l}\text { BRAF } \\
\text { mutation }\end{array}$ \\
\hline
\end{tabular}


Table 2. Cont.

\begin{tabular}{|c|c|c|c|c|c|c|c|c|c|c|c|c|c|}
\hline Reference & Age & Gender & $\begin{array}{c}\text { Histo- } \\
\text { Pathology }\end{array}$ & $\begin{array}{c}\text { Primary } \\
\text { Tumor Site }\end{array}$ & $\begin{array}{c}\text { Treatment of } \\
\text { Primary } \\
\text { Tumor }\end{array}$ & $\begin{array}{l}\text { Metastasis } \\
\text { Site }\end{array}$ & $\begin{array}{l}\text { Systemic } \\
\text { Treatment }\end{array}$ & RT & $\begin{array}{l}\text { Irradiation } \\
\text { Site }\end{array}$ & $\begin{array}{c}\text { Non- } \\
\text { Irradiated } \\
\text { Abscopal } \\
\text { Regression }\end{array}$ & $\begin{array}{l}\text { Time } \\
\text { Frame for } \\
\text { Abscopal } \\
\text { Response }\end{array}$ & $\begin{array}{l}\text { Immuno- } \\
\text { Therapy }\end{array}$ & $\begin{array}{c}\text { Reported } \\
\text { Parameters }\end{array}$ \\
\hline \multirow{2}{*}{$\begin{array}{c}\text { Kuhara } \\
\text { et al. (2020) } \\
\text { [92] }\end{array}$} & \multirow[t]{2}{*}{69} & \multirow[t]{2}{*}{ F } & \multirow[t]{2}{*}{$\begin{array}{c}\text { Un- } \\
\text { resectable } \\
\text { gastric } \\
\text { cancer } \\
\text { (UGC) }\end{array}$} & \multirow[t]{2}{*}{$\begin{array}{l}\text { Lower } \\
\text { portion of } \\
\text { stomach }\end{array}$} & \multirow{2}{*}{$\begin{array}{l}\text { Chemo- } \\
\text { therapy (S-1 } \\
\text { plus } \\
\text { oxaliplatin } \\
\text { (SOX) + } \\
\text { Herceptin } \\
\text { (HER)) }\end{array}$} & \multirow{2}{*}{$\begin{array}{c}\text { Para-aortic, } \\
\text { mediastinal, } \\
\text { right iliac + } \\
\text { Virchow LNs, } \\
\text { bilateral } \\
\text { subclavian + } \\
\text { mediastinal } \\
\text { LNs, left } \\
\text { axillary LNH, } \\
\text { peritoneal } \\
\text { metastasis, left } \\
\text { iliac, right } \\
\text { diaphragm } \\
\text { LN, left } \\
\text { adrenal gland }\end{array}$} & \multirow{2}{*}{$\begin{array}{l}\text { Chemot- } \\
\text { herapy (S-1 } \\
\text { plus } \\
\text { oxaliplatin } \\
\text { (SOX) + } \\
\text { Herceptin } \\
\text { (HER)), } \\
\text { immuno- } \\
\text { therapy }\end{array}$} & $\begin{array}{l}55 \mathrm{~Gy}, \\
22 \mathrm{fr}\end{array}$ & $\begin{array}{l}\text { Neck + me- } \\
\text { diastinum }\end{array}$ & $\begin{array}{c}\text { Bilateral } \\
\text { subclavian } \\
\text { + mediasti- } \\
\text { nal } \\
\text { LNs }\end{array}$ & \multirow[t]{2}{*}{13 months } & \multirow[t]{2}{*}{$\begin{array}{c}\text { Nivolumab } \\
\text { (PD-1) }\end{array}$} & \multirow[t]{2}{*}{ EGF-2 } \\
\hline & & & & & & & & $\begin{array}{l}50 \mathrm{~Gy}, \\
10 \mathrm{fr}\end{array}$ & $\begin{array}{c}\text { Left } \\
\text { adrenal }\end{array}$ & $\begin{array}{c}\text { Para-aortic, } \\
\text { bilateral } \\
\text { iliac, right } \\
\text { diaphragm } \\
\text { LNs }\end{array}$ & & & \\
\hline $\begin{array}{c}\text { Levitin } \\
\text { et al. (2020) } \\
\text { [93] }\end{array}$ & 83 & M & $\begin{array}{l}\text { Renal cell } \\
\text { carcinoma } \\
\text { (RCC) }\end{array}$ & Left kidney & $\begin{array}{l}\text { Pazopanib, } \\
\text { SBRT 40Gy, } \\
5 \mathrm{fr}\end{array}$ & $\begin{array}{l}\text { Right lung left } \\
\text { femur, brain, } \\
\text { mediastinal } \\
\text { lym- } \\
\text { phadenopathy, } \\
\text { pelvis }\end{array}$ & $\begin{array}{l}\text { Receptor } \\
\text { tyrosine } \\
\text { kinase } \\
\text { inhibitor } \\
\text { (pazopanib), } \\
\text { immuno- } \\
\text { therapy }\end{array}$ & $\begin{array}{c}\text { GKS } \\
20 \text { Gy }\end{array}$ & Brain & $\begin{array}{l}\text { Regression } \\
\text { metastases }\end{array}$ & 2 years & $\begin{array}{c}\text { Nivolumab } \\
\text { (PD-1) }\end{array}$ & \\
\hline \multirow[t]{2}{*}{$\begin{array}{c}\text { Nakajima } \\
\text { et al. (2020) } \\
\text { [94] }\end{array}$} & \multirow[t]{2}{*}{56} & \multirow[t]{2}{*}{ F } & \multirow[t]{2}{*}{$\begin{array}{l}\text { Clear cell } \\
\text { carcinoma }\end{array}$} & \multirow[t]{2}{*}{ Kidney } & \multirow[t]{2}{*}{ Nephrectomy } & \multirow{2}{*}{$\begin{array}{l}\text { Left lung } \\
\text { hilum, } \\
\text { subcutaneous } \\
\text { + lung } \\
\text { metastases, } \\
\text { right renal, } \\
\text { right iliac } \\
\text { bone }\end{array}$} & \multirow{2}{*}{$\begin{array}{l}\text { Receptor } \\
\text { tyrosine } \\
\text { kinase } \\
\text { inhibitor } \\
\text { (pazopanib, } \\
\text { axitinib), } \\
\text { immuno- } \\
\text { therapy }\end{array}$} & \multirow[t]{2}{*}{$\begin{array}{l}30 \mathrm{~Gy}, \\
10 \mathrm{fr}\end{array}$} & \multirow[t]{2}{*}{$\begin{array}{l}\text { Right iliac } \\
\text { bone }\end{array}$} & $\begin{array}{l}\text { Lung, right } \\
\text { kidney, } \\
\text { subcuta- } \\
\text { neous } \\
\text { tissue }\end{array}$ & 5 months & \multirow[t]{2}{*}{$\begin{array}{l}\text { Nivolumab } \\
\text { (PD-1) }\end{array}$} & \\
\hline & & & & & & & & & & $\begin{array}{l}\text { Primary } \\
\text { tumor }\end{array}$ & 9 months & & \\
\hline $\begin{array}{c}\text { Sohal et al. } \\
(2020) \\
{[95]}\end{array}$ & 66 & M & Melanoma & $\begin{array}{l}\text { Right nasal } \\
\text { cavity }\end{array}$ & RT & $\begin{array}{l}\text { Left proximal } \\
\text { humerus, } \\
\text { upper thoracic } \\
\text { spine, liver, } \\
\text { lateral left fifth } \\
\text { rib, third, } \\
\text { eighth, } \\
\text { eleventh } \\
\text { thoracic } \\
\text { vertebral } \\
\text { bodies }\end{array}$ & $\begin{array}{l}\text { Immuno- } \\
\text { therapy }\end{array}$ & $\begin{array}{l}25 \mathrm{~Gy}, \\
5 \mathrm{fr}\end{array}$ & Nose & $\begin{array}{c}\text { All } \\
\text { metastasis }\end{array}$ & 4 months & $\underset{(\text { PD-1) }}{\text { Nivolumab }}$ & $\begin{array}{c}\text { Cancer history, } \\
\text { transplanta- } \\
\text { tion history, } \\
\text { BRAF, NRAS } \\
\text { mutation }\end{array}$ \\
\hline \multirow[t]{2}{*}{$\begin{array}{l}\text { Wang et al. } \\
(2020) \\
{[96]}\end{array}$} & \multirow[t]{2}{*}{57} & \multirow[t]{2}{*}{$\mathrm{M}$} & \multirow{2}{*}{$\begin{array}{l}\text { Squamous } \\
\text { cell } \\
\text { carcinoma } \\
\text { (SCC) }\end{array}$} & \multirow[t]{2}{*}{$\begin{array}{c}\text { Right } \\
\text { upper lung }\end{array}$} & \multirow[t]{2}{*}{$\begin{array}{l}\text { Resection, } \\
\text { adjuvant RT, } \\
\text { chemotherapy }\end{array}$} & \multirow{2}{*}{$\begin{array}{l}\text { Pancreas, } \\
\text { metastatic } \\
\text { nodules in left } \\
\text { lower lobe }\end{array}$} & \multirow{2}{*}{$\begin{array}{l}\text { Chemo- } \\
\text { therapy } \\
\text { (gemcitabine, } \\
\text { cisplatin) }\end{array}$} & $\begin{array}{l}55 \mathrm{~Gy}, \\
25 \mathrm{fr}\end{array}$ & $\begin{array}{l}\text { Resection } \\
\text { margin }\end{array}$ & & & \multirow[t]{2}{*}{$\begin{array}{l}\text { Pembrolizumab } \\
\quad \text { (PD-1) }\end{array}$} & \multirow{2}{*}{$\begin{array}{c}\text { PD-L1, ALK } \\
\text { genetic status, } \\
\text { history of } \\
\text { tobacco use, } \\
\text { whole-exome } \\
\text { sequencing }\end{array}$} \\
\hline & & & & & & & & $\begin{array}{c}60.2 \mathrm{~Gy}, 28 \\
\mathrm{fr}\end{array}$ & Pancreas & $\begin{array}{l}\text { Left lung } \\
\text { nodules }\end{array}$ & 1 month & & \\
\hline
\end{tabular}

\begin{tabular}{|c|c|c|c|c|c|c|c|c|c|c|c|c|c|}
\hline \multirow{3}{*}{$\begin{array}{c}\text { Watanabe } \\
\text { et al. (2020) } \\
\text { [97] }\end{array}$} & 69 & $\mathrm{~F}$ & $\begin{array}{l}\text { Melanoma } \\
\text { (BRAF- } \\
\text { wild-type) }\end{array}$ & $\begin{array}{l}\text { Upper left } \\
\text { leg }\end{array}$ & $\begin{array}{l}\text { Resection, also } \\
\text { sentinel LNs }\end{array}$ & $\begin{array}{l}\text { Left groin LN, } \\
\text { liver, muscle } \\
\text { in upper left } \\
\text { leg, left groin }\end{array}$ & $\begin{array}{l}\text { Immuno- } \\
\text { therapy, } \\
\text { corticos- } \\
\text { teroids, } \\
\text { adjuvant } \\
\text { IFN- } \alpha \\
\text { therapy }\end{array}$ & $\begin{array}{l}45 \mathrm{~Gy}, \\
3 \mathrm{fr}\end{array}$ & $\begin{array}{l}\text { Liver } \\
\text { lesions }\end{array}$ & $\begin{array}{l}\text { Left groin } \\
\text { LN, liver, } \\
\text { muscle in } \\
\text { upper left } \\
\text { leg, left } \\
\text { groin }\end{array}$ & 8 weeks & $\begin{array}{l}\text { Nivolumab } \\
\text { (PD-1) }\end{array}$ & \multirow{3}{*}{$\begin{array}{l}\text { CD8 cells, } \\
\text { PD-1, PD-L1, } \\
\text { TIM-3, LAG-3, } \\
\text { TOX, IFN- } \gamma \text {, } \\
\text { perforin, } \\
\text { granzymes, } \\
\text { IL-2, TNF- } \alpha \text {, } \\
\text { DCXCL9, } \\
\text { CXCL10, CCL, } \\
\text { CXCL13, } \\
\text { IDO1, CD4+ } \\
\text { Tregs, } \\
\text { arginase, } \\
\text { MHC I, MHC } \\
\text { II, APCs, } \beta 2- \\
\text { microglobulin, } \\
\text { Ki67, CD3+ } \\
\text { cells, tumor } \\
\text { burden, FoxP3, } \\
\text { exhausted T } \\
\text { cells, BRAF- } \\
\text { mutation }\end{array}$} \\
\hline & 77 & M & $\begin{array}{l}\text { Melanoma } \\
\text { (BRAF- }\end{array}$ & $\begin{array}{l}\text { Right } \\
\text { breast }\end{array}$ & $\begin{array}{l}\text { Resection, also } \\
\text { sentinel }\end{array}$ & $\begin{array}{l}\text { Liver, lung, } \\
\text { abdominal LN }\end{array}$ & Immunotherapy & $\begin{array}{l}45 \mathrm{~Gy}, \\
3 \mathrm{fr}\end{array}$ & $\begin{array}{c}\text { Liver } \\
\text { metastases }\end{array}$ & Stable & 6 weeks & \multirow{2}{*}{$\begin{array}{l}\text { Pembroli } \\
\text { zumab } \\
\text { (PD-1) }\end{array}$} & \\
\hline & & & & & & & & $\begin{array}{l}60 \mathrm{~Gy}, \\
8 \mathrm{fr}\end{array}$ & LN, liver & $\begin{array}{l}\text { Other liver } \\
\text { lesions, } \\
\text { lung }\end{array}$ & 1 month & & \\
\hline \multirow{2}{*}{$\begin{array}{l}\text { Hotta et al. } \\
(2021) \\
{[98]}\end{array}$} & \multirow[t]{2}{*}{42} & \multirow[t]{2}{*}{$\mathrm{F}$} & \multirow{2}{*}{$\begin{array}{l}\text { Adeno- } \\
\text { carcinoma } \\
\text { (lung) }\end{array}$} & \multirow[t]{2}{*}{$\begin{array}{l}\text { Lung (left } \\
\text { upper lobe) }\end{array}$} & \multirow{2}{*}{$\begin{array}{l}\text { EGFR tyrosine } \\
\text { kinase } \\
\text { inhibitor, } \\
\text { steroid }\end{array}$} & \multirow[t]{2}{*}{$\begin{array}{l}\text { Bone, brain, } \\
\text { thoracic spine }\end{array}$} & \multirow{2}{*}{$\begin{array}{l}\text { EGFR tyrosine } \\
\text { kinase } \\
\text { inhibitor, } \\
\text { steroid }\end{array}$} & $\begin{array}{l}30 \mathrm{~Gy}, \\
10 \mathrm{fr}\end{array}$ & $\begin{array}{l}\text { Whole } \\
\text { brain }\end{array}$ & Lung & 4 days & \multirow[t]{2}{*}{$\begin{array}{l}\text { Atezolizumab } \\
\text { (PDL1) }\end{array}$} & \multirow[t]{2}{*}{$\begin{array}{l}\text { EGFR. PD-L1, } \\
\text { CEA }\end{array}$} \\
\hline & & & & & & & & $\begin{array}{l}36 \mathrm{~Gy}, \\
12 \mathrm{fr}\end{array}$ & $\begin{array}{l}\text { Thoracic } \\
\text { spine }\end{array}$ & Lung & 2 weeks & & \\
\hline
\end{tabular}


Table 2. Cont.

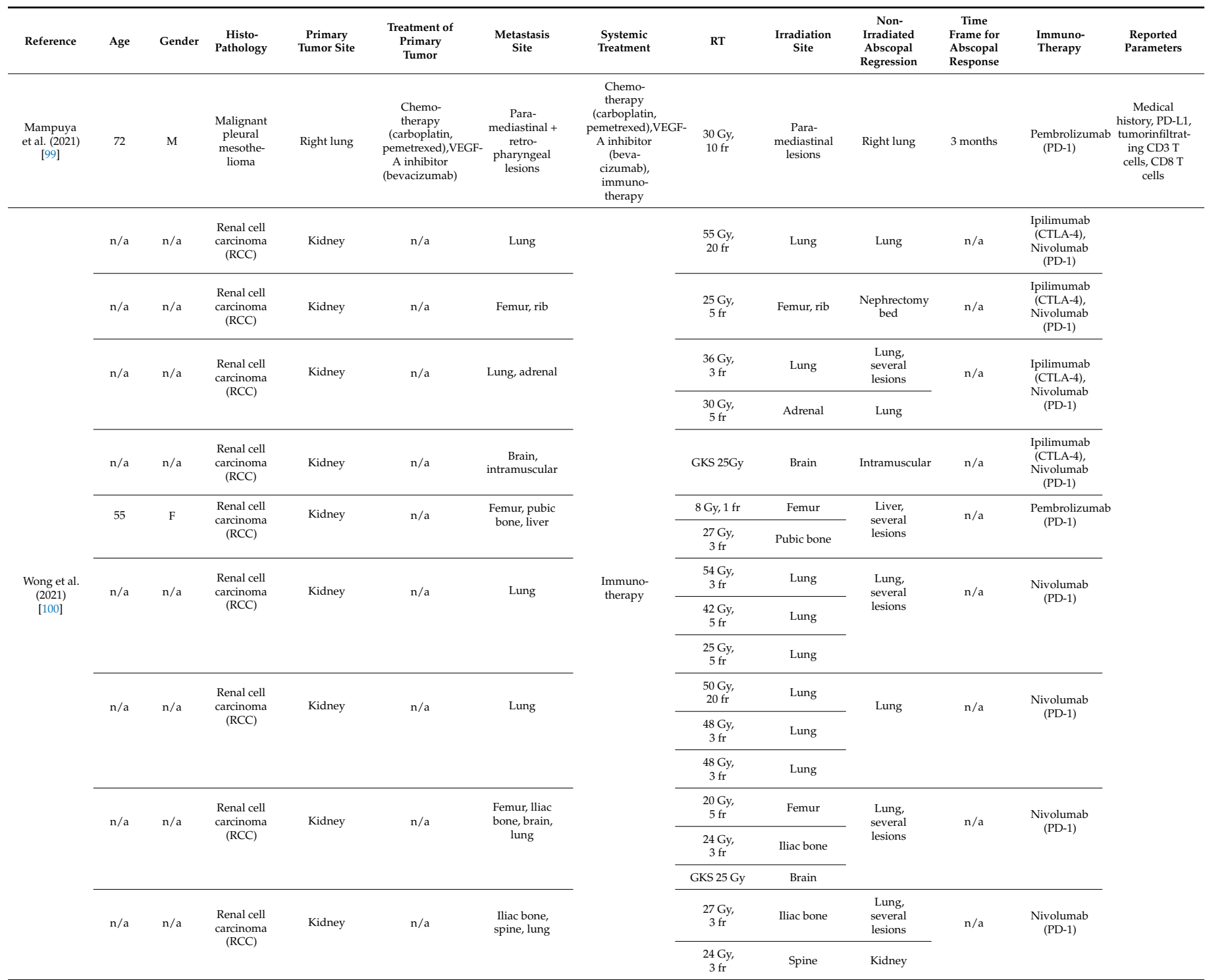

Abbreviations: M: male; F: female; n/a: not available; RT: radiotherapy; LN: lymph nodes; fr: fractions; CTLA-4: cytotoxic T-lymphocyteassociated protein 4; ALC: Absolute lymphocyte counts; AEC: absolute eosinophil counts; TIA-1: TIA1 Cytotoxic Granule Associated RNA Binding Protein; Tregs: regulatory T cells; CK: cytokeratin; TTF-1: thyroid transcription factor 1; CDX2: Caudal Type Homeobox 2; CEA: carcinoembryonic antigen; MEGA3: Melanoma antigen A3; PASD1: PAS domain containing 1; DC-CIK: cytokine-induced killer cells; PD-1: programmed cell death protein 1; DC: dendritic cell; CA 19-9: carbohydrate antigen 19-9; ctDNA: circulating tumor DNA, NGS: next generation sequencing; PD-L1: PD-1 receptor-ligand 1; MSI-H: high levels of microsatellite instability; CA-125: cancer antigen 125; GM-CSF: granulocyte-macrophage colony-stimulating factor; MAF: mutant allele frequency; EGFR: epidermal growth factor receptor; ALK: anaplastic lymphoma kinase; FISH: fluorescent in situ hybridization; LDH: lactate dehydrogenase; EGF: epidermal growth factor; TIM-3: T cell immunoglobulin and mucin-domain containing-3; LAG-3: lymphocyte-activation gene 3; TOX: thymocyte selection-associated high mobility group box protein; IFN- $\gamma$ : interferon gamma; TNF- $\alpha$ : tumor necrosis factor alpha; MHC: major histocompatibility complex; APC: antigen-presenting cells.

All reported cases had received prior treatments such as chemotherapy or resection surgery of the primary site or metastasis. Only a few patients had received RT previously. Immunotherapy was administered simultaneously with or immediately after RT. In these cases of $\mathrm{AbE}$, the patients received markedly different RT dose schemes (8-70 Gy), fractionation sessions (1-35), and dose per fraction (1.8-28 Gy) with or immediately after additional immunotherapy. The vast majority of patients was treated with moderate hypofractionated (3-6 Gy/fr) or hypofractionated doses (>7 Gy/fr) at metastasis sites.

In fact, most AbEs have been reported in melanoma patients undergoing RT treatment along with immunotherapy (27 cases). Most patients received a total dose of $30 \mathrm{~Gy}$ 
(predominantly 3 Gy / fr), however, the RT schemes differed widely in doses (13.2-66 Gy) and number of fractionation sessions (1-52). Based on the number of AbEs reported after administration of checkpoint inhibitors, the blocking of the immune checkpoints seems to support AbE events.

\section{Abscopal Effect Immune-Related Mechanisms}

The precise mechanism of AbE remains unidentified, however, there are several independent and dependent mechanisms involved that are induced by certain radiation dose and fractionation schemes.

RT is a highly effective anti-cancer therapy achieved by tumor cell lethality, prompted by irradiation-induced lethal DNA double-strand breaks (DSBs). Furthermore, the generation of free radicals also plays a role, as radiolysis of water in cells leads to production of reactive oxygen species (ROS) producing cascade of DNA damage in tumor microenvironment (TME) cells [101,102].

Recent advances in RT techniques allow for a more accurate delivery of higher doses per fraction [103]. Localized RT presents not only immunosuppressive but also immune-stimulatory effects, inducing the release of immune-stimulating tumor antigens via ICD [104]. Thus, it modulates the TME as a result of the induction of endothelial cell death and vascular damage as well as increased $T$ cell priming in lymphoid tissues [105].

Demaria et al. revealed $\mathrm{AbE}$ to be dependent on the immune-mediated action of functional $\mathrm{T}$ cells. Hence, immune promotion is mainly supported by $\mathrm{T}$ cell priming against novel tumor-specific antigens [106]. Thereby, irradiated tumors can act as an in situ immunization, being functional T lymphocytes essential effector cells in such response [107]. Irradiation-modulated TME releases diverse cytokines and chemokines that recruit and mature antigen-presenting cells (APCs), namely dendritic cells (DCs) and macrophages to the tumor site. Decreasing tumor cells release elevated amounts of antigens, which are recognized and processed by APCs $[108,109]$. Tumor-related APCs prime antigen-specific effector $\mathrm{T}$ cells by presenting tumor peptide antigens to naïve $\mathrm{T}$ cells in tumor-draining lymph nodes (LNs) [110]. In fact, cytotoxic T lymphocytes (CTLs) recognize radiationinduced antigens and activated $\mathrm{T}$ cells that travel through the bloodstream to combat the residual tumor cells present in the non-irradiated distant metastatic sites which seems to lead to an effective anti-tumor immune response and cancer control [111].

Due to the stress response after the irradiation of the tumor cells, the damaged and dying cells release damage-associated molecular patterns (DAMPs) including heat shock protein 70 (Hsp70), calreticulin, adenosine- $5^{\prime}$-triphosphate (ATP), and high mobility group protein B1 (HMGB1) [112]. Hsp70 has been seen to induce resistance against apoptosis when present inside the cells, however, extracellularly, it promotes apoptosis and contributes to an innate and adaptive immune response $[113,114]$. Calreticulin acts as an 'eat me' signal for DCs when exposed to the membrane resulting in enhanced phagocytosis of the cancer cells by DCs and, thus, results in an increased release of tumor-specific antigens (TSAs) $[104,109,115]$. Moreover, ATP binds to P2X purinoreceptor 7 (P2X7R) on inflammatory cells, activating the NOD-, LRR- and pyrin domain-containing protein 3 (NLRP3) inflammasome, a multiprotein complex that produces active caspase- 1 and stimulates the production of interleukin (IL) $1 \beta$ and IL-18 [116,117]. Il-1 $\beta$ mediates the antitumor-specific priming of the CD8+ T cells, IFN- $\gamma$ production as well as the activation and maturation of DCs to APCs [118]. HMGB1 activates DCs, promoting their maturation and ATP release, leading to the enhancement of CD8+ effector T cells antigen presentation and their anti-tumor-specific activation $[112,119]$.

Local RT induces the release of both pro- and antitumor cytokines due to irradiationinduced DNA damage. In the cytoplasm of irradiated cells, cyclic GMP-AMP synthase (cGAS) binds to translocated double-stranded DNA fragments (dsDNA) induced by RT and activates a signaling cascade via the second messenger $2^{\prime} 3^{\prime}$-cGAMP (cGAMP) and stimulator of interferon genes (STING) to produce type I interferons (IFNs) in the TME [120-124]. Radiation-induced interferons play a major role in the therapeutic effect of RT. In fact, irradiated tumor cells 
produce IFN- $\beta$ and are, in turn, responsible for the release of IFN- $\gamma$ by T cells $[125,126]$. IFN- $\gamma$ consecutively promote cytotoxic $\mathrm{T}$ cell activation along with upregulating programmed cell death protein 1 (PD-1) receptor-ligand 1 (PD-L1) [127]. Following the irradiation-induced release of IFN- $\gamma$, there is an upregulation of pro-inflammatory chemokines CXCL10 and CXCL16 which are in turn responsible for the recruitment and activation of T cells into the TME [128-130]. ROS production leads to IL- $1 \alpha$, IL- $1 \beta$ and IL- 6 production as well as tumor necrosis factor alpha $(\mathrm{TNF}-\alpha)$ and transforming growth factor beta (TGF- $\beta$ ) [131].

Moreover, there are various mechanisms that can concomitantly suppress AbE such as those dependent on factors with immune system inhibitory effects. In particular, the environment of the irradiated volume plays an important role in this process. Thus, prevalence of immunosuppressive cytokines and cells present at the post-irradiated site could limit AbE regardless of immunotherapy treatment [132].

The hypoxic milieu within the irradiated tumor promotes recruitment of immunosuppressive regulatory T cells (Tregs) which induce immunosuppression in the TME $[133,134]$. Moreover, hypoxia impacts the antigen-presenting ability of APCs by reducing major histocompatibility complex (MHC) class I molecules. This reduction is correlated with a lower recognition of cytotoxic $\mathrm{T}$ cells and hence a reduced killing of tumor cells by these $\mathrm{T}$ cells [135].

In fact, a study correlated the frequency of AbE with the extent of adrenergic stress in a murine model. Enhanced norepinephrine production prevented T cell activation and consequently the abscopal response [136].

In most cases, RT alone is insufficient to overcome the established immune suppressive mechanisms of the TME. The immune effect of irradiation is affected by the applied dose, fractionation, and application volume making prediction of immunological reactions intricate [137]. RT in combination with immunotherapy may be advantageous in overcoming this immune tolerance and enhance AbE patient response. Preclinical studies have already illustrated how important the optimal RT dose, fractionation scheme, administration timing and dosing of the immunotherapeutics are to provide systemic antitumoral effects [106,138-143]. Identification of AbE prediction biomarkers may be crucial to develop an individualized medical approach.

Recently, in the course of the ongoing Severe Acute Respiratory Syndrome Coronavirus 2 (SARS-CoV-2) pandemic, the effects of infectious diseases on the immune system have come into focus. The virus triggers inflammatory responses in the respiratory tract and induces a broad production of cytokines, which are also associated with the mechanism of $\mathrm{AbE}$ [123].

Herrscher et al. reported the first case of AbE in a SARS-CoV-2 infected patient with melanoma. The 84-year-old woman was diagnosed in early 2020 with peritoneal and a nodal recurrence of melanoma which was handled with palliative care. In late 2020, palliative RT was performed for a metastatic cervical node ( $20 \mathrm{~Gy}, 5$ fractions). The patient was diagnosed with coronavirus disease 2019 (COVID-19) in early 2021. At this time point, metastases presented a shrinkage of $20-25 \%$ which may suggest an abscopal response linked to the activation of the innate immune system due to the SARS-CoV-2 infection and their influence on the production of pro-inflammatory cytokines [144].

Spontaneous tumor regression has been described over the last centuries being often correlated with acute bacterial, fungal, viral, or protozoal infections as well as vaccine therapy. In $25-80 \%$ of documented cases of spontaneous regression of cancer, the acute infections cause a strong immunological reaction presenting with fever, which in turn supports the regression of the tumor $[145,146]$. Thus, the increase in the anti-tumor response may also be responsible for the noted AbE after COVID-19 infection.

\section{Abscopal Effect in Different Tumor Entities}

AbEs have been reported in a variety of cancer types. In studies where additional immune therapy was absent, AbE occurred remarkably in cases of adenocarcinoma of different origins. Nevertheless, $\mathrm{AbE}$ were observed more frequently in melanoma patients 
also treated with immunotherapy. In breast and prostate cancer patients, the preclinical evidence for $\mathrm{AbE}$ cases is more robust compared to the frequency of reported clinical cases. Table 3 provides an overview of the frequencies of case reports of ABE in various tumor entities juxtaposed with their worldwide incidence and mortality.

Table 3. Abscopal effect case reports in different tumor entities.

\begin{tabular}{|c|c|c|c|c|c|}
\hline \multirow{2}{*}{ Tumor Entities } & \multirow{2}{*}{$\begin{array}{c}\text { Incidence } \\
\text { New Cases } \\
\text { Worldwide in } 2020 \\
\text { (\% of All Sites) [147] }\end{array}$} & \multirow{2}{*}{$\begin{array}{c}\text { Mortality } \\
\text { New Deaths } \\
\text { Worldwide in 2020 } \\
\text { (\% of All Sites) [147] }\end{array}$} & \multicolumn{3}{|c|}{ Cases of $\mathrm{AbE}$} \\
\hline & & & Total & Without ICB & Under ICB \\
\hline Breast & $11.7 \%$ & $6.9 \%$ & 2 & 2 & - \\
\hline Lung & $11.4 \%$ & $18.0 \%$ & 18 & 6 & 12 \\
\hline Colorectum & $10.0 \%$ & $9.4 \%$ & 2 & 1 & 1 \\
\hline Prostate & $7.3 \%$ & $3.8 \%$ & 1 & - & 1 \\
\hline Stomach & $5.6 \%$ & $7.7 \%$ & 1 & 1 & - \\
\hline Esophagus & $3.1 \%$ & $5.5 \%$ & 2 & 2 & - \\
\hline Thyroid & $3.0 \%$ & $0.4 \%$ & 1 & 1 & - \\
\hline Bladder & $3.0 \%$ & $2.1 \%$ & 2 & 1 & 1 \\
\hline Kidney & $2.2 \%$ & $1.8 \%$ & 23 & 5 & 20 \\
\hline Melanoma & $1.7 \%$ & $0.6 \%$ & 29 & 2 & 27 \\
\hline
\end{tabular}

\subsection{Adenocarcinoma}

Adenocarcinomas are malignancies arising from the epithelial cells of the glandular tissue in multiple sites of the body [148]. They usually originate in organs such as the gastrointestinal tract, esophagus, lung, breast, prostate or pancreas. However, in the case of metastasis, the determination of the primary site of origin is complex. In fact, adenocarcinomas account for $70 \%$ of cancers with unknown origin [149]. Twelve cases of $\mathrm{AbE}$ were observed under conventional treatment of adenocarcinomas, and 13 additional cases occurred after additional immunotherapy.

Ehlers et al. reported the first clinical case of $\mathrm{AbE}$ in papillary adenocarcinoma of unknown origin. The 37-year-old female patient showed metastases in the bilateral neck, right axilla, and mediastinum LN. The bilateral neck and supraclavicular regions were treated with a total dose of $40 \mathrm{~Gy}$ in 20 fractions. After two weeks, the non-irradiated right axilla and mediastinum mass regressed, presenting the treated neck node only a partial response [8].

Adenocarcinoma $\mathrm{AbE}$ case reports of a digestive origin are underrepresented (three reports in total) considering that adenocarcinoma accounts for $95 \%$ of colon and rectal cancers [150]. In fact, Chuang et al. described a case of AbE after whole-brain irradiation in a female patient with metastatic adenocarcinoma of colorectal origin. Along with multiple brain metastases, the patient presented a huge metastatic lung mass. Treatment consisted of $30 \mathrm{~Gy}$ in 10 fractions without any adjuvant systemic therapy. The mass in the left lung markedly regressed two months later. These results suggest that $\mathrm{AbE}$ inducing factors are able to trespass the blood-brain barrier (BBB) [37]. Bonilla et al. reported a case of a patient with unresectable advanced gastric adenocarcinoma with extensive retroperitoneal LN involvement. The gastric mass and margins were treated with RT (30 Gy total), observing three months later a complete response of the non-irradiated retroperitoneal paraaortic adenopathy and gastro-hepatic ligament along with the tumor markers angiotensin-converting enzyme (ACE), carbohydrate antigen 19-9 (CA19-9) and cancer antigen 125 (CA-125) [41]. Furthermore, another AbE case was described in an adenocarcinoma patient undergoing RT (48 Gy; 24 fractions) at the primary tumor site for recurrent disease, along with adoptive T-cell immunotherapy and DC therapy. Two months after RT the metastatic lesion size had decreased in addition to serum tumor marker CA19-9 [60]. 
$\mathrm{AbE}$ have also been investigated in colon adenocarcinoma preclinical murine models. In fact, Baba et al. revealed an increased $\mathrm{AbE}$ in C57BL/6 mice related to the irradiated tumor volume and applied radiation dose, excluding anti-PD-1 immunotherapy [151].

Two cases of AbE in esophageal adenocarcinoma were reported until today. Esophageal adenocarcinoma starts in the mucus glands that line the lower part of the esophagus. When it metastasizes, the tumor cells accumulate in the LNs, lungs, liver, bones, adrenal glands, or brain [152]. Rees et al. reported $\mathrm{AbE}$ of all lung metastasis in a patient with lower esophageal adenocarcinoma. After irradiation of the primary esophageal tumor, lung metastases regressed for 14 months before cancer further progressed [13]. More recently, a patient treated with RT and esophagectomy for the primary tumor and associated LNs, presented signs of metastases regression twelve months following treatment [34].

\subsection{Lung Cancer}

Up to $85 \%$ of lung cancers are NSCLCs, with adenocarcinoma being the main subtype $[153,154]$. The pulmonary cancer cells spread typically to the contralateral lung, adrenal glands, bones, brain, or liver. Even if resection is the standard of care for earlystage NSCLC, RT is utilized as a first-line treatment for elderly, comorbid patients or as a palliative treatment in later stages [155-157]. In advanced or metastatic NSCLC, the combination of immunotherapy and RT significantly improves 1- and 3-year overall survival; as well as progression-free survival, though but is also beneficial in adenocarcinomas and PD-L1-negative patients [158].

Rees et al. reported the first $\mathrm{AbE}$ in a patient with metastatic lung adenocarcinoma treated with palliative radiation to the left lung and the mediastinum. After two weeks, the patient showed a regression in subcutaneous metastases in the forehead and the left shoulder [13]. Ever since there have been 17 more case reports of AbE in NSCLCs, respectively eight in lung adenocarcinoma. Five $\mathrm{AbE}$ cases resulted from irradiation of malignant tissue without support from any immunotherapy $[24,36,43]$, wherein two of these reported cases described $\mathrm{AbE}$ as a result of the irradiation of brain metastases [27,38].

One case of NSCLC in the right upper lung lobe and metastases in the brain, left adrenal gland, left lower lung lobe, and the liver was treated with chemotherapy and brain RT. One month after RT, the adrenal, lung and liver lesions had diminished [27]. Furthermore, another patient with brain metastasis was treated with RT (25 Gy, five fractions) resulting in the regression of the primary tumor as well as a metastatic lesion in the left mediastinum one month following treatment [38].

A more recent study described an adenocarcinoma case with an origin in the right upper lung lobe. Three months post irradiation, the patient presented regression of the primary tumor and several non-irradiated LN. Serum carcinoembryonic antigen (CEA) levels were decreased in correlation with $\mathrm{AbE}$, whereas CD8+ lymphocyte counts were low at the time the $\mathrm{AbE}$ was documented yet increased with metastases growth [43].

Between 2012 and 2021, twelve AbE cases were reported in pulmonary adenocarcinoma after treatment with RT and immunotherapy. Thereby, the AbE seems to occur after irradiation of the contralateral lung, the brain, liver and metastatic LNs $[52,58,59,64,74,87,98]$. In fact, four cases were described where patients received RT for their brain metastasis (from two weeks to four months after) with a resulting abscopal regression of the primary lung tumor after receiving anti-PD-L1 (atezolizumab) or anti-PD-1 (pembrolizumab) therapy $[77,81,98]$.

\subsection{Kidney Cancer}

Renal cell carcinoma represents $3-5 \%$ of all new adult malignancies. Localized RCC is normally treated first line by resection with adjuvant immunotherapy or receptor tyrosine kinase (RTK) inhibitor therapy $[159,160]$. Stereotactic ablative radiotherapy (SABR) is recommended as treatment option for medically inoperable patients, though RT plays mainly a role as a palliative therapeutic option for relieving the symptoms of metastatic lesions [159]. 
The first AbE in renal cell carcinoma was reported in 1981 by Fairlamb. The 73year-old female patient was diagnosed with lung, hila, and pubic bone metastasis next to her primary left kidney tumor. After nephrectomy, she was treated with palliative radiation to the groin ( $40 \mathrm{~Gy}, 15$ fractions) which resulted in regression of the lung lesions two months after RT and remained disease-free for 4.5 years [10]. Since then five AbEs have been observed in RCC without adjuvant immunotherapy, while $18 \mathrm{AbE}$ cases have been reported with predominantly nivolumab (anti-PD-1) as immunotherapy. In 1994, MacManus et al. identified a RCC (right kidney) patient presenting lung and mediastinal metastases. The patient received palliative radiation (20 Gy, 10 fractions) for pain relief, and after six months the paratracheal lymphadenopathy was reduced and lung metastases were non-detectable, suggesting an AbE. Cytokine assays (TNF- $\alpha$, TNF- $\beta$, interferon gamma (IFN- $\gamma$ ), IL-2 receptor, IL-6) performed on a single serum sample during the regression of the metastases did not reveal any significant differences compared to the reference values [14].

Moreover, $\mathrm{AbE}$ was detected following irradiation of brain metastasis in a patient that underwent nephrectomy. Computed tomography (CT) examination leads to the identification of multiple metastases in bone, brain, lung, and mediastinum. The patient was treated with stereotactic radiosurgery to a dose of 18 Gy. Additionally, the patients vertebral bone lesion was irradiated with $40 \mathrm{~Gy}$ in five fractions. Treatment resulted in the regression of lung and mediastinal disease. Follow-up CT, one month after RT, revealed slight regression of the untreated multiple lung metastases and lymphadenopathy. However, three months following RT the patient developed new brain lesions, suggesting $\mathrm{AbE}$ to be organ-dependent and incapable of crossing the BBB [22]. Another report described the case of an RCC patient with multiple mediastinal, retroperitoneal, and cervical LN metastasis. The subject was treated after nephrectomy with the tyrosine kinase inhibitors (sunitinib) followed by a combination of anti-PD-1 antibody (AB) pembrolizumab and stereotactic body radiation therapy (SBRT) (32 Gy, four fractions). The patient achieved a systemic complete response within two months [63].

Most recently, Wong et al. identified nine cases of AbEs in the patient cohort of a descriptive and retrospective study of RCC. Approximately $20 \%$ of all observed patients revealed a regression in a non-irradiated tumor. The patients received besides RT either a single-agent anti-PD-1 AB (nivolumab, pembrolizumab) or a combination of anti-CTLA-4 and anti-PD-1 treatment (ipilimumab-nivolumab). RT was delivered in different radiation schemes depending on treatment indication and the location of the irradiated volume. AbE occurred in $26.7 \%$ of patients treated with combined immunotherapy and $16.1 \%$ of patients treated with a single agent. In addition, the abscopal response patterns were very divergent between the patients. Most patients experienced isolated abscopal responses in one to two lesions, while two patients presented a more extensive response in lung and liver [100].

\subsection{Melanoma}

The most effective treatment modality for localized melanoma is surgery, but RT plays a prominent role in the management of the disease. ICB is established as a standard of care for advanced melanoma [161]. With the employment of immunotherapy (pembrolizumab and nivolumab) for melanoma treatment in $30-40 \%$ of the patients a complete response was observed [162,163]. Adjuvant RT following lymphadenectomy and systemic therapy prevents local and regional recurrence. Thus, RT is highly effective and widely used as a palliative treatment being mostly utilized in brain, lung, liver or bone metastases.

Preclinical studies have investigated the influence of PD-1 expression on the systemic antitumor response induced by RT. A combination of RT in addition to PD 1 blockade results in the complete regression of the irradiated primary tumor as well as a reduction in size of non-irradiated secondary tumors outside of the radiation field. The tumors present infiltration of activated, cytotoxic CD8+ T cells, even in the non-irradiated tumors $[164,165]$.

Since Postow et al. first discovered a correlation between $\mathrm{AbE}$ and immune checkpoint inhibitors, 26 other cases of AbEs associated with immunotherapy in melanoma patients 
have been observed, being the cancer type with the most reported abscopal immune responses [49].

One melanoma patient with melanoma of an unknown primary showed an AbE after conventional chemotherapy and palliative radiotherapy (total dose $20 \mathrm{~Gy}$ ) for bilateral inguinal LNs. The other metastases were found to have gradually decreased in size, as seen on CT scan [35].

Different studies aiming to determine the occurrence rate for $\mathrm{AbE}$ in melanoma cases handled with RT combined with ICB. In a prospective clinical trial in which the combination of RT and systemic immunotherapy (ipilimumab) for melanoma was tested, the occurrence of an AbE was detected in 3 out of 16 patients (18.75\%) (NCT01449279) [166]. Similarly, in another study $20-21 \%$ of melanoma patients who received RT in addition to ipilimumab exhibited an AbE following treatment [167]. Moreover, eleven cases of AbE were detected in a retrospective analysis of 21 patients with advanced melanoma which progressed after receiving ipilimumab and were subsequently treated with local RT. The median overall survival was extended to 22.4 months as a result of the AbE [54]. Another study reported two oligometastatic melanoma patients treated with anti-PD-1 and SBRT. One patient was diagnosed with BRAF-wild-type melanoma on the upper left leg with three liver metastases, a muscle lesion and a lesion in the left groin. The treatment consisted of RT to the three liver lesions along with adjuvant ICB (nivolumab). The LN metastases presented with a strong exhaustion signature defined by the markers PD-1, PD-L1, T cell immunoglobulin and mucin-domain containing-3 (TIM-3), lymphocyte-activation gene 3 (LAG-3), and the transcription factor thymocyte selection-associated high mobility group box protein (TOX). Moreover, a high level of the T cell-attracting chemokines CXCL9, CXCL10, CCL5, and CXCL13 were discovered. The patient rapidly developed a complete tumor regression, ongoing for more than 4.5 years. The other patient, however, was described with an unfavorable pre-treatment immune signature of the tumor mass without evidence of infiltration by exhausted $\mathrm{T}$ cells, the targets of anti-PD-1 treatment. The patient presented a primary melanoma in the right chest region followed by a single liver metastasis which were both surgically resected. Thereafter, more recent detected liver metastases were treated with RT (45 Gy, three fractions). A second SBRT was delivered displaying a month later, a complete regression of all metastases, lasting for over 2.5 years [97].

\subsection{Breast Cancer}

Breast cancer is the most commonly diagnosed cancer with an estimated 2.3 million new cases in 2020 [147]. RT is an effective tool for local tumor control, and decreases the risk of tumor cells dispersing within breast, chest area or axillary LNs. RT is also utilized as palliative treatment of symptomatic lesions in patients with metastatic breast cancer. RT is used to treat limited metastatic sites in only patients for whom surgical intervention is not an option (location of the metastases, general health state).

In fact, a study described an $\mathrm{AbE}$ in a patient with metastatic breast cancer, after receiving RT alone. The patient presented with a $10 \mathrm{~cm}$ tumor in the right breast and multiple associated metastases in lung, bones and LNs, and was treated with RT alone as a palliative treatment, due to her performance status score of 3-4 in the Eastern Cooperative Oncology Group (ECOG). The applied radiation dose was distributed into 60 Gy to the right breast, 28 Gy to the left femur and 39 Gy to the lumbar vertebrae and sacrum. Following 10 months of RT, the lesions in the lung and LNs showed a prominent regression with normalized serum levels of CEA and cancer antigen 15-3 (CA15-3) [33]. Another report described an $\mathrm{AbE}$ in stage IV breast carcinoma after multiple fractions of high dose radiation [39].

The combination of RT and immunotherapy was also tested in metastatic breast cancer in clinical trials. Formenti et al. reported the results of a clinical trial investigating the different doses of a TGF- $\beta$ inhibitor with RT (NCT01401062). Twenty-three patients with at least three distinct metastatic sites were randomized in two treatment arms. As a result, one patient with triple-negative breast cancer (TNBC), invasive breast cancer with limited 
treatment options and worse prognosis, showed a $28 \%$ reduction in the non-irradiated lesions. Unfortunately, no more details of this case were reported [168]. A separate study regarding patients with TNBC, performed post-mastectomy RT and reported a beneficial impact on 3-year breast cancer-specific survival which was dependent on the pathological stage of the patients [169].

Furthermore, preclinical models of metastatic breast cancer revealed a significant survival advantage when RT is combined with immune checkpoint inhibitors $[138,139,170]$. In fact, a study with a metastatic breast cancer murine model (TS/A) conducted irradiation of one of the tumors with different RT regimes in combination with an anti-CTLA-4 AB. Fractionated RT in combination with the AB leads to significant regression of the secondary tumor, nonetheless, RT alone did not induce AbE in this model [139]. In another murine breast tumor model (4T1) study with bilateral tumors, the non-irradiated tumor was growth restricted by RT and combined with anti-PD-1 AB resulting in prolonged survival, in addition to a reduction in spontaneous lung metastases. These results suggest that an effective modification of the immune microenvironment of non-irradiated tumor is generated by means of combination therapy [170].

Krombach et al. employed TNBC cells to examine the initial steps of RT-induced antitumor priming which is crucial for $\mathrm{AbE}$ advent, observing the strongest effects with high single doses [171]. In addition, in another murine TNBC model, RT effect was enhanced due to AbEs by immune checkpoint inhibitors and hyperthermia (HT). After implanting 4T1Luc cells into the mammary glands of BALB/c mice, the primary tumors of the animals received RT (24 Gy, three fractions), HT, anti-PD-1 and anti-CTLA-4 immunotherapy. Results revealed a moderate reduction in both the primary tumors and the lung metastasis but improvement with respect to survival was observed [172].

\subsection{Prostate Cancer}

Prostate cancer is the second most frequently diagnosed cancer with $7.3 \%$ of all estimated cases in males worldwide [147,173]. The most aggressive form of this cancer type is defined by disease progression despite androgen deprivation therapy, carrying a poor prognosis with a median survival of less than three years [174]. The so-called castrationresistant prostate cancer (CRPC) is associated with a variety of symptoms such as bone metastases, spinal cord compression and advanced pelvic disease. The bone metastases are often radiosensitive and treated with palliative RT for pain relief $[175,176]$.

The therapeutic response improvement in prostate cancer of RT in combination with immunotherapy has also been tested in clinical trials. In a phase I/II study, patients with metastatic CRPC received ipilimumab (anti-CTLA-4) as a monotherapy or in combination with RT. Patients treated with $10 \mathrm{mg} / \mathrm{kg}$ ipilimumab and RT showed the strongest response, however, no AbE was observed [177]. Furthermore, similar results were observed in a multicenter phase III trial with 799 patients, where a combination of ipilimumab and RT was used to treat bone metastatic castration-resistant prostate cancer (8 Gy), unable to induce $\mathrm{AbE}$ [178]. In a $\mathrm{DC}$ vaccine clinical trial an $\mathrm{AbE}$ was detected in a patient with advanced CRPC. In addition to the prostate mass, the patient showed metastases in the lungs, bone marrow and mediastinal and inguinal LNs. Six months following several cycles of DC vaccine with an immunostimulant and irradiation of the prostatic tumor as well as the inguinal LNs (24 Gy, three fractions), the size of mediastinal and retroperitoneal lesions was significantly reduced. Prostate-specific antigen (PSA) serum concentration post RT was decreased whereas CD3+ and CD8+ T cells as well as IL-6 serum concentration were slightly enhanced. All other assessed parameters were within range [67].

In prostate cancer, the incidence of an $\mathrm{AbE}$ is reduced by a characteristic suppression of the anti-tumor immune response as a reaction to RT. The immune response can be hindered by the recruitment of myeloid cells with immunosuppressive function to irradiated TME. A study determined that after primary tumor site irradiation, expression of macrophage colony-stimulating factor 1 (CSF1) increased significantly both in patients and preclinical prostate models. CSF1 enhanced recruitment of immunosuppressive myeloid-derived 
suppressor cells (MDSCs), thereby limiting the therapeutic response to RT and suppressing the immune-related mechanism of AbE [179].

$\mathrm{AbE}$ prospect in prostate cancer has been demonstrated in the preclinical stage. In fact, a CRPC preclinical model observed an increased median overall survival and AbE with combination of RT and immune checkpoint inhibition. Mice's leg tumors were irradiated with $20 \mathrm{~Gy}$, and additionally treated with anti-PD-1 or anti-PD-L1 ABs. Thus, RT leads to a local response in the irradiated tumor followed by a similar regression of the non-irradiated tumor graft in this model. This response was mediated by CD8+ T cells [180].

\section{Description of Hypothetical AbE Patient}

Based on the reported cases, the profile of a patient who is most likely to develop an $\mathrm{AbE}$ was created as a summary of the current data situation.

The patient who is most likely to develop an AbE is a man aged between 42.4 and 72.6 years suffering from metastatic melanoma cancer. His primary tumor and also most likely this sentinel lymph nodes will be resected before the metastatic status is treated with systemic treatments (most probably ICB). Then, some of his metastases will be treated additionally with RT applied as a total dose of $30 \mathrm{~Gy}$ in 10 fractions. It will most likely be a brain metastasis that will be irradiated and the patient will receive at least four cycles of anti-PD-1 immunotherapy. This will most probably be $3 \mathrm{mg}$ per kg body weight nivolumab every three weeks, and also the same dose of pembrolizumab. Around three months after this treatment, the irradiation of the brain metastases is most likely to result in the regression of non-irradiated lesions of the lungs followed by malignant LNs and liver lesions. However, a complete response could also be possible as a treatment result.

Previously reported cases of AbE were predominantly observed in male patients under immunotherapy whereas the numbers of case reports of female patients were nearly the same with or without ICB. The mean age mentioned in the case reports was 57.5 years with a standard deviation of 15.1 years. The number of reports indicates that the highest probability for an $\mathrm{AbE}$ is the strongest after combined RT and immunotherapy in melanoma ( 27 cases), followed by RCC (18 cases) and then adenocarcinomas of lung origin (12 cases). In the most reported AbE cases, the primary tumor was resected (31 cases), systemic chemotherapy (19 cases) is indicated as the second primary treatment followed by RT (seven cases) as the third treatment procedure. In most AbE cases, the RT is applied as palliative treatment and most patients received a total dose of $30 \mathrm{~Gy}$ applied in 10 fractions. In melanoma cases, more than half of the AbEs occurred after irradiation of brain metastasis. As the most commonly used ICB agent, nivolumab was applied in a total of 39 cases of $\mathrm{AbE}$ followed by 17 cases previously treated with pembrolizumab. With a spread of 3.1 months, an average of 3.2 months elapsed between the applied RT and the abscopal response. The combination of RT and ICB were correlated in 37 cases with the abscopal regression of lung metastases, in at least 17 cases with the regression of malignant LNs and in ten cases where the non-irradiated liver lesions responded. A total response was described in 11 patients who showed an abscopal response (Table 2).

With the available data, no specific size or localization of the primary tumor, metastases nor radiation field could be defined that would enable an $\mathrm{AbE}$ to be predicted. Most reported clinical cases do not provide detailed information regarding blood parameters or other molecular tumor markers.

Due to the relation between the appearance of an $\mathrm{AbE}$ and the anti-tumor immune reaction of the patient, the specific immunological pattern of patients would contribute significantly to the prediction of such a response. In particular, the change in the status of CD4+ and CD8+ T cells and the ratio of these cell groups to immunosuppressive Tregs or MDSCs during the entire treatment would be of particular interest. Unfortunately, only ten case reports in total provide details on this matter. When administering an immunotherapeutic agent, the determination of the PD-L1 status should be determined routinely. In 16 cases of $\mathrm{AbE}$, this biomarker not only provided information for the benefit of an ICB but it also correlated with an abscopal response. In addition, the AbEs we have 
seen so far identify further markers that may potentially provide a pattern for predicting such an immunologically-driven effect.

\section{Potential Predictors for Abscopal Effect}

It remains unclear whether an abscopal response can be predicted. AbEs occur unexpectedly after the irradiated tumors begin to grow following RT, as some cases may have gone clinically undetected or discovered by chance during routine examinations [50]. Therefore, predictive biomarkers would promote a better monitoring and investigation of this phenomenon.

The T cell trafficking model was discussed as a predictive tool. In fact, Poleszczuk et al. developed a mathematical model to estimate the distribution of activated $\mathrm{T}$ cells between metastatic lesions. Thereby, they proposed that the migration of activated $\mathrm{T}$ cells from the activation site (irradiation field) to a specific metastasis depended on the physiologic blood flow to the organ involved. They aimed to identify treatment targets with the highest probability for AbE occurrence. They revealed that not all metastatic sites respond to the systemic immune response in an equal manner and that the dissemination of activated $\mathrm{T}$ cells among multiple metastatic sites is intricate. Consequently, the abscopal responses of the virtual patients presented the same metastatic sites, being highly patient-specific and could not be predicted from the data of previous cases [181]. Nevertheless, their model has some clinical limitations such as the gradual process of $\mathrm{T}$ cell priming and the influence of immune enhancement or suppression [182].

The current data situation only allows the application of a mathematical model to a small part of the mechanism behind an $\mathrm{AbE}$, thus potentially misleading the clinical trial design. Therefore, timely identification of biomarkers associated with an abscopal response is necessary for predictive purposes. Even though some $\mathrm{AbE}$ biomarkers have already been discussed in literature no precise biomarkers have yet been validated to accurately predict $\mathrm{AbE}$, especially in the context of combined treatment regimens. Thus, it is also worth considering immunotherapy predictive biomarkers for cancer immunotherapy and immune checkpoint inhibitors. Potential predictors for systemic responses to RT and immunotherapy include cytokine profiles as well as changes in AB titer and peripheral blood and/or tumor-infiltrating immune cells as listed in Table 4 .

Table 4. Potential predictive biomarkers for abscopal effects.

\begin{tabular}{|c|c|c|c|c|}
\hline Potential Predictor & \multicolumn{2}{|c|}{ Preclinical Evidence } & \multicolumn{2}{|c|}{ Clinical Evidence } \\
\hline \multirow[t]{2}{*}{ Tumor protein p53 } & Camphausen et al. [183] & $\begin{array}{l}\text { Requirement of intact p53 to } \\
\text { induce } \mathrm{AbE}\end{array}$ & & \\
\hline & Strigari et al. [184] & $\begin{array}{l}\text { Non-irradiated tumors with } \\
\text { functional p53 respond } \\
\text { systematically to irradiation }\end{array}$ & & \\
\hline Calreticulin & Gameiro et al. [115] & $\begin{array}{c}\text { Calreticulin expression as } \\
\text { evidence for enhanced CTL } \\
\text { lysis of non-irradiated tumor } \\
\text { cells }\end{array}$ & & \\
\hline Hsp70 & Bayer et al. [185] & $\begin{array}{l}\text { Plasma levels of Hsp70 } \\
\text { associated with tumor } \\
\text { burden, level correlates with } \\
\text { tumor progression and } \\
\text { radiation-induced tumor } \\
\text { regression }\end{array}$ & & \\
\hline$\gamma-\mathrm{H} 2 \mathrm{AX}$ & & & Siva et al. [186] & $\begin{array}{c}\gamma-\mathrm{H} 2 \mathrm{AX} \text { foci in } \\
\text { non-irradiated PBL and hair } \\
\text { follicles indicates AbE in } \\
\text { normal tissue }\end{array}$ \\
\hline \multirow{2}{*}{ PD-L1 } & & & Yaguchi et al. [88] & \multirow{2}{*}{$\begin{array}{l}\text { Correlation of PD-L1 } \\
\text { expression to abscopal } \\
\text { response }\end{array}$} \\
\hline & & & Watanabe et al. [97] & \\
\hline
\end{tabular}


Table 4. Cont.

\begin{tabular}{|c|c|c|c|}
\hline Potential Predictor & Preclinical Evidence & \multicolumn{2}{|c|}{ Clinical Evidence } \\
\hline - SCC antigen & & Joe et al. [31] & $\begin{array}{l}\text { SCC Ag levels decreases due } \\
\text { to systemic response }\end{array}$ \\
\hline • S100 (melanoma) & & Watanabe et al. [97] & $\begin{array}{l}\text { Correlation of decrease in } \\
\text { S100 with AbE }\end{array}$ \\
\hline \multirow[t]{2}{*}{ - CEA } & & Golden et al. [52] & $\begin{array}{l}\text { Drastic drop to normal levels } \\
\text { during systemic response }\end{array}$ \\
\hline & & Kuroda et al. [43] & $\begin{array}{l}\text { Drop in plasma levels during } \\
\text { occurrence of } \mathrm{AbE}\end{array}$ \\
\hline - CA15-3 & & Leung et al. [39] & $\begin{array}{l}\text { Significant decrease in } \\
\text { CA15-3 levels during } \\
\text { abscopal reaction }\end{array}$ \\
\hline - CA19-9 & & Bonilla et al. [41] & $\begin{array}{l}\text { Reduced plasma levels } \\
\text { during } \mathrm{AbE}\end{array}$ \\
\hline • CA125 & & Tomita et al. [48] & $\begin{array}{l}\text { Reduced plasma levels } \\
\text { during AbE }\end{array}$ \\
\hline \multirow{3}{*}{$\begin{array}{l}\text { ctDNA abundance and tumor } \\
\text { mutational burden (TMB) }\end{array}$} & & Xie et al. [63] & $\begin{array}{l}\text { Correlation of ctDNA } \\
\text { abundance with abscopal } \\
\text { extinction of tumor cells }\end{array}$ \\
\hline & & Zhao et al. [72] & $\begin{array}{c}\text { ctDNA analysis for mutation } \\
\text { monitoring associated with } \\
\text { AbE }\end{array}$ \\
\hline & & Sharabi et al. [61] & $\begin{array}{c}\text { Correlation of elevated TMB } \\
\text { with } \mathrm{AbE}\end{array}$ \\
\hline \multicolumn{4}{|l|}{ Tumor antigens } \\
\hline $\begin{array}{l}\text { - melanoma antigen A3 } \\
\text { (MAGEA3) }\end{array}$ & & \multirow[t]{2}{*}{ Stamell et al. [53] } & \multirow[t]{2}{*}{$\begin{array}{l}\text { Association of } A B \text { to tumor } \\
\text { antigens with } A b E\end{array}$} \\
\hline $\begin{array}{l}\text { - PAS domain-containing } 1 \\
\text { (PASD1) }\end{array}$ & & & \\
\hline • NY-ESO-1 & & Postow et al. [49] & $\begin{array}{l}\text { AB titers against NY-ESO-1 } \\
\text { correlated positively with } \\
\text { disease progression }\end{array}$ \\
\hline \multirow{8}{*}{$\begin{array}{l}\text { Absolute lymphocyte count } \\
\text { (ALC) }\end{array}$} & & Antoniades et al. [9] & $\begin{array}{c}\text { Correlation of } \\
\text { irradiation-induced decrease } \\
\text { in ALC with increase in } \\
\text { neutrophils }\end{array}$ \\
\hline & & Desar et al. [28] & \multirow{4}{*}{$\begin{array}{l}\text { Monitoring changes of } \\
\text { lymohocytes during AbE }\end{array}$} \\
\hline & & Kuroda et al. [43] & \\
\hline & & Postow et al. [49] & \\
\hline & & Blattner et al. [187] & \\
\hline & & Golden et al. [52] & $\begin{array}{l}\text { Disease progression tracked } \\
\text { by ALCs, white blood cells } \\
\text { (WBCs) and absolute } \\
\text { eosinophil counts (AECs) }\end{array}$ \\
\hline & & Grimaldi et al. [54] & $\begin{array}{l}\text { ALC was increased before RT } \\
\text { if } \mathrm{AbE}\end{array}$ \\
\hline & & Chen et al. [188] & $\begin{array}{c}\text { Correlation between } \\
\text { increased ALC value after RT } \\
\text { and AbE }\end{array}$ \\
\hline \multirow{2}{*}{$\mathrm{T}$ cell values } & & Kuroda et al. [43] & $\begin{array}{c}\text { low CD8+ lymphocyte counts } \\
\text { at the time of } \mathrm{AbE}\end{array}$ \\
\hline & & Postow et al. [49] & $\begin{array}{c}\text { IFN } \gamma \text {-producing CD8+ and } \\
\text { CD4+ T cells decrease due to } \\
\text { RT and increase slightly } \\
\text { during } \mathrm{AbE}\end{array}$ \\
\hline $\begin{array}{l}\text { Neutrophil-to-lymphocyte } \\
\text { ratio }\end{array}$ & & Golden et al. [189] & $\begin{array}{c}\text { significantly lower baseline in } \\
\text { non-responders }\end{array}$ \\
\hline
\end{tabular}


Table 4. Cont.

\begin{tabular}{|c|c|c|c|}
\hline Potential Predictor & Preclinical Evidence & \multicolumn{2}{|c|}{ Clinical Evidence } \\
\hline \multirow{4}{*}{$\begin{array}{l}\text { Tumor-infiltrating } \\
\text { lymphocytes }\end{array}$} & & Joe et al. [31] & $\begin{array}{l}\text { Infiltration pattern of tumor } \\
\text { reacting with } \mathrm{AbE}\end{array}$ \\
\hline & & Hori et al. [121] & $\begin{array}{l}\text { Infiltration of non-irradiated } \\
\text { lesion by CD8+ T cells }\end{array}$ \\
\hline & & Teulings et al. [25] & $\begin{array}{l}\text { Infiltration of abscopal } \\
\text { reacting tumors with CD8+ T } \\
\text { cells }\end{array}$ \\
\hline & & Mampuya et al. [99] & $\begin{array}{l}\text { Moderate infiltration of } \mathrm{CD} 3+ \\
\text { cells after occurrence of } \mathrm{AbE}\end{array}$ \\
\hline Cytokine profiles & & Ohba et al. [15] & $\begin{array}{c}\text { Monitoring serum } \\
\text { concentrations of various } \\
\text { cytokines in } \mathrm{AbE}, \mathrm{TNF}-\alpha \\
\text { serum levels increased in } \mathrm{AbE}\end{array}$ \\
\hline Exosomes & & Chen et al. [188] & $\begin{array}{l}\text { Circulating TEXs analysis } \\
\text { could distinguish responders } \\
\text { from non-responders }\end{array}$ \\
\hline
\end{tabular}

\subsection{Tumor Protein $p 53$}

The tumor suppressor gene $\mathrm{p} 53$ regulates the expression of crucial proteins responsible for tumor cell proliferation, apoptosis, and DNA repair. The gene possesses a checkpoint function critical for preventing the replication of damaged DNA, thereby hindering thereby the growth of tumors, a function that is inhibited in mutated p53 [190]. Altered gene p53 functions are predominant driver mutations in numerous carcinomas.

Various preclinical studies have demonstrated p53 being involved in the mechanism behind AbE suggesting that p53 status could help predict the possibility of its occurrence.

Camphausen et al. examined the dependence of AbE on the function of p53 after RT. They irradiated the normal tissue of non-tumor-bearing legs of wild-type (wt) p53 mice and p53-null mice to induce abscopal response in distant lung carcinomas and fibrosarcomas. Only the tumors in mice with a non-inhibited p53 protein complex showed markedly reduced growth rate after irradiation. These results may suggest that intact p53 could be necessary to trigger the $\mathrm{AbE}$ tumor which is independent yet radiation-dose dependent. Its transcription function could be essential for the expression of cytokines or to affect a systemic antiangiogenic effect resulting in an abscopal signal [183]. Furthermore, another study proved that non-irradiated tumors respond systematically to irradiation only if they express functional p53. Implanted human colon cancer cells in wt-p53 and p53-null mice were irradiated (dose of 10 or $20 \mathrm{~Gy}$ ) delivered to only one flank tumor leaving the contralateral side non-irradiated. The irradiated tumors reacted dose-dependently but presented a tumor retardation independent of p53 status. A significant growth inhibition of non-irradiated tumors was observed exclusively in wt-p53 animals, displaying a higher effect at higher doses [184]. This preclinical data may suggest that p53-dependent signals might be responsible for $\mathrm{AbE}$ and that the evaluation of p53-status could help predict the possibility of an $\mathrm{AbE}$, even a verification in a clinical environment is still pending.

\subsection{Calreticulin}

Calreticulin, as a calcium-binding endoplasmic reticulum protein, plays an essential function in antigen presentation ensuring the appropriate loading of cellular antigens [191]. Thus, calreticulin expression may also give some predictive information about a potential abscopal response to immunotherapy and radiotherapy [192]. Calreticulin is essential for the recognition of tumor cells by DCs and subsequently by T cells, in fact, depletion of calreticulin in the tumor cells reduced the T cell killing [193]. Sublethal irradiated tumor cells increase their calreticulin expression while radiation induces the translocation of calreticulin from the endoplasmic reticulum to the cell surface. The exposure on the cell surface, in turn, affects the induction of immunogenic cell death and enhances antigen processing which promotes the uptake of irradiated tumor cells by APCs [115,194,195]. 
Gameiro et al. examined the calreticulin expression in vitro on human breast, lung and prostate carcinoma cells in comparison to untreated control cells. Cells exposed to sublethal doses increased their susceptibility to CD8+ CTL-mediated lysis. Moreover, exogenous calreticulin also increased the CTL lyses of non-irradiated tumor cells regardless of their p53 or triple-negative phenotype [115].

\section{3. $H s p 70$}

The highly stress-inducible heat shock protein 70 (Hsp70) is overexpressed inside tumor cells in many different cancer types, being an indicator for enhanced cell growth, protection against lethal damage, resistance to radiation-induced cell death or shorter overall survival [196,197]. Hsp70 is known as a useful biomarker for the prediction of hepatocellular carcinoma, prostate cancer, serum squamous cell carcinoma (SCC) of the esophagus, endometrial carcinoma or node-negative breast carcinoma [198-201]. Moreover, Hsp70 is actively released by viable tumor cells within exosomes. The plasma levels of the Hsp70 have been linked to tumor burden in a mice model correlating levels with tumor progression as well as radiation-induced regression of the tumors [185]. Following RT, Hsp70 is emitted into the extracellular matrix by dying tumor cells in a smaller amounts than by viable tumor cells [202]. Herein, Hsp70 acts as a danger signal stimulating the innate and adaptive immune system [203]. Natural killer cells (NKs) are activated after binding to free Hsp70, which then migrate to Hsp70 positive tumor cells to eradicate them [204]. Furthermore, the free Hsp70 can bind tumor-derived antigenic peptides that stimulate T cells via antigen cross-presentation on MHC molecules of APCs [205]. Thus, free Hsp70 seems to be a potential biomarker for a radiation-induced anti-tumor immune response and hence, for $\mathrm{AbE}$.

\section{4. $\gamma-H 2 A X$}

Phosphorylated histone H2AX ( $\gamma-\mathrm{H} 2 \mathrm{AX})$ molecule amount measured after irradiation is an essential biomarker utilized to determine the DNA damage induced by radiation but may also give some information about AbE. In response to irradiation-induced DNA DSBs, cells phosphorylate thousands of H2AX molecules specifically at the damaged sites [206]. The amount of these $\mathrm{y}-\mathrm{H} 2 \mathrm{AX}$ foci is proportional to the radiation dose and can also be visualized in the chromatin of human peripheral blood lymphocytes (PBL) and hair follicles for use in biodosimetry $[186,206]$. Siva et al. observed the $\gamma$-H2AX foci in non-irradiated PBL and hair follicles of irradiated NSCLC patients to determine the abscopal response of the irradiation in normal tissue. They also correlated this to changes in plasma levels of CCL22 and CCL3 cytokines [186].

\section{5. $P D-L 1$}

PD-L1 expression is the sole biomarker typically used in clinical practice for the prediction of immunotherapy responses. PD-1 is an immune checkpoint receptor expressed on activated $\mathrm{T}$ cells that regulate the $\mathrm{T}$ cell response antagonistically. The interaction of PD-1 and its ligand PD-L1, which is expressed on tumor cells and other cells in the TME affects $T$ cell activation, resulting in an immune escape for cancer cells. The expression of PD-L1 on tumor-infiltrating lymphocytes must also be considered as a factor influencing its predictive value. Herbst et al. related the response to checkpoint inhibitors with increased levels of PD-L1 on the surface of the tumor-infiltrating lymphocytes but not on T cells [207].

Numerous studies have shown a correlation between a high PD-L1 expression and the response to immunotherapy [208-211]. PD-L1 expression alone has limitations in successfully predicting responses to immunotherapy, as it may also indicate $\mathrm{T}$ cell exhaustion and thus reduced systemic efficacy. Thus, it may imply either a limitation or complete absence of $\mathrm{AbE}[132,212]$.

Nevertheless, PD-L1 expression may deliver important information for an AbE event but not as a comprehensive and independent clinical biomarker. Several AbE reports correlated the expression of PD-L1 with patients' systemic response [88,97]. Yaguchi et al. 
reported a PD-L1 positive immunohistochemistry (IHC) analysis in an AbE of a patient with recurrent pulmonary pleomorphic carcinoma and rapidly progressive metastases in the brain, bone, and pulmonary pleurae. The resected lung tumor strongly expressed PD-L1 and the non-irradiated metastases responsed as nearly complete after three cycles of anti-PD-1 immunotherapy [88]. Watanabe et al. analyzed PD-L1 status in two melanoma patients. One patient presented PD-L1 positive tumor lesions with a $40 \%$ chance of complete response due to the anti-PD-1 treatment alone. Hence, the authors questioned the role of $\mathrm{RT}$ in the outcome. The AbE in the other patient was correlated with the RT due to lack of the PD-L1 expression [97].

PD-L1 expression, may also serve to define the role of the RT in an AbE, however, the temporal and spatial heterogeneity of PD-L1 expression must also be taken into account [213]. Nonetheless, PD-L1 negative patients may also benefit from checkpoint therapy because PD-L1 expression in metastases do not correspond with the expression in the primary tumor $[73,82,90]$. A study of metastatic NSCLC demonstrated a substantial variation in the PD-L1 expression across different sites and clinical states. PD-L1 expression levels in the lung or distant metastatic biopsies correlated with a higher response rate, whilst no association could be observed in LN metastases [214].

\subsection{Tumor Markers}

Tumor markers could be used to monitor the response of the tumor masses; therefore, longitudinal marker measurement also allows detection of an ongoing $\mathrm{AbE}$.

Serum squamous cell carcinoma antigen (SCC Ag), a specific marker in SCC, could be associated with the outcome of RT. Elevated SCC Ag represents RT-resistant tumors whereas a reduction in its levels predicts a positive tumor response [215]. In the case of $\mathrm{AbE}$, the SCC Ag levels also decrease due to irradiation and the following systemic response [31].

Similarly, the melanoma marker S100, commonly used as a marker for immunohistochemical identification of malignant melanoma, could help determine an abscopal response if measured longitudinally in short intervals. S100 levels were seen to correlate both with the tumor burden in distant metastases and the degree of infiltration of the liver and skeleton [216,217]. Immunotherapy combined with RT can lead to a decrease in S100 which could be associated with an AbE [97].

CEA is expressed as a non-specific tumor marker on the surface of many cancer cells, whereas CEA plasma levels are very faint $(0$ to $5 \mathrm{ng} / \mathrm{mL})$. Increased CEA levels act as a determiner for the tumor stage and as a predictor of the response to therapy for gastric cancer [218-220]. In NSCLC, a CEA plasma level could be used as a prognostic marker for overall survival, recurrence or progression-free survival [221]. Additionally, a group analyzed CEA levels in a patient with metastatic NSCLC and reported an AbE following treatment, consistent with a drastic drop to normal levels in CEA levels during the systemic response [52]. Kuroda et al. also observed a significant drop in the plasma levels of a lung adenocarcinoma patient after RT and during the time of the occurrence of the AbE. CEA levels increased in accordance with the progression of a non-responder metastasis [43].

In breast cancer, high preoperative CA15-3 and CEA serum levels were described as directly related to tumor burden and outcome predictors [222,223]. In fact, Leung et al. reported a substantial decline CA15-3 levels in a breast cancer patient, along with a continuous decrease in CEA during the occurrence of the abscopal response [39].

Carbohydrate antigen 19-9 (CA19-9) is most commonly used as a tumor marker for pancreatic ductal adenocarcinoma [224], during an abscopal response this marker has seen to be reduced. Bonilla et al. reported a corresponding plasma concentration curve for a patient with gastric adenocarcinoma presenting an AbE following palliative RT [41]. Most recently, a case report of a patient with endometrioid adenocarcinoma reported decreasing plasma levels of CA125 during the time of the AbE event [48].

Unfortunately, most patients with $\mathrm{AbE}$ do not reflect the disease progress through specific tumor marker signatures $[60,98]$. 


\section{7. ctDNA Amount and Tumor Mutational Burden}

Circulating tumor DNA (ctDNA) are found in cell-free blood fraction and are described as a potent biomarker that enables the detection of tumor-specific sequence alterations [225-227]. Tissue tumor mutational burden (TMB) is a viable biomarker for the response to immunotherapy, helping to quantify tumor immunogenicity [228]. Elevated TMB supports the enhanced expression of tumor-associated neo-antigens following RT and subsequent anti-tumor immune response $[229,230]$.

ctDNA abundance, the peripheral blood ratio between ctDNA and total circulating DNA, might also give information about tumor burden or disease progression. An independent predictor of the response to immunotherapy has been described as having a TMB higher than 16 when measured in ctDNA abundance [231]. ctDNA levels seem to be correlated to pseudo-progression in KRAS-mutated adenocarcinoma, a mutation associated with an improved outcome under immunotherapy. In pseudo-progressive patients, ctDNA levels decrease drastically whereas in progressive patients they appears strongly elevated [232].

Xie et al. measured the ratio between ctDNA and the total free DNA in the peripheral blood of an RCC patient which presented an AbE both before and during RT and pembrolizumab treatment. ctDNA abundance decreased before it unexpectedly rose two months after combination treatment and then drastically decreased again, suggesting its correlation with the extinction of tumor cells as corroborated by CT images [63]. Another study reported an $\mathrm{AbE}$ in a neuroendocrine cervical carcinoma patient with metastatic lesions in the liver, pelvic and retroperitoneal LNs. After performing a ctDNA test (70 genes), they found alterations in 19 genes indicating an elevated TMB. Tissue next-generation sequencing (NGS) also revealed a high TMB (53 mutations per megabase) [61].

Zhao et al. presented a case of an abscopal response in a patient with esophageal carcinoma and multiple LN metastases. Esophagectomy was performed followed by several cycles of chemotherapy, pembrolizumab and RT (42 Gy, six fractions) targeting the left retroperitoneal LN. After two months all LN metastases displayed complete regression. The ctDNA was analyzed to monitor the TP53 mutation. Results suggested that these mutations decreased significantly due to the applied combination therapy [72].

The changes in ctDNA release during or immediately after RT are a result of irradiationinduced immunogenic cell death. ctDNA presents a half-life of $0.5-2 \mathrm{~h}$, therefore blood samples should be taken periodically and at shorter intervals to obtain more accurate information on the ctDNA alterations during patient treatment [233].

\subsection{Tumor Antigens and Antibodies}

RT generates tumor tissue damage leading to enhanced tumor-specific antigen release, which could function as an in situ immunization and induce AbE [107]. Consequently, serum analysis of tumor antigens alterations may be used as an abscopal response marker for RT alone and/or in combination with immunotherapy.

The antigen load or more precisely the load of neoantigens, which are the number of mutations actually targeted by $\mathrm{T}$ cells, is associated with the response to immunotherapy $[234,235]$. Indeed, a study correlated a significantly increased neoantigen load in tumors of NSCLC patients after PD-1 blockade with a higher clinical response and improved progression-free survival. Thereby, the neoantigen-induced $\mathrm{T}$ cell response was detected after therapy initiation with its highest level three weeks following treatment starting with a progressive reduction [236]. AbE have been described to occur at different time points, suggesting that abscopal immune reactions might stimulate the priming of new $T$ cells in addition to the initially primed one, originating a broader and more specific $\mathrm{T}$ cell response [182].

Measuring the concentration of specific antibodies against tumor-associated antigens may be illustrative. In effect, the serum of a melanoma patient was tested for auto-AB levels against melanoma antigen A3 (MAGEA3), revealing a systemic antitumor immune response. Following RT and immunotherapy the patient responded to cancer antigen 
PAS domain-containing 1 (PASD1) achieving complete remission [53]. Another research group reported an $\mathrm{AbE}$ of a melanoma patient treated with RT and ipilimumab. The cancer cells of the patient expressed the cancer antigen NY-ESO-1, an antigen found in $30-40 \%$ of advanced melanoma patients. The titers of $\mathrm{AB}$ against epitopes within the central portion of NY-ESO-1 in the serum samples collected during the treatment correlated positively with the disease progression. In fact, after RT and immunotherapy, the titers were increased by a factor of more than 30 corresponding to disease resolution [49].

Antigen immunogenicity, the ability of released antigens to elicit an anti-tumor immune response, is fundamental to the occurrence of abscopal responses and thus may be the limiting factor for an $\mathrm{AbE}$ [237]. Therefore, a further study promoted the determination of the tumor immunogenicity score (TIGS), represented as tumor antigenicity multiplied by antigen processing and presenting status, as an effective biomarker for immunotherapy response prediction [238]. TIGS may be best determined during the treatment period, on account of the relation between $\mathrm{AbE}$ and the immune response to tumor antigens.

\subsection{Absolute Lymphocyte Count and Amount of Blood Immune Cells}

The absolute lymphocyte count (ALC) and/or the count of specific immune cells could also act as conceivable predictive biomarkers for $\mathrm{AbE}$. However, to date, only a few cases have given further details on the immune cell status of the respective patients during treatment.

In 1977, Antoniades et al. counted the absolute leukocytes as well as the subpopulations of neutrophils, monocytes, eosinophils, and basophils in their patients' blood before and after irradiation compared with values of a healthy donor. The two patients with metastatic lymphoma exhibited a marked reduction in the size of non-treated abdominal LNs. Both patients showed an irradiation-induced decrease in the ALC corresponding with an increased ratio of neutrophils [9]. A more recent study analyzed leukocytes, neutrophils, lymphocytes, and monocytes in the blood of a patient with a diffuse-type giant cell tumor showing an $\mathrm{AbE}$ at one month after RT treatment of the right hilar in the left lung [28].

Diverse studies have shown that if more of these standard values were reported, changes in the immune cell amounts may be correlated with the occurrence of an $\mathrm{AbE}[43,49,52,54,187,188]$. More precise information of the immune condition also enables an assessment of the immunosuppressive status that counteracts a possible $\mathrm{AbE}$.

Golden et al. reported a case of $\mathrm{AbE}$ in a treatment-resistant lung cancer patient treated with RT and ipilimumab. Two to three months following RT to hepatic metastases, the non-irradiated lesions showed a decrease in size. Disease progression was tracked by ALCs, white blood cells (WBCs) and absolute eosinophil counts (AECs). Other studies associated an ALC increase of $\geq 1000 / \mu \mathrm{L}$ in whole blood with improved survival rates $[239,240]$. Indeed, the patient showed a correspondingly elevated ALC due to the RT and ipilimumab treatment combined with an AbE. The AEC was also enhanced by more than $100 / \mu \mathrm{L}$ whole blood, an increase which was previously also correlated with prolonged survival. Tumorinfiltrating lymphocytes (cytotoxic $\mathrm{T}$ cell, cytotoxic granules and regulatory $\mathrm{T}$ cells) also increased due to the treatment [52]. In a retrospective analysis of 21 advanced melanoma patients, an $\mathrm{AbE}$ was reported in 11 patients treated with a combination of ipilimumab and RT. In patients presenting AbE, ALC was increased prior to RT [54]. Another retrospective study analyzed 153 cases of patients with various cancer types treated with a combination of RT and immunotherapy, where at least one non-contiguous lesion was not irradiated. The results suggested a correlation between an enhanced post-RT ALC and abscopal response. Moreover, a lower post-RT APC results in a poorer progression-free and overall survival [188]. In brief, these data suggest ALC as a potential predictive AbE marker, however, this hypothesis requires additional data from clinical trials.

Due to their prominent role in $\mathrm{AbE}$, different case reports also reported CD8+ lymphocytes values in blood at different treatment time points. There are reports of low CD8+ lymphocyte counts at the time of $\mathrm{AbE}$, which increased again with disease progression [43]. A study measured the amounts of patients CD14+ MDSCs, CD8+ and CD4+ T cells as well as their activation status during the treatment period via flow cytometry. CD4+ ICOShigh $\mathrm{T}$ 
cells decreased during RT response while MDSCs first decreased severely before increasing again within the abscopal response period. The frequencies of IFN- $\gamma$-producing CD8+ and CD4+ T cells were decreased due to cell irradiation, yet increased slightly during AbE [49].

Additionally, the neutrophil-to-lymphocyte ratio may be an effective AbE predictive factor. In fact, eleven patients with different cancer entities presented an $\mathrm{AbE}$ with a combined RT and granulocyte-macrophage colony-stimulating factor (GM-CSF) treatment. A comparison was made between the baseline features of abscopal responders and non-responders. Accordingly, no significant differences were observed in phenotype parameters such as age, sex, previous numbers of RT or chemotherapy regimens nor in laboratory values (hemoglobin, albumin, WBC count) between responders and nonresponders. However, a significantly lower baseline was noted in non-responders for the neutrophil-to-lymphocyte ratio [189].

\subsection{Tumor-Infiltrating Lymphocytes}

The evaluation of the tumor-infiltrating lymphocytes (TILs) may also give a potential indication of abscopal response. In preclinical studies, enhanced amounts of CD8+ cells in non-irradiated tumors were associated with the enhanced probabilities of AbE [151]. Clinically, the effectiveness of immunotherapy could be predicted as a result of TIL count determination [241].

Joe et al. analyzed the tissue of squamous carcinoma of the anal canal tumor with a complete response four months after palliative RT to the pelvic metastasis. Immunohistochemical staining for CD163, CD3, CD4, and CD8 showed heterogeneity of cell distribution. Some tumor regions were densely infiltrated with lymphocytes, including CD8+ and CD4+ $\mathrm{T}$ cells, suggesting a profuse immune response [31].

Moreover, a recent case report of a metastatic RCC patient reported a high heterogeneous infiltration of the non-irradiated primary lesion by CD8+ T cells. The patient showed regression of a lung metastasis six months after RT and immunotherapy treatment. Nevertheless, only a part of the tumor was considered immunogenic before anti-PD-1 treatment [90]. Teulings et al. performed a detailed immunological analysis of biopsies from a melanoma patient presenting AbE twelve months after irradiation of the axillary region and brain. Axillary LN sections exhibited a lymphocyte infiltration, whereas brain metastasis was mainly infiltrated by CD8+ T cells. Melanocyte-specific CD8+ T cells were found to represent an effector memory subgroup in both skin biopsies and blood. These data suggested a systemic and local anti-melanoma response against melanocyte differentiation antigens from the primary tumor and metastases [25]. Furthermore, the immunohistochemical analysis of the non-irradiated retropharyngeal metastasis of a patient with malignant pleural mesothelioma revealed a moderate infiltration of CD3+ cells after the occurrence of $\mathrm{AbE}$. The intra-tumoral $\mathrm{T}$ cell population was composed of around $25 \%$ CD8+ T cells [99].

\subsection{Cytokine Profiles}

Radiation, as part of the cellular repair response, induces the release of cytokines and chemokines which in turn play various roles in systemic immune response modulation. Longitudinal observation of cytokine profiles could provide an overview about the systemic immune response. This information could provide some valuable therapy success predictive data in addition to assessing AbE incidence.

Animal models have already shown that increased levels of specific cytokines have a significant role in cytotoxic $\mathrm{T}$ cell responses and $\mathrm{AbE}$ [139]. In prostate cancer, several blood-based biomarker studies correlated elevated levels of different cytokines with disease progression and poor prognosis. After exposure to RT, the plasma levels of diverse cytokines, namely IL- $1 \alpha$, IL-4, IL- 6 , TNF- $\alpha$, TGF- $\beta$, IFN- $\gamma$ and macrophage colony stimulating factor (M-CSF) were increased and correlated with RT-induced toxicity [242-245]. In breast cancer studies, IL- 6 and IL- 8 were considered as potential markers for metastasis and disease progression [246-248]. Moreover, in patients with NSCLC undergoing pallia- 
tive thoracic RT, significant changes in CCL15, CCL23, CCL24, CXCL2, CXCL6, CX3CL1, IL-6, and IL-8 serum levels were observed before, during, and after RT, correlating with metabolic tumor burden [249]. In hepatocellular carcinoma patients treated with RT, levels of IL-6 and IL-10 were seen to be valuable predictors of infield- and outfield-intrahepatic treatment failure [250]. Ohba et al. measured the serum concentrations of IL-1 $\beta$, IL-2, IL-4, IL-6, TNF- $\alpha$, and hepatocyte growth factor (HGF) in series before and after RT in a patient with hepatocellular carcinoma who presented AbE ten months after the irradiation of a thoracic vertebral metastasis. Most cytokine levels did not significantly change, except for TNF- $\alpha$ serum levels which had increased. The authors associated this increase with an enhanced NK cell activity along with increased AbE occurrence [15].

Immunosuppressive cytokines reduce the probability of AbE occurrence. Consequently, the balance between immune promoting and suppressing cytokines systemically and within the tumor environment before and after irradiation is crucial for treatment response. Levels of the cytokines TGF- $\beta$, IL-10 and adenosine should be particularly monitored. Radiation-induced cell death leads to the activation of M2 macrophages and TGF- $\beta$ and IL-10 production within the irradiation field [251]. Moreover, Tregs are enriched in the irradiated tumor, releasing TGF- $\beta$ and IL-10 [252]. In fact, increased Treg amounts together with radiation-induced recruitment of MDSCs exerts an impact on the production of immunosuppressive adenosine by irradiation stressed or injured cells [253]. On the other hand, IL-8, which primarily comes from circulating and intra-tumoral myeloid cells, inhibits the adaptive immune response by blocking the antitumor activity of effector $\mathrm{T}$ cells as well as antigen presentation $[254,255]$. Studies examining the clinical benefits of immune-checkpoint inhibitors linked high baseline levels of IL-8 in patients plasma to the poor prognosis of checkpoint inhibitor therapy. Consequently, a reduced immune response as a result of the IL-8 expression additionally suppresses the occurrence of an AbE.

\subsection{Exosomes}

Extracellular vesicles, including microvesicles and exosome, are small vesicles that contain bioactive cargo such as proteins, DNA or RNA, mediating intercellular communication in both physiological and pathological settings [256]. Exosomes secreted from tumor cells can carry both immune-stimulatory and immune-suppressive factors that partially mimic the profile of the releasing tumoral cells. Most previous studies have highlighted the immune-suppressive functions of these tumor-derived exosomes (TEXs). However, TEXs also transport immune-stimulatory TSAs as well as (co-)stimulatory immune molecules [257]. They play a crucial role in RT-associated immunity due to the antigen presentation and immune regulation dependent on the immune status of the TME [256]. TEXs have been studied to serve as liquid biopsy markers with high clinical diagnostic and prognostic value in lung, pancreatic, gastrointestinal cancer and hepatocellular carcinoma [258]. TEXs not only affect the local microenvironment around their releasing site but also circulate in the blood to distant metastatic sites promoting/suppressing tumor growth [257]. The immune-promoting effect is mainly based on the delivery of exosomederived TSA to dendritic cells and on the activation of cytotoxic $T$ cells to generate a specific anti-tumor response [259].

Following the irradiation production of TEXs containing DAMPs, chemokines and TSA are enhanced, however they vary according to the originally irradiated tissue $[257,260,261]$. The TEXs are processed by antigen-presenting cells, and trigger the activation of cytotoxic T cells which then migrate to distant non-targeted tumor cells and can induce AbE [257]. In case of AbE, Hsp70 surface-positive tumor-derived exosomes may be enriched in the irradiated field, facilitating their uptake by APC and thus triggering an enhanced anti-tumor response by NK cells $[262,263]$.

In metastatic melanoma, TEXs could be used to predict the tumor response to anti-PDL1 checkpoint inhibition. In this case, the level of circulating TEXs with surface PD-L1 could correlate with IFN- $\gamma$ levels, which could distinguish responders from non-responders [264]. 
Additionally, exosomes may potentially be used to identify NSCLS patients who respond positively to immune therapy [265].

\section{Clinical Studies on Abscopal Effect}

Even after almost a decade of radioimmunotherapy and numerous studies on different immunotherapeutic agents, the occurrence of abscopal immune reactions has not been regularly achieved in clinical trials. The most frequently reported cases of $\mathrm{AbE}$ were correlated with the co-administration of RT and ICB, in particular with the administration of the anti-PD-1 therapy nivolumab. Nevertheless, a similar effectiveness has not yet been observed in clinical trials. Accordingly, trial design and evaluation must be performed taking into consideration many different aspects, namely, patient and endpoint selection, RT parameters, the particular definition of AbE, therapy sequence, among others, making the discovery of the optimal conditions extremely challenging [266].

A clinical trial tested the combination of RT with GM-CSF in patients with metastatic solid tumors of different origin (NCT02474186). The primary endpoint of the study was the proportion of patients with an abscopal response. Eleven of the fourty-one patients enrolled (26.8\%) presented abscopal responses (four patients with metastatic NSCLC, 5 , breast cancer patients and two, thymic cancer patients) [189]. A phase I study treated 20 stage IV melanoma patients with a combination of RT, nivolumab (anti-PD-1), and ipilimumab (anti-CTLA4), receiving immunotherapy shortly before and after palliative RT. Patients who received a conventional irradiation dose (3 Gy, 10 fractions) experienced in a $50 \%$ ratio an abscopal reaction extrinsic of the irradiation field whereas $11.1 \%$ of patients treated with hypofractionated irradiated scheme ( $9 \mathrm{~Gy}$, three fractions) responded in a similar manner [267].

Contrary results were reported by a phase II trial examining the combination of RT and immune therapy in 20 patients with inoperable or metastatic melanoma (NCT02821182). The overall response rate (ORR) of the non-irradiated lesions increased by up to $45 \%$ with three complete and six partial responses similar to nivolumab monotherapy, however, no $\mathrm{AbE}$ was detected [268]. Subsequently, another study failed to observe an $\mathrm{AbE}$ in patients with metastatic head and neck squamous cell carcinoma (HNSCC) in a randomized, phase II trial of nivolumab combined with RT (NCT02684253). RT was delivered to one safely irradiated metastatic lesion between the first and second dose of nivolumab in three fractions adding up to a dose of $27 \mathrm{~Gy}$. The patients in this treatment arm showed no significant prolonged survival compared to the immune monotherapy arm [269].

Current ongoing trials with $\mathrm{AbE}$ as their primary or secondary outcome mainly investigate the combination of RT and the inhibition of the PD-1/PD-L1 pathway in various cancers such as NSCLC, metastatic gastro-intestinal cancer, metastatic melanoma and metastatic breast cancer (Table 5). Several of them depict promising outcomes which may provide further insights into potential $\mathrm{AbE}$ predictive biomarkers.

Table 5. Currently ongoing clinical trials.

\begin{tabular}{|c|c|c|c|c|c|c|c|c|}
\hline Study Identifier & Study Title & Status & $\begin{array}{l}\text { Condition or } \\
\text { Disease }\end{array}$ & Therapy & RT Scheme & Cohort N & $\begin{array}{l}\text { Planned Primary } \\
\text { Outcome Measures }\end{array}$ & $\begin{array}{l}\text { Planned Secondary } \\
\text { Outcome Measures }\end{array}$ \\
\hline NCT03480334 & $\begin{array}{l}\text { Abscopal Effect of } \\
\text { Radiotherapy and } \\
\text { Nivolumab in } \\
\text { Relapsed Hodgkin } \\
\text { Lymphoma After } \\
\text { Anti-PD-1 Therapy } \\
\text { (AERN) }\end{array}$ & Recruiting & $\begin{array}{l}\text { Classical Hodgkin } \\
\text { lymphoma }\end{array}$ & Nivolumab + RT & 20 Gy & 29 & $\begin{array}{l}\text { Abscopal response } \\
\text { rate }\end{array}$ & - \\
\hline \multirow{6}{*}{ NCT03396471 } & \multirow{6}{*}{$\begin{array}{c}\text { Study of } \\
\text { Pembrolizumab and } \\
\text { Concurrent } \\
\text { Radiation in Patients } \\
\text { With Previously } \\
\text { Treated Carcinoma } \\
\text { of Unknown } \\
\text { Primary }\end{array}$} & \multirow{6}{*}{ Recruiting } & \multirow{6}{*}{$\begin{array}{l}\text { Carcinoma, } \\
\text { unspecified site }\end{array}$} & \multirow{6}{*}{$\begin{array}{c}\text { Pembrolizumab }+ \\
\text { EBRT }\end{array}$} & \multirow{6}{*}{$\begin{array}{c}20-30 \mathrm{~Gy}, \\
5 \mathrm{fr}\end{array}$} & \multirow{6}{*}{34} & \multirow{6}{*}{$\begin{array}{l}\text { Abscopal response } \\
\text { rate }\end{array}$} & Response rate \\
\hline & & & & & & & & $\begin{array}{l}\text { Assess adverse } \\
\text { events }\end{array}$ \\
\hline & & & & & & & & $\begin{array}{l}\text { Progression free } \\
\text { survival }\end{array}$ \\
\hline & & & & & & & & Overall survival \\
\hline & & & & & & & & Time-to-progression \\
\hline & & & & & & & & Disease control rate \\
\hline
\end{tabular}


Table 5. Cont

\begin{tabular}{|c|c|c|c|c|c|c|c|c|}
\hline Study Identifier & Study Title & Status & $\begin{array}{l}\text { Condition or } \\
\text { Disease }\end{array}$ & Therapy & RT Scheme & Cohort N & $\begin{array}{c}\text { Planned Primary } \\
\text { Outcome Measures }\end{array}$ & $\begin{array}{l}\text { Planned Secondary } \\
\text { Outcome Measures }\end{array}$ \\
\hline \multirow{5}{*}{ NCT04238169 } & \multirow{5}{*}{$\begin{array}{l}\text { Clinical Trial } \\
\text { Assessing the } \\
\text { Efficacy of Abscopal } \\
\text { Effect Induced by } \\
\text { SBRT and } \\
\text { Immunotherapy in } \\
\text { Advanced NSCLC }\end{array}$} & \multirow{5}{*}{ Recruiting } & \multirow{5}{*}{$\begin{array}{l}\text { Non-Small-Cell } \\
\text { Lung Cancer } \\
\text { (NSCLC) }\end{array}$} & \multirow{5}{*}{$\begin{array}{c}(\text { Bevacizumab +) } \\
\text { Toripalimab + SBRT }\end{array}$} & \multirow{5}{*}{$30-50$ Gy, 5 fr } & \multirow{5}{*}{60} & \multirow{2}{*}{$\begin{array}{l}\text { Objective response } \\
\text { rate }\end{array}$} & $\begin{array}{l}\text { Progression free } \\
\text { survival }\end{array}$ \\
\hline & & & & & & & & Duration of response \\
\hline & & & & & & & \multirow{3}{*}{$\begin{array}{l}\text { Objective response } \\
\text { of non-target lesion }\end{array}$} & Overall survival \\
\hline & & & & & & & & $\begin{array}{l}\text { Incidence of adverse } \\
\text { events }\end{array}$ \\
\hline & & & & & & & & Quality of life \\
\hline \multirow{4}{*}{ NCT04873440 } & \multirow{4}{*}{$\begin{array}{l}\text { An Open-label, } \\
\text { Phase I/II Study of } \\
\text { Manganese Plus } \\
\text { Radiotherapy in } \\
\text { Patients With } \\
\text { Metastatic Solid } \\
\text { Tumors or } \\
\text { Lymphoma }\end{array}$} & \multirow{4}{*}{ Recruiting } & \multirow{2}{*}{ Solid tumor } & \multirow{4}{*}{$\begin{array}{l}\text { Manganese Chloride } \\
\text { + RT (Chemo- } \\
\text { immuno-therapy) }\end{array}$} & \multirow{4}{*}{$\begin{array}{l}\text { standard-of-care RT } \\
\text { or SBRT to one } \\
\text { metastatic site }\end{array}$} & \multirow{4}{*}{10} & \multirow{2}{*}{$\begin{array}{l}\text { Proportion of } \\
\text { subjects with an } \\
\text { abscopal response }\end{array}$} & Disease control rate \\
\hline & & & & & & & & $\begin{array}{l}\text { Progression free } \\
\text { survival }\end{array}$ \\
\hline & & & \multirow{2}{*}{ Lymphoma } & & & & Number of & Overall survival \\
\hline & & & & & & & adverse events & $\begin{array}{c}\text { Number of } \\
\text { participants with } \\
\text { laboratory test } \\
\text { abnormalities }\end{array}$ \\
\hline \multirow{6}{*}{ NCT04168320 } & \multirow{6}{*}{$\begin{array}{l}\text { SBRT-based PArtial } \\
\text { Tumor Irradiation of } \\
\text { HYpoxic Segment } \\
\text { (SBRT-PATHY) }\end{array}$} & \multirow{6}{*}{ Recruiting } & \multirow{6}{*}{$\begin{array}{l}\text { Unresectable } \\
\text { malignant solid } \\
\text { neoplasm bulky } \\
\text { tumors }\end{array}$} & \multirow{6}{*}{ SBRT } & \multirow{6}{*}{$\begin{array}{c}\text { SBRT-based PArtial } \\
\text { Tumor irradiation } \\
\text { targeting HYpoxic } \\
\text { segment }\end{array}$} & \multirow{6}{*}{30} & \multirow{6}{*}{$\begin{array}{l}\text { Bystander and } \\
\text { abscopal effects }\end{array}$} & Overall survival \\
\hline & & & & & & & & $\begin{array}{l}\text { Progression free } \\
\text { survival }\end{array}$ \\
\hline & & & & & & & & $\begin{array}{c}\text { Patient-reported } \\
\text { outcome }\end{array}$ \\
\hline & & & & & & & & $\begin{array}{c}\text { Incidence of adverse } \\
\text { events }\end{array}$ \\
\hline & & & & & & & & $\begin{array}{l}\text { Response evaluation } \\
\text { criteria in solid } \\
\text { tumors }\end{array}$ \\
\hline & & & & & & & & Timing \\
\hline \multirow{3}{*}{ NCT03449238 } & Pembrolizumab & & $\begin{array}{l}\text { Metastatic breast } \\
\text { cancer }\end{array}$ & & $\mathrm{n} / \mathrm{a}$ & & $\begin{array}{c}\text { Tumor response for } \\
\text { non-irradiated brain } \\
\text { lesions }\end{array}$ & \\
\hline & $\begin{array}{l}\text { And Stereotactic } \\
\text { Radiosurgery (Srs) } \\
\text { Of Selected Brain } \\
\text { Metastases In Breast }\end{array}$ & Recruiting & Brain metastases & $\begin{array}{c}\text { Pembrolizumab + } \\
\text { Stereotactic } \\
\text { Radiosurgery }\end{array}$ & & 41 & $\begin{array}{l}\text { Correlation of } \\
\text { abscopal responses } \\
\text { with the radiation } \\
\text { dose received }\end{array}$ & $\begin{array}{l}\text { Number of } \\
\text { participants with } \\
\text { abscopal response }\end{array}$ \\
\hline & & & & & & & Overall survival & \\
\hline & & & & & $40 \mathrm{~Gy}, 20 \mathrm{fr}$ & & & $\begin{array}{l}\text { Recurrence-free } \\
\text { survival after } \\
\text { resection }\end{array}$ \\
\hline & Multimodality & & Non-Small-Cell & & & & & Overall survival \\
\hline NCT04245514 & $\begin{array}{l}\text { Treatment in Stage } \\
\text { III Non-small Cell }\end{array}$ & Recruiting & $\begin{array}{l}\text { Lung Cancer } \\
\text { (NSCLC) }\end{array}$ & Durvalumab + RT & $25 \mathrm{~Gy}, 5 \mathrm{fr}$ & 90 & Event-free survival & Objective response \\
\hline & $\begin{array}{l}\text { Lung Cancer } \\
\text { (NSCLC) }\end{array}$ & & & & & & & $\begin{array}{c}\text { Pathological } \\
\text { complete response }\end{array}$ \\
\hline & & & & & $24 \mathrm{~Gy}, 3 \mathrm{fr}$ & & & $\begin{array}{l}\text { Major pathological } \\
\text { response }\end{array}$ \\
\hline & & & & & & & & Complete resection \\
\hline & & & & & & & & Overall survival \\
\hline NCT04530708 & Addition of & Recruiting & Non-Small-Cell & Thoracic RT vs. & $36 \mathrm{~Gy}$ & 162 & Difference in quality & $\begin{array}{l}\text { Progression free } \\
\text { survival }\end{array}$ \\
\hline & $\begin{array}{l}\text { Radiotherapy to } \\
\text { Standard Medical } \\
\text { Treatment for Stage } \\
\text { IV NSCLC (MARS) }\end{array}$ & & $\begin{array}{l}\text { Lung Cancer } \\
\text { (NSCLC) }\end{array}$ & standard of care & & & of life & $\begin{array}{c}\text { Toxicity of } \\
\text { esophagitis, } \\
\text { pneumonitis, } \\
\text { dyspnea, fatigue, } \\
\text { cough }\end{array}$ \\
\hline & Irreversible & & & & & & & $\begin{array}{l}\text { ORR of primary } \\
\text { tumor site } \\
\text { (pancreas) }\end{array}$ \\
\hline NCT04212026 & $\begin{array}{l}\text { Electroporation } \\
\text { (IRE) Followed by } \\
\text { Nivolumab in }\end{array}$ & Recruiting & $\begin{array}{c}\text { Metastatic } \\
\text { pancreatic cancer }\end{array}$ & Nivolumab & $\mathrm{n} / \mathrm{a}$ & 15 & $\begin{array}{l}\text { Overall response } \\
\text { rate (ORR) of the }\end{array}$ & $\begin{array}{c}\text { ORR of IRE-treated } \\
\text { liver metastasis }\end{array}$ \\
\hline & $\begin{array}{l}\text { Patients With } \\
\text { Metastatic }\end{array}$ & & & & & & $\begin{array}{l}\text { reference liver } \\
\text { metastasis }\end{array}$ & $\begin{array}{l}\text { Progression free } \\
\text { survival (PFS) }\end{array}$ \\
\hline & Pancreatic Cancer. & & & & & & & Overall survival \\
\hline & & & & & & & & Adverse events \\
\hline NCT03474497 & $\begin{array}{l}\text { IL-2, Radiotherapy, } \\
\text { and Pembrolizumab } \\
\text { in Patients }\end{array}$ & Recruiting & $\begin{array}{l}\text { NSCLC, Head and } \\
\text { neck squamous cell } \\
\text { carcinoma, }\end{array}$ & $\begin{array}{c}\text { IL-2 }+ \\
\text { Pembrolizumab }+\end{array}$ & $\begin{array}{c}24 \mathrm{~Gy}, \\
3 \text { fr. palliative }\end{array}$ & 45 & Abscopal response & Maximum tolerated \\
\hline & $\begin{array}{c}\text { Refractory to } \\
\text { Checkpoint }\end{array}$ & & $\begin{array}{l}\text { Metastatic } \\
\text { melanoma }\end{array}$ & RT & regimen & & & \\
\hline & Blockade & & Metastatic RCC & & & & & \\
\hline
\end{tabular}


Table 5. Cont

\begin{tabular}{|c|c|c|c|c|c|c|c|c|}
\hline Study Identifier & Study Title & Status & $\begin{array}{l}\text { Condition or } \\
\text { Disease }\end{array}$ & Therapy & RT Scheme & Cohort N & $\begin{array}{l}\text { Planned Primary } \\
\text { Outcome Measures }\end{array}$ & $\begin{array}{l}\text { Planned Secondary } \\
\text { Outcome Measures }\end{array}$ \\
\hline \multirow{10}{*}{ NCT03548428 } & \multirow{10}{*}{$\begin{array}{l}\text { Stereotaxic Body } \\
\text { Irradiation of } \\
\text { Oligometastase in } \\
\text { Sarcoma (Stereosarc) }\end{array}$} & \multirow{10}{*}{ Recruiting } & \multirow{10}{*}{ Sarcoma } & \multirow{10}{*}{$\begin{array}{c}\text { Atezolizumab + } \\
\text { SBRT }\end{array}$} & \multirow{10}{*}{$\begin{array}{l}3 \text { to } 5 \mathrm{fr} \text { depending } \\
\text { on tumor size }\end{array}$} & \multirow{10}{*}{103} & \multirow{10}{*}{$\begin{array}{l}\text { Progression-free } \\
\text { survival (PFS) rate }\end{array}$} & $\begin{array}{l}\text { PFS by immune } \\
\text { response criteria }\end{array}$ \\
\hline & & & & & & & & $\begin{array}{c}\text { Ratio PFS after } \\
\text { RT/PFS during } \\
\text { previous treatment }\end{array}$ \\
\hline & & & & & & & & $\begin{array}{l}\text { Objective response } \\
\text { rate }\end{array}$ \\
\hline & & & & & & & & Toxicity of treatment \\
\hline & & & & & & & & Overall survival \\
\hline & & & & & & & & Quality of life \\
\hline & & & & & & & & $\begin{array}{l}\text { Evaluation of the } \\
\text { cost of treatment }\end{array}$ \\
\hline & & & & & & & & $\begin{array}{l}\text { Rate of PET-CT at } \\
\text { inclusion }\end{array}$ \\
\hline & & & & & & & & $\begin{array}{c}\text { Impact of } \\
\text { biomarkers on PFS } \\
\text { or response rate }\end{array}$ \\
\hline & & & & & & & & $\begin{array}{l}\text { Developing } \\
\text { mathematical } \\
\text { models }\end{array}$ \\
\hline \multirow{8}{*}{ NCT03927898 } & \multirow{8}{*}{$\begin{array}{l}\text { Phase II Study of } \\
\text { Toripalimab Plus } \\
\text { Stereotactic Body } \\
\text { Radiotherapy in } \\
\text { Colorectal Cancer } \\
\text { Patients With } \\
\text { Oligometastasis }\end{array}$} & \multirow{8}{*}{ Recruiting } & \multirow{8}{*}{$\begin{array}{l}\text { Metastatic colorectal } \\
\text { cancer }\end{array}$} & \multirow{8}{*}{ Toripalimab + SBRT } & \multirow{8}{*}{$\begin{array}{l}\text { SBRT (BED >80Gy) } \\
\text { to oligometastatic } \\
\text { lesions }\end{array}$} & \multirow{8}{*}{40} & \multirow{8}{*}{$\begin{array}{l}1 \text { year progression } \\
\text { free survival (PFS) }\end{array}$} & $\begin{array}{l}\text { Acute adverse } \\
\text { events }\end{array}$ \\
\hline & & & & & & & & $\begin{array}{l}\text { Objective response } \\
\text { rate }\end{array}$ \\
\hline & & & & & & & & $\begin{array}{l}2 \text { year local control } \\
\text { rate }\end{array}$ \\
\hline & & & & & & & & $\begin{array}{c}2 \text { year overall } \\
\text { survival }\end{array}$ \\
\hline & & & & & & & & $\begin{array}{l}\mathrm{T} \text { cell receptor } \\
\text { repertoire/T cell } \\
\text { clones in blood }\end{array}$ \\
\hline & & & & & & & & $\begin{array}{c}\text { Expression of PD-1, } \\
\text { Ki-67 on T cell }\end{array}$ \\
\hline & & & & & & & & $\begin{array}{l}\text { Expression of PD-L1 } \\
\text { on exosomes in } \\
\text { blood }\end{array}$ \\
\hline & & & & & & & & $\begin{array}{l}\text { Expression of PD-L1 } \\
\text { on circulation tumor } \\
\text { cell }\end{array}$ \\
\hline \multirow{5}{*}{ NCT03774732 } & \multirow{5}{*}{$\begin{array}{l}\text { PD-1 Inhibitors and } \\
\text { Chemotherapy With } \\
\text { Concurrent } \\
\text { Irradiation at Varied } \\
\text { Tumour Sites in } \\
\text { Advanced } \\
\text { Non-small Cell } \\
\text { Lung Cancer } \\
\text { (NIRVANA-LUNG) }\end{array}$} & \multirow{5}{*}{ Recruiting } & \multirow{5}{*}{$\begin{array}{l}\text { Non-Small-Cell } \\
\text { Lung Cancer } \\
\text { (NSCLC) }\end{array}$} & & \multirow{5}{*}{ at least $18 \mathrm{~Gy}$ in $3 \mathrm{fr}$} & \multirow{5}{*}{460} & \multirow{5}{*}{ Overall survival } & Tumour response \\
\hline & & & & & & & & $\begin{array}{l}\text { Progression free } \\
\text { survival }\end{array}$ \\
\hline & & & & $\begin{array}{c}\text { Pembrolizumab + } \\
\text { Chemotherapy + } \\
\text { Radiotherapy }\end{array}$ & & & & $\begin{array}{l}\text { Local and distant } \\
\text { controls in } \\
\text { irradiated patients }\end{array}$ \\
\hline & & & & Pembrolizumab + & & & & Quality of life \\
\hline & & & & & & & & Acute/late toxicities \\
\hline \multirow{3}{*}{ NCT04299646 } & \multirow{3}{*}{$\begin{array}{l}\text { Study Assessing } \\
\text { Stereotactic } \\
\text { Radiotherapy in } \\
\text { Therapeutic Strategy } \\
\text { of Oligoprogressive } \\
\text { Renal Cell } \\
\text { Carcinoma } \\
\text { Metastases } \\
\text { (GETUG-StORM-01) }\end{array}$} & \multirow{3}{*}{ Recruiting } & \multirow{3}{*}{ Metastatic RCC } & & & & & $\begin{array}{l}\text { Treatment-related } \\
\text { adverse events }\end{array}$ \\
\hline & & & & Stereotactic RT + & $n / a$ & 114 & Progression free & Local control rate \\
\hline & & & & systemic treatment & & & $\begin{array}{l}\text { survival } \\
\text { sural }\end{array}$ & Overall control rate \\
\hline NCT03316872 & $\begin{array}{c}\text { Study of } \\
\text { Pembrolizumab and } \\
\text { Radiotherapy in }\end{array}$ & Recruiting & $\begin{array}{l}\text { Hepatocellular } \\
\text { carcinoma }\end{array}$ & $\begin{array}{c}\text { Pembrolizumab + } \\
\text { SBRT }\end{array}$ & $\mathrm{n} / \mathrm{a}$ & 30 & $\begin{array}{l}\text { Overall response } \\
\text { rate }\end{array}$ & $\begin{array}{c}\text { Response rate in } \\
\text { non-irradiated } \\
\text { tumor lesions }\end{array}$ \\
\hline & Liver Cancer & & & & & & & $\begin{array}{l}\text { Progression free } \\
\text { survival rate }\end{array}$ \\
\hline & & & & & & & & Overall survival rate \\
\hline & & & $\begin{array}{l}\text { Recurrent } \\
\text { gyneco-logical } \\
\text { cancer }\end{array}$ & & & & & $\begin{array}{l}\text { Overall response } \\
\text { rate }\end{array}$ \\
\hline & $\begin{array}{c}\text { Durvalumab, } \\
\text { Tremelimumab + }\end{array}$ & & $\begin{array}{l}\text { Metastatic cervical } \\
\text { cancer }\end{array}$ & & & & & Local response rate \\
\hline NCT03277482 & $\begin{array}{l}\text { Radiotherapy in } \\
\text { Gynecologic Cancer }\end{array}$ & Recruiting & $\begin{array}{l}\text { Metastatic ovarian } \\
\text { cancer }\end{array}$ & $\begin{array}{c}\text { Durvalumab + } \\
\text { Tremelimumab + RT }\end{array}$ & $\mathrm{n} / \mathrm{a}$ & 32 & $\begin{array}{l}\text { Maximum tolerated } \\
\text { dose }\end{array}$ & $\begin{array}{l}\text { Abscopal response } \\
\text { rate }\end{array}$ \\
\hline & & & $\begin{array}{l}\text { Metastatic vaginal } \\
\text { cancer }\end{array}$ & & & & & Response duration \\
\hline & & & $\begin{array}{l}\text { Metastatic vulvar } \\
\text { cancer }\end{array}$ & & & & & $\begin{array}{l}\text { Progression free } \\
\text { survival }\end{array}$ \\
\hline & & & $\begin{array}{c}\text { Metastatic } \\
\text { endometrial cancer }\end{array}$ & & & & & \\
\hline
\end{tabular}


Table 5. Cont

\begin{tabular}{|c|c|c|c|c|c|c|c|c|}
\hline Study Identifier & Study Title & Status & $\begin{array}{l}\text { Condition or } \\
\text { Disease }\end{array}$ & Therapy & RT Scheme & Cohort N & $\begin{array}{c}\text { Planned Primary } \\
\text { Outcome Measures }\end{array}$ & $\begin{array}{l}\text { Planned Secondary } \\
\text { Outcome Measures }\end{array}$ \\
\hline \multirow{7}{*}{ NCT03085719 } & \multirow{7}{*}{$\begin{array}{l}\text { Targeting PD-1 } \\
\text { Therapy Resistance } \\
\text { With Focused High } \\
\text { or High and Low } \\
\text { Dose Radiation in } \\
\text { SCCHN }\end{array}$} & \multirow{7}{*}{ Recruiting } & \multirow{7}{*}{$\begin{array}{l}\text { Head and neck } \\
\text { cancer }\end{array}$} & \multirow{7}{*}{$\begin{array}{l}\text { High dose radiation } \\
\text { + Pembrolizumab }\end{array}$} & \multirow{7}{*}{$\mathrm{n} / \mathrm{a}$} & \multirow{7}{*}{26} & \multirow{7}{*}{$\begin{array}{l}\text { Overall response } \\
\text { rate }\end{array}$} & Overall survival \\
\hline & & & & & & & & $\begin{array}{l}\text { Progression free } \\
\text { survival }\end{array}$ \\
\hline & & & & & & & & $\begin{array}{l}\text { Treatment-related } \\
\text { adverse events }\end{array}$ \\
\hline & & & & & & & & $\begin{array}{l}\text { Immune-related } \\
\text { response }\end{array}$ \\
\hline & & & & & & & & Local response \\
\hline & & & & & & & & Clinical benefit rate \\
\hline & & & & & & & & Abscopal response \\
\hline \multirow{6}{*}{ NCT03176173 } & \multirow{6}{*}{$\begin{array}{l}\text { Radical-Dose Image } \\
\text { Guided Radiation } \\
\text { Therapy in Treating } \\
\text { Patients With } \\
\text { Metastatic } \\
\text { Non-small Cell Lung } \\
\text { Cancer Undergoing } \\
\text { Immunotherapy }\end{array}$} & \multirow{6}{*}{ Recruiting } & \multirow{6}{*}{$\begin{array}{l}\text { Non-Small-Cell } \\
\text { Lung Cancer } \\
\text { (NSCLC) }\end{array}$} & \multirow{6}{*}{$\begin{array}{l}\text { Immunotherapy + } \\
\text { Image Guided RT }\end{array}$} & \multirow{6}{*}{$\mathrm{n} / \mathrm{a}$} & \multirow{6}{*}{85} & \multirow{6}{*}{$\begin{array}{l}\text { Progression free } \\
\text { survival }\end{array}$} & $\begin{array}{c}\text { Change in ctDNA } \\
\text { levels }\end{array}$ \\
\hline & & & & & & & & $\begin{array}{l}\text { Immune marker } \\
\text { levels from } \\
\text { peripheral blood }\end{array}$ \\
\hline & & & & & & & & $\begin{array}{l}\text { Acute and late } \\
\text { toxicity }\end{array}$ \\
\hline & & & & & & & & Overall survival \\
\hline & & & & & & & & $\begin{array}{l}\text { Patterns of response } \\
\text { and progression }\end{array}$ \\
\hline & & & & & & & & $\begin{array}{l}\text { Time to } \\
\text { discontinuation of } \\
\text { study }\end{array}$ \\
\hline \multirow{4}{*}{ NCT04221893 } & \multirow{4}{*}{$\begin{array}{l}\text { Radiation Therapy } \\
\text { for the Treatment of } \\
\text { Metastatic } \\
\text { Gastrointestinal } \\
\text { Cancers }\end{array}$} & \multirow{4}{*}{ Recruiting } & $\begin{array}{c}\text { Esophageal } \\
\text { adenocarcinoma }\end{array}$ & \multirow{4}{*}{ RT } & \multirow{4}{*}{$\mathrm{n} / \mathrm{a}$} & \multirow{4}{*}{28} & \multirow{4}{*}{$\begin{array}{l}\text { Overall response } \\
\text { rate }\end{array}$} & $\begin{array}{l}\text { Progression free } \\
\text { survival }\end{array}$ \\
\hline & & & $\begin{array}{l}\text { Esophageal } \\
\text { squamous cell } \\
\text { carcinoma }\end{array}$ & & & & & $\begin{array}{c}\text { Overall survival } \\
\text { Determine local } \\
\text { control in radiated } \\
\text { lesion(s) }\end{array}$ \\
\hline & & & Gastric cancer & & & & & $\begin{array}{l}\text { Tumor measurement } \\
\text { change }\end{array}$ \\
\hline & & & $\begin{array}{l}\text { Adenocarcinoma of } \\
\text { gastroesophageal } \\
\text { junction }\end{array}$ & & & & & $\begin{array}{l}\text { New metastatic } \\
\text { lesions } \\
\text { Adverse events }\end{array}$ \\
\hline \multirow{13}{*}{ NCT03385226 } & \multirow{13}{*}{$\begin{array}{l}\text { A Trial Assessing the } \\
\text { Effect of } \\
\text { Pembrolizumab } \\
\text { Combined With } \\
\text { Radiotherapy in } \\
\text { Patients With } \\
\text { Relapsed, Refractory, } \\
\text { Specified Stages of } \\
\text { Cutaneous T-cell } \\
\text { Lymphoma (CTCL) } \\
\text { Mycosis Fungoides } \\
\text { (MF)/Sezary } \\
\text { Syndrome (SS) } \\
\text { (PORT) }\end{array}$} & \multirow{13}{*}{ Recruiting } & \multirow{13}{*}{$\begin{array}{l}\text { Cutaneous } \mathrm{T} \text { cell } \\
\text { lymphoma }\end{array}$} & \multirow{13}{*}{$\begin{array}{c}\text { Pembrolizumab }+ \\
\text { RT }\end{array}$} & \multirow{13}{*}{$12 \mathrm{~Gy}, 3 \mathrm{fr}$} & & & $\begin{array}{l}\text { Response and } \\
\text { duration }\end{array}$ \\
\hline & & & & & & & & Safety and toxicity \\
\hline & & & & & & & & $\begin{array}{l}\text { Progression free } \\
\text { survival }\end{array}$ \\
\hline & & & & & & & & Overall survival \\
\hline & & & & & & & & Abscopal effect rate \\
\hline & & & & & & & & $\begin{array}{l}\text { Changes in immune } \\
\text { status }\end{array}$ \\
\hline & & & & & & 46 & e & $\begin{array}{c}\text { Plasma HMGB-1 } \\
\text { levels }\end{array}$ \\
\hline & & & & & & & (global assessment) & $\begin{array}{l}\text { Functional analysis } \\
\text { of isolated cell } \\
\text { populations }\end{array}$ \\
\hline & & & & & & & & $\begin{array}{l}\text { Assessment of } \\
\text { diversity and } \\
\text { clonality of T cells }\end{array}$ \\
\hline & & & & & & & & $\begin{array}{l}\text { Immune signatures } \\
\text { for responders and } \\
\text { non-responders }\end{array}$ \\
\hline & & & & & & & & $\begin{array}{l}\text { Tumor-infiltrating } \\
\text { lymphocyte-specific } \\
\text { neo-antigens }\end{array}$ \\
\hline & & & & & & & & $\begin{array}{c}\text { Expression of } \\
\text { immunological } \\
\text { checkpoints }\end{array}$ \\
\hline & & & & & & & & $\begin{array}{l}\text { Investigation of } \\
\text { tumor immune } \\
\text { microenvironment }\end{array}$ \\
\hline
\end{tabular}


Table 5. Cont

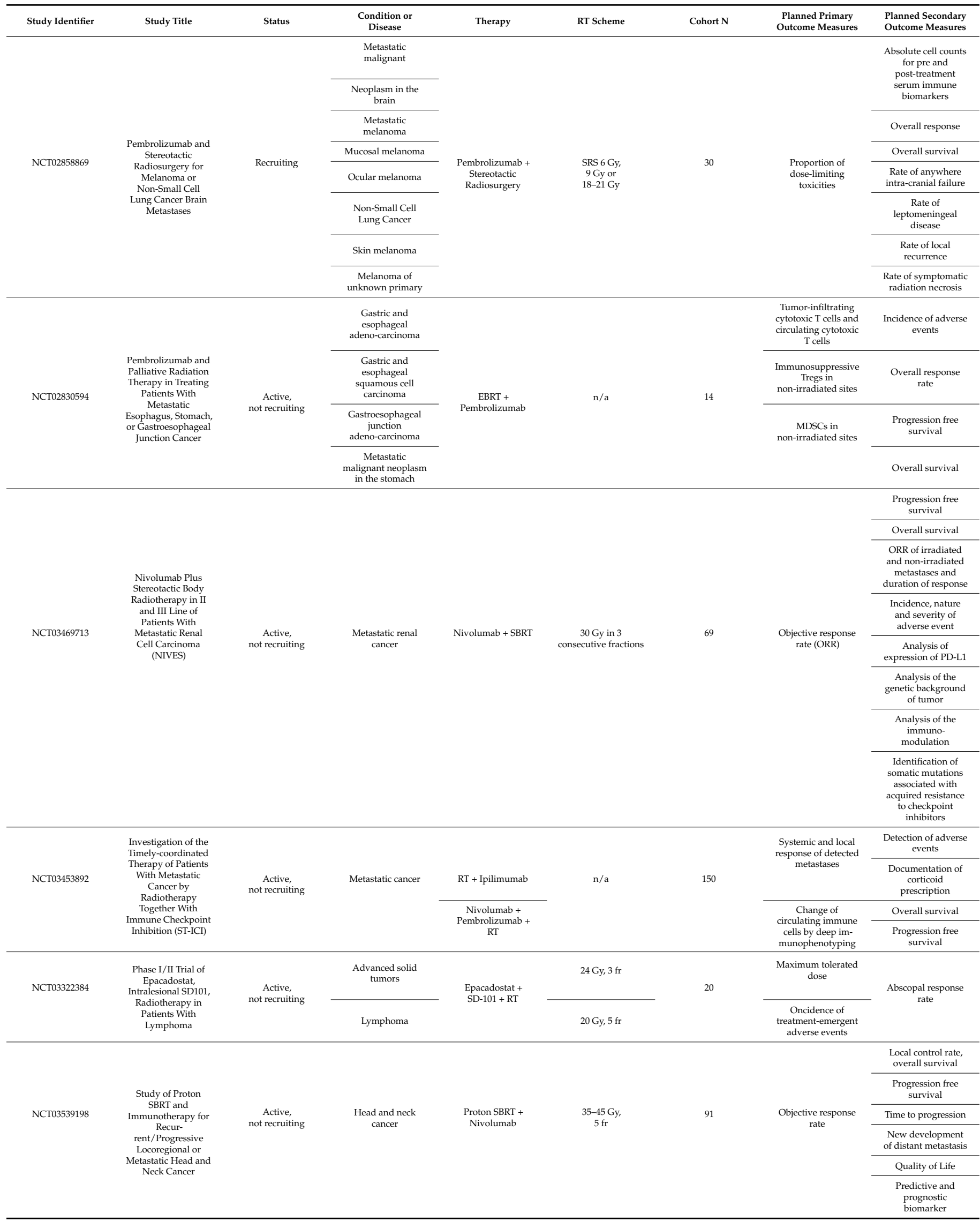


Table 5. Cont.

\begin{tabular}{|c|c|c|c|c|c|c|c|c|}
\hline Study Identifier & Study Title & Status & $\begin{array}{c}\begin{array}{c}\text { Condition or } \\
\text { Disease }\end{array} \\
\end{array}$ & Therapy & RT Scheme & Cohort N & $\begin{array}{c}\text { Planned Primary } \\
\text { Outcome Measures }\end{array}$ & $\begin{array}{l}\text { Planned Secondary } \\
\text { Outcome Measures }\end{array}$ \\
\hline \multirow{4}{*}{ NCT03042156 } & \multirow{4}{*}{$\begin{array}{l}\text { Immunotherapy } \\
\text { And Palliative } \\
\text { Radiotherapy } \\
\text { Combined In } \\
\text { Patients With } \\
\text { Advanced } \\
\text { Malignancy }\end{array}$} & \multirow{4}{*}{$\begin{array}{c}\text { Active, } \\
\text { not recruiting }\end{array}$} & \multirow{4}{*}{ Advanced cancer } & \multirow{4}{*}{ Palliative RT } & \multirow{4}{*}{$n / a$} & \multirow{4}{*}{30} & \multirow{4}{*}{$\begin{array}{l}\text { Number of patients } \\
\text { showing toxicity }\end{array}$} & $\begin{array}{l}\text { In-field response on } \\
\text { imaging and } \\
\text { evidence of out of } \\
\text { field (abscopal) } \\
\text { response }\end{array}$ \\
\hline & & & & & & & & $\begin{array}{l}\text { Biomarkers analyses } \\
\text { as indicator of } \\
\text { abscopal response }\end{array}$ \\
\hline & & & & & & & & $\begin{array}{l}\text { Patient-reported } \\
\text { outcome }\end{array}$ \\
\hline & & & & & & & & $\begin{array}{c}\text { Inflammatory and } \\
\text { radiation sensitivity } \\
\text { signatures }\end{array}$ \\
\hline \multirow{8}{*}{ NCT03483012 } & \multirow{8}{*}{$\begin{array}{l}\text { Atezolizumab + } \\
\text { Stereotactic } \\
\text { Radiation in } \\
\text { Triple-negative } \\
\text { Breast Cancer and } \\
\text { Brain Metastasis }\end{array}$} & \multirow{8}{*}{$\begin{array}{l}\text { Active, } \\
\text { not recruiting }\end{array}$} & \multirow{8}{*}{ Breast cancer } & \multirow{8}{*}{$\begin{array}{c}\text { Atezolizumab + } \\
\text { stereotactic } \\
\text { radiosurgery (SRS) }\end{array}$} & \multirow{8}{*}{$\mathrm{n} / \mathrm{a}$} & \multirow{8}{*}{45} & \multirow{8}{*}{$\begin{array}{l}\text { Progression free } \\
\text { survival }\end{array}$} & $\begin{array}{l}\text { Extracranial } \\
\text { objective response } \\
\text { rate }\end{array}$ \\
\hline & & & & & & & & $\begin{array}{l}\text { Abscopal response } \\
\text { rate }\end{array}$ \\
\hline & & & & & & & & Clinical benefit rate \\
\hline & & & & & & & & Overall survival \\
\hline & & & & & & & & $\begin{array}{l}\text { Patient-reported } \\
\text { outcome }\end{array}$ \\
\hline & & & & & & & & $\begin{array}{l}\text { Development of } \\
\text { radiation necrosis }\end{array}$ \\
\hline & & & & & & & & $\begin{array}{l}\text { Assessed } \\
\text { neurological } \\
\text { evaluation }\end{array}$ \\
\hline & & & & & & & & $\begin{array}{c}\text { Dose-limiting } \\
\text { toxicity }\end{array}$ \\
\hline \multirow{8}{*}{ NCT02888743 } & \multirow{8}{*}{$\begin{array}{l}\text { Durvalumab and } \\
\text { Tremelimumab With } \\
\text { or Without High or } \\
\text { Low-Dose Radiation } \\
\text { Therapy in Treating } \\
\text { Patients With } \\
\text { Metastatic } \\
\text { Colorectal or } \\
\text { Non-small Cell } \\
\text { Lung Cancer }\end{array}$} & \multirow{8}{*}{$\begin{array}{c}\text { Active, } \\
\text { not recruiting }\end{array}$} & \multirow{3}{*}{ Metastatic colorectal } & \multirow{4}{*}{$\begin{array}{c}\text { Tremelimumab + } \\
\text { Durvalumab }\end{array}$} & \multirow{8}{*}{$\mathrm{n} / \mathrm{a}$} & \multirow{8}{*}{180} & \multirow{8}{*}{$\begin{array}{l}\text { Overall response } \\
\text { rate }\end{array}$} & $\begin{array}{l}\text { Progression free } \\
\text { survival }\end{array}$ \\
\hline & & & & & & & & Overall survival \\
\hline & & & & & & & & Objective response \\
\hline & & & & & & & & $\begin{array}{l}\text { Incidence of adverse } \\
\text { events }\end{array}$ \\
\hline & & & $\begin{array}{l}\text { Carcinoma } \\
\text { metastatic lung }\end{array}$ & \multirow{4}{*}{$\begin{array}{c}\text { Tremelimumab + } \\
\text { Durvalumab + RT }\end{array}$} & & & & $\begin{array}{l}\text { Local control rate } \\
\text { and abscopal } \\
\text { response rates }\end{array}$ \\
\hline & & & Non-Small Cell & & & & & $\begin{array}{l}\text { Prognostic effect of } \\
\text { PD-L1 expression }\end{array}$ \\
\hline & & & Carcinoma & & & & & $\begin{array}{l}\text { Prognostic effect of } \\
\text { T-cell infiltration }\end{array}$ \\
\hline & & & & & & & & $\begin{array}{c}\text { Symptomatic } \\
\text { adverse events }\end{array}$ \\
\hline \multirow{6}{*}{ NCT02587455 } & \multirow{6}{*}{$\begin{array}{l}\text { Pembrolizumab and } \\
\text { Palliative } \\
\text { Radiotherapy in } \\
\text { Lung (PEAR) }\end{array}$} & \multirow{6}{*}{$\begin{array}{c}\text { Active, } \\
\text { not recruiting }\end{array}$} & \multirow{6}{*}{ Thoracic tumours } & \multirow{6}{*}{$\begin{array}{c}\text { Pembrolizumab + } \\
\text { RT }\end{array}$} & \multirow{6}{*}{$\mathrm{n} / \mathrm{a}$} & & & $\begin{array}{l}\text { Progression free } \\
\text { survival rates }\end{array}$ \\
\hline & & & & & & & & $\begin{array}{l}\text { Overall survival } \\
\text { rates }\end{array}$ \\
\hline & & & & & & 48 & Toxicity rate & $\begin{array}{c}\text { Duration of clinical } \\
\text { benefit }\end{array}$ \\
\hline & & & & & & & Maximum tolerated & Response rates \\
\hline & & & & & & & dose & $\begin{array}{l}\text { Assessing individual } \\
\text { lesion response }\end{array}$ \\
\hline & & & & & & & & $\begin{array}{l}\text { Identify biomarkers } \\
\text { and correlate with } \\
\text { clinical benefit }\end{array}$ \\
\hline
\end{tabular}


Table 5. Cont.

\begin{tabular}{|c|c|c|c|c|c|c|c|c|}
\hline Study Identifier & Study Title & Status & $\begin{array}{l}\text { Condition or } \\
\text { Disease }\end{array}$ & Therapy & RT Scheme & Cohort N & $\begin{array}{l}\text { Planned Primary } \\
\text { Outcome Measures }\end{array}$ & $\begin{array}{l}\text { Planned Secondary } \\
\text { Outcome Measures }\end{array}$ \\
\hline \multirow{12}{*}{ NCT03601455 } & \multirow{12}{*}{$\begin{array}{l}\text { Radiation Therapy } \\
\text { and Durvalumab } \\
\text { With or Without } \\
\text { Tremelimumab in } \\
\text { Treating Participants } \\
\text { With Unresectable, } \\
\text { Locally Advanced, } \\
\text { or Metastatic } \\
\text { Bladder Cancer }\end{array}$} & \multirow{12}{*}{$\begin{array}{c}\text { Active, } \\
\text { not recruiting }\end{array}$} & \multirow{12}{*}{$\begin{array}{l}\text { Bladder urothelial } \\
\text { carcinoma }\end{array}$} & \multirow[b]{6}{*}{ RT + Durvalumab } & \multirow{12}{*}{$\mathrm{n} / \mathrm{a}$} & \multirow{12}{*}{13} & \multirow{6}{*}{$\begin{array}{l}\text { Incidence of adverse } \\
\text { events }\end{array}$} & $\begin{array}{l}\text { Local control at } \\
\text { primary irradiate } \\
\text { site }\end{array}$ \\
\hline & & & & & & & & $\begin{array}{l}\text { Pathologic complete } \\
\text { rate of irradiated } \\
\text { tumor }\end{array}$ \\
\hline & & & & & & & & $\begin{array}{l}\text { Overall response } \\
\text { rate }\end{array}$ \\
\hline & & & & & & & & Abscopal response \\
\hline & & & & & & & & Duration of response \\
\hline & & & & & & & & $\begin{array}{l}\text { Disease-specific } \\
\text { survival }\end{array}$ \\
\hline & & & & \multirow{6}{*}{$\begin{array}{c}\mathrm{RT}+\text { Durvalumab + } \\
\text { Tremelimumab }\end{array}$} & & & \multirow{6}{*}{$\begin{array}{l}\text { Progression free } \\
\text { survival }\end{array}$} & Overall survival \\
\hline & & & & & & & & $\begin{array}{l}\text { Incidence of adverse } \\
\text { events }\end{array}$ \\
\hline & & & & & & & & $\begin{array}{c}\text { Immune cell subsets } \\
\text { and PD-L1 in tumor } \\
\text { biopsies }\end{array}$ \\
\hline & & & & & & & & $\begin{array}{l}\text { Gene signature } \\
\text { biomarker }\end{array}$ \\
\hline & & & & & & & & $\begin{array}{l}\text { Circulating immune } \\
\text { cell subsets }\end{array}$ \\
\hline & & & & & & & & $\begin{array}{l}\text { Circulating and } \\
\text { tumor-infiltrating } \\
\text { T-cell receptor } \\
\text { repertoire }\end{array}$ \\
\hline
\end{tabular}

Abbreviations: RT: radiotherapy; NSCLC: Non-Small-Cell Lung Cancer; fr: fractions; SBRT: stereotactic body radiotherapy; $\mathrm{n} / \mathrm{a}$ : not available; ORR: overall response rate; IRE: irreversible electroporation; PFS: progression free survival; RCC: renal cell carcinoma; PET-CT: positron emission tomography; CT: computed tomography; BED: radiation biologically effective dose; PD-1: programmed cell death protein 1; PD-L1: PD-1 receptor-ligand 1; ctDNA: circulating tumor DNA; HMGB1: high-mobility group box 1; SRS: stereotactic radiosurgery.

In the ongoing clinical trial NCT03385226, among other objectives, the combination of RT (12 Gy, three fractions) and pembrolizumab is being observed over a period of 2 years for $\mathrm{AbE}$ rate. Immune cells will be functionally analyzed along with the diversity of $\mathrm{T}$ cell clones and tumor-infiltrating lymphocyte-specific neo-antigens and the expression of immunological checkpoints [270]. Moreover, another clinical trial aims to evaluate the treatment response at non-irradiated and extra-cranial sites of melanoma or NSCLC patients with brain metastasis, after receiving pembrolizumab along with stereotactic radiosurgery (6 Gy, 9 Gy, 18-21 Gy) (NCT02858869). As a secondary objective, potential immune biomarkers will be compared, analyzing blood samples for absolute cell counts, major lymphocyte populations as well as other serum immune biomarkers pre-, during and post-treatment for up to three years [271]. Another phase II study investigates the effect of pembrolizumab and palliative radiation therapy in patients with a metastatic esophagus, stomach or with gastroesophageal junction cancer (NCT02830594). Its primary endpoint aims to determine changes in tumor-infiltrating and circulating cytotoxic $\mathrm{T}$ cells, immunosuppressive Tregs and MDSCs at the metastatic examined sites. Cell populations will be correlated with the response rates of irradiated and non-irradiated tumors [272]. The benefit of radio-immunotherapy for advanced metastatic patients is being tested in a trial with a stratified patient cohort (NCT03453892). The systemic immune-modulating effect of the treatment will be assessed by deep immunophenotyping, evaluating up to 30 immune cell subtypes with their activation markers at various time points of the treatment [273]. Similar targets are being investigated in another trial (NCT03042156), which researches the effect of immune therapy and palliative RT combined treatment, along with inflammatory and irradiation-induced signatures as indicators for an $\mathrm{AbE}$, particularly those extrinsic to irradiated sections [274].

\section{Conclusions and Recommendations in the Frame-Work of 3P Medicine}

$\mathrm{AbE}$ is a rare clinical phenomenon associated with RT, which, however, is becoming more frequent now towards improved radiation delivery and the development of immunotherapeutic drugs. The addition of ICB to conventional RT has led to an increase in the incidence of abscopal responses due to the involvement of various immune pathways in 
their occurrence. Nevertheless, the exact mechanism responsible for an AbE is still in question. It is observed after different treatment regimens and it takes weeks to months before an $\mathrm{AbE}$ becomes noticeable which makes it difficult to predict under typical clinical conditions.

The wide variation of the applied treatments often does not allow for a precise identification of the AbE's origin, its triggers and contributors. Systemic therapies namely chemotherapy as well as immunotherapy may have delayed effects that later cannot be assigned to a specific treatment. To this end, the immune system of the patients can be affected by typical cancer pain management or immunosuppressive drugs such as corticosteroids. Furthermore, normal tissue in the radiation field also receives a small but still significant radiation dose during RT. Therefore, the observed AbE could also be related to low-dose radiation effects which are a result of the applied irradiation.

The costs of a combined therapy of ICB and RT has been estimated by Giuliani et al. to be 5866 EUR more expensive than immunotherapy alone, translates to $707 €$ to $1086 €$ per month of overall survival of NSCLC patients [275]. Targeted induction or an accurate prediction of an $\mathrm{AbE}$ by biomarkers could lead to a personalized, more precise and more cost-effective treatment strategy.

The reported clinical cases allow for the identification of several promising biomarker candidates which need to be further analyzed in the context of their predictive power. Validated biomarkers might be of great clinical utility

- $\quad$ to stratify patients

- $\quad$ to prognose treatment response individually by applying associated diagnostics

- $\quad$ to optimize treatment strategies tailored to every individual

- $\quad$ to create advanced multi-level diagnostic approaches based on the application of artificial intelligence (AI) for big-data analysis in the context of 3P medicine improving cost-efficacy of treatments and individual outcomes [276-280].

Author Contributions: Conceptualization, B.L. and O.G.; validation, B.L. and A.T.C.; investigation; B.L.; writing—original draft preparation, B.L., A.T.C., M.H., F.A.G. and O.G., writing-review and editing, B.L. and O.G.; supervision, O.G. All authors have read and agreed to the published version of the manuscript.

Funding: This research received no external funding.

Institutional Review Board Statement: Not applicable.

Informed Consent Statement: Not applicable.

Data Availability Statement: Data have been included within the article. Therefore, no additional data file is required.

Conflicts of Interest: There is no conflict of interest with respect to this manuscript.

\section{References}

1. Formenti, S.C.; Demaria, S. Systemic effects of local radiotherapy. Lancet Oncol. 2009, 10, 718-726. [CrossRef]

2. Andrews, J.R. The Radiobiology of Human Cancer Radiotherapy, 2nd ed.; University Park Press: Baltimore, MD, USA, 1978; ISBN 0-8391-1161-4.

3. Mole, R.H. Whole body irradiation; radiobiology or medicine? Br. J. Radiol. 1953, 26, 234-241. [CrossRef]

4. Marín, A.; Martín, M.; Liñán, O.; Alvarenga, F.; López, M.; Fernández, L.; Büchser, D.; Cerezo, L. Bystander effects and radiotherapy. Rep. Pract. Oncol. Radiother. 2014, 20, 12-21. [CrossRef]

5. Abuodeh, Y.; Venkat, P.; Kim, S. Systematic review of case reports on the abscopal effect. Curr. Probl. Cancer 2016, 40, 25-37. [CrossRef]

6. Dagoglu, N.; Karaman, S.; Caglar, H.B.; Oral, E.N. Abscopal Effect of Radiotherapy in the Immunotherapy Era: Systematic Review of Reported Cases. Cureus 2019, 11, e4103. [CrossRef]

7. Lome, L.G.; Navani, S.; Aral, I.M. Spontaneous regression of pulmonary metastases from transitional cell carcinoma of the bladder. Cancer 1970, 26, 415-418. [CrossRef]

8. Ehlers, G.; Fridman, M. Abscopal effect of radiation in papillary adenocarcinoma. Br. J. Radiol. 1973, 46, 220-222. [CrossRef] [PubMed] 
9. Antoniades, J.; Brady, L.W.; Lightfoot, D.A. Lymphangiographic demonstration of the abscopal effect in patients with malignant lymphomas. Int. J. Radiat. Oncol. Biol. Phys. 1977, 2, 141-147. [CrossRef]

10. Fairlamb, D.J. Spontaneous regression of metastases of renal cancer: A report of two cases including the first recorded regression following irradiation of a dominant metastasis and review of the world literature. Cancer 1981, 47, 2102-2106. [CrossRef]

11. Rees, G.J.G. Abscopal regression in lymphoma: A mechanism in common with total body irradiation? Clin. Radiol. 1981, 32, 475-480. [CrossRef]

12. Robin, H.I.; AuBuchon, J.; Varanasi, V.R.; Weinstein, A.B. The abscopal effect: Demonstration in lymphomatous involvement of kidneys. Med. Pediatr. Oncol. 1981, 9, 473-476. [CrossRef] [PubMed]

13. Rees, G.J.; Ross, C.M. Abscopal regression following radiotherapy for adenocarcinoma. Br. J. Radiol. 1983, 56, 63-66. [CrossRef] [PubMed]

14. MacManus, M.P.; Harte, R.J.; Stranex, S. Spontaneous regression of metastatic renal cell carcinoma following palliative irradiation of the primary tumour. Ir. J. Med. Sci. 1994, 163, 461-463. [CrossRef] [PubMed]

15. Ohba, K.; Omagari, K.; Nakamura, T.; Ikuno, N.; Saeki, S.; Matsuo, I.; Kinoshita, H.; Masuda, J.; Hazama, H.; Sakamoto, I.; et al. Abscopal regression of hepatocellular carcinoma after radiotherapy for bone metastasis. Gut 1998, 43, 575-577. [CrossRef]

16. Nam, S.W.; Han, J.-Y.; Kim, J.I.; Park, S.H.; Cho, S.H.; Han, N.I.; Yang, J.M.; Kim, J.K.; Choi, S.W.; Lee, Y.S.; et al. Spontaneous regression of a large hepatocellular carcinoma with skull metastasis. J. Gastroenterol. Hepatol. 2005, 20, 488-492. [CrossRef] [PubMed]

17. Wersäll, P.J.; Blomgren, H.; Pisa, P.; Lax, I.; Kälkner, K.-M.; Svedman, C. Regression of non-irradiated metastases after extracranial stereotactic radiotherapy in metastatic renal cell carcinoma. Acta Oncol. 2006, 45, 493-497. [CrossRef]

18. Takaya, M.; Niibe, Y.; Tsunoda, S.; Jobo, T.; Imai, M.; Kotani, S.; Unno, N.; Hayakawa, K. Abscopal effect of radiation on toruliform para-aortic lymph node metastases of advanced uterine cervical carcinoma-A case report. Anticancer Res. 2007, 27, 499-503.

19. Isobe, Y.; Aritaka, N.; Sasaki, M.; Oshimi, K.; Sugimoto, K. Spontaneous regression of natural killer cell lymphoma. J. Clin. Pathol. 2009, 62, 647-650. [CrossRef]

20. Lakshmanagowda, P.B.; Viswanath, L.; Thimmaiah, N.; Dasappa, L.; Supe, S.S.; Kallur, P. Abscopal effect in a patient with chronic lymphocytic leukemia during radiation therapy: A case report. Cases J. 2009, 2, 204. [CrossRef]

21. Okuma, K.; Yamashita, H.; Niibe, Y.; Hayakawa, K.; Nakagawa, K. Abscopal effect of radiation on lung metastases of hepatocellular carcinoma: A case report. J. Med. Case Rep. 2011, 5, 111. [CrossRef]

22. Ishiyama, H.; Teh, B.S.; Ren, H.; Chiang, S.; Tann, A.; Blanco, A.I.; Paulino, A.C.; Amato, R. Spontaneous regression of thoracic metastases while progression of brain metastases after stereotactic radiosurgery and stereotactic body radiotherapy for metastatic renal cell carcinoma: Abscopal effect prevented by the blood-brain barrier? Clin. Genitourin. Cancer 2012, 10, 196-198. [CrossRef]

23. Tubin, S. A Case Report on Metastatic Thyroid Carcinoma: Radiation-induced Bystander or Abscopal Effect? J. Cancer Sci. Ther. 2012, 4, 408-411. [CrossRef]

24. Siva, S.; Callahan, J.; MacManus, M.P.; Martin, O.; Hicks, R.J.; Ball, D.L. Abscopal corrected effects after conventional and stereotactic lung irradiation of non-small-cell lung cancer. J. Thorac. Oncol. 2013, 8, e71-e72. [CrossRef] [PubMed]

25. Teulings, H.E.; Tjin, E.P.M.; Willemsen, K.J.; Krebbers, G.; van Noesel, C.J.; Kemp, E.H.; Nieuweboer-Krobotova, L.; van der Veen, J.P.W.; Luiten, R.M. Radiation-induced melanoma-associated leucoderma, systemic antimelanoma immunity and disease-free survival in a patient with advanced-stage melanoma: A case report and immunological analysis. Br. J. Dermatol. 2013, 168, 733-738. [CrossRef]

26. Lock, M.; Muinuddin, A.; Kocha, W.I.; Dinniwell, R.; Rodrigues, G.; D'souza, D. Abscopal Effects: Case Report and Emerging Opportunities. Cureus 2015, 7, e344. [CrossRef]

27. Yarchoan, M.; Lim, M.; Brahmer, J.R.; Ettinger, D. Oligometastatic Adenocarcinoma of the Lung: A Therapeutic Opportunity for Long-Term Survival. Cureus 2015, 7, e409. [CrossRef]

28. Desar, I.M.E.; Braam, P.M.; Kaal, S.E.J.; Gerritsen, W.R.; Oyen, W.J.G.; van der Graaf, W.T.A. Abscopal effect of radiotherapy in a patient with metastatic diffuse-type giant cell tumor. Acta Oncol. 2016, 55, 1510-1512. [CrossRef]

29. Orton, A.; Wright, J.; Buchmann, L.; Randall, L.; Hitchcock, Y.J. A Case of Complete Abscopal Response in High-Grade Pleiomorphic Sarcoma Treated with Radiotherapy Alone. Cureus 2016, 8, e821. [CrossRef]

30. Saba, R.; Saleem, N.; Peace, D. Long-term survival consequent on the abscopal effect in a patient with multiple myeloma. BMJ Case Rep. 2016, 2016, bcr2016215237. [CrossRef] [PubMed]

31. Joe, M.B.; Lum, J.J.; Watson, P.H.; Tonseth, R.P.; McGhie, J.P.; Truong, P.T. Radiation generates an abscopal response and complete resolution of metastatic squamous cell carcinoma of the anal canal: A case report. J. Gastrointest. Oncol. 2017, 8, E84-E89. [CrossRef]

32. Lesueur, P.; Chevalier, F.; Stefan, D.; Habrand, J.-L.; Lerouge, D.; Gervais, R. Review of the mechanisms involved in the abscopal effect and future directions with a focus on thymic carcinoma. Tumori 2017, 103, 217-222. [CrossRef]

33. Azami, A.; Suzuki, N.; Azami, Y.; Seto, I.; Sato, A.; Takano, Y.; Abe, T.; Teranishi, Y.; Tachibana, K.; Ohtake, T. Abscopal effect following radiation monotherapy in breast cancer: A case report. Mol. Clin. Oncol. 2018, 9, 283-286. [CrossRef] [PubMed]

34. Bruton Joe, M.; Truong, P.T. Abscopal Effect after Palliative Radiation Therapy for Metastatic Adenocarcinoma of the Esophagus. Cureus 2018, 10, e3089. [CrossRef] [PubMed]

35. Chantharasamee, J.; Treetipsatit, J. Metastatic Melanoma of Uncertain Primary with 5-Year Durable Response after Conventional Therapy: A Case Report with Literature Review. Case Rep. Oncol. Med. 2018, 2018, 7289896. [CrossRef] 
36. Chino, F.; Pollis, K.E.; Choi, S.; Salama, J.K.; Palta, M. Stereotactic Body Radiation Therapy-Induced Abscopal Effect on Hepatocellular Carcinoma After Treatment for Lung Cancer: A Case Report. Hepatology 2018, 68, 1653-1655. [CrossRef]

37. Chuang, C.-H.; Hsu, J.-F.; Shen, Y.-T.; Yang, C.-J. Regression of a metastatic lung mass after receiving whole brain irradiation: Can the abscopal effect cross the blood-brain barrier? Asia Pac. J. Clin. Oncol. 2018, 14, e548-e550. [CrossRef]

38. Hamilton, A.J.; Seid, J.; Verdecchia, K.; Chuba, P. Abscopal Effect after Radiosurgery for Solitary Brain Metastasis from Non-small Cell Lung Cancer. Cureus 2018, 10, e3777. [CrossRef]

39. Leung, H.W.; Wang, S.-Y.; Jin-Jhih, H.; Chan, A.L. Abscopal effect of radiation on bone metastases of breast cancer: A case report. Cancer Biol. Ther. 2018, 19, 20-24. [CrossRef]

40. Agyeman, M.B.; Vanderpuye, V.D.; Yarney, J. Abscopal Effect of Radiotherapy in Imatinib-resistant Dermatofibrosarcoma Protuberans. Cureus 2019, 11, e3857. [CrossRef]

41. Bonilla, C.E.; Esguerra, J.; Mendoza Díaz, S.; Álvarez, A.; Morales, R.L. Abscopal Effect after Palliative Radiotherapy in a Patient with a Gastric Adenocarcinoma Disseminated to Retroperitoneal Space: Case Report from a Latin American Reference Center and Review of the Literature. Cureus 2019, 11, e6235. [CrossRef] [PubMed]

42. Kim, J.O.; Kim, C.A. Abscopal Resolution of a Hepatic Metastasis in a Patient with Metastatic Cholangiocarcinoma Following Radical Stereotactic Body Radiotherapy to a Synchronous Early Stage Non-small Cell Lung Cancer. Cureus 2019, 11, e4082. [CrossRef] [PubMed]

43. Kuroda, A.; Tabuchi, T.; Iwami, E.; Sasahara, K.; Matsuzaki, T.; Nakajima, T.; Tsutsumi, Y.; Eguchi, K.; Terashima, T. Abscopal effect of radiation on multiple lung metastases of lung adenocarcinoma: A case report. BMC Cancer 2019, 19, 336. [CrossRef]

44. Ellerin, B.E.; Demandante, C.G.N.; Martins, J.T. Pure abscopal effect of radiotherapy in a salivary gland carcinoma: Case report, literature review, and a search for new approaches. Cancer Radiother. 2020, 24, 226-246. [CrossRef] [PubMed]

45. Guan, S.; Wang, H.; Qi, X.-H.; Guo, Q.; Zhang, H.-Y.; Liu, H.; Zhu, B.-J. Abscopal effect of local irradiation treatment for thymoma: A case report. Am. J. Transl. Res. 2020, 12, 2234-2240.

46. Ohmatsu, K.; Hashimoto, Y.; Kawanishi, M.; Ishii, Y.; Kono, S.; Kuribayashi, S.; Ariizumi, S.; Karasawa, K. Abscopal complete regression of hepatocellular carcinoma with multiple pleural metastases. Int. Cancer Conf. J. 2021, 10, 54-58. [CrossRef]

47. Mazzaschi, G.; Tommasi, C.; Pietri, E.; Corcione, L.; de Giorgi, A.; Bini, P.; Bui, S. Abscopal effect as part of treatment of oligometastatic head and neck cancer: A case report. Clin. Case Rep. 2021, 9, 1334-1338. [CrossRef]

48. Tomita, N.; Ogawa, S.; Aikawa, G. Abscopal Effect of Pelvic Intensity Modulated Radiation Therapy on Lung Metastases in a Patient with Recurrent Endometrial Cancer. Adv. Radiat. Oncol. 2021, 6, 100563. [CrossRef]

49. Postow, M.A.; Callahan, M.K.; Barker, C.A.; Yamada, Y.; Yuan, J.; Kitano, S.; Mu, Z.; Rasalan, T.; Adamow, M.; Ritter, E.; et al. Immunologic correlates of the abscopal effect in a patient with melanoma. N. Engl. J. Med. 2012, 366, 925-931. [CrossRef] [PubMed]

50. Adjepong, D.; Malik, B.H. Radiation Therapy as a Modality to Create Abscopal Effects: Current and Future Practices. Cureus 2020, 12, e7054. [CrossRef]

51. Hiniker, S.M.; Chen, D.S.; Reddy, S.; Chang, D.T.; Jones, J.C.; Mollick, J.A.; Swetter, S.M.; Knox, S.J. A systemic complete response of metastatic melanoma to local radiation and immunotherapy. Transl. Oncol. 2012, 5, 404-407. [CrossRef] [PubMed]

52. Golden, E.B.; Demaria, S.; Schiff, P.B.; Chachoua, A.; Formenti, S.C. An abscopal response to radiation and ipilimumab in a patient with metastatic non-small cell lung cancer. Cancer Immunol. Res. 2013, 1, 365-372. [CrossRef] [PubMed]

53. Stamell, E.F.; Wolchok, J.D.; Gnjatic, S.; Lee, N.Y.; Brownell, I. The abscopal effect associated with a systemic anti-melanoma immune response. Int. J. Radiat. Oncol. Biol. Phys. 2013, 85, 293-295. [CrossRef] [PubMed]

54. Grimaldi, A.M.; Simeone, E.; Giannarelli, D.; Muto, P.; Falivene, S.; Borzillo, V.; Giugliano, F.M.; Sandomenico, F.; Petrillo, A.; Curvietto, M.; et al. Abscopal effects of radiotherapy on advanced melanoma patients who progressed after ipilimumab immunotherapy. Oncoimmunology 2014, 3, e28780. [CrossRef]

55. Thallinger, C.; Prager, G.; Ringl, H.; Zielinski, C. Abscopal-Effekt in der Therapie des malignen Melanoms. Hautarzt 2015, 66, 545-548. [CrossRef]

56. Okwan-Duodu, D.; Pollack, B.P.; Lawson, D.; Khan, M.K. Role of radiation therapy as immune activator in the era of modern immunotherapy for metastatic malignant melanoma. Am. J. Clin. Oncol. 2015, 38, 119-125. [CrossRef]

57. Michot, J.-M.; Mazeron, R.; Dercle, L.; Ammari, S.; Canova, C.; Marabelle, A.; Rose, S.; Rubin, E.; Deutsch, E.; Soria, J.-C.; et al. Abscopal effect in a Hodgkin lymphoma patient treated by an anti-programmed death 1 antibody. Eur. J. Cancer 2016, 66, 91-94. [CrossRef]

58. Cong, Y.; Shen, G.; Wu, S.; Hao, R. Abscopal regression following SABR for non-small-cell-lung cancer: A case report. Cancer Biol. Ther. 2017, 18, 1-3. [CrossRef] [PubMed]

59. Komatsu, T.; Nakamura, K.; Kawase, A. Abscopal Effect of Nivolumab in a Patient with Primary Lung Cancer. J. Thorac. Oncol. 2017, 12, e143-e144. [CrossRef]

60. Sato, H.; Suzuki, Y.; Yoshimoto, Y.; Noda, S.-E.; Murata, K.; Takakusagi, Y.; Okazaki, A.; Sekihara, T.; Nakano, T. An abscopal effect in a case of concomitant treatment of locally and peritoneally recurrent gastric cancer using adoptive T-cell immunotherapy and radiotherapy. Clin. Case Rep. 2017, 5, 380-384. [CrossRef] 
61. Sharabi, A.; Kim, S.S.; Kato, S.; Sanders, P.D.; Patel, S.P.; Sanghvi, P.; Weihe, E.; Kurzrock, R. Exceptional Response to Nivolumab and Stereotactic Body Radiation Therapy (SBRT) in Neuroendocrine Cervical Carcinoma with High Tumor Mutational Burden: Management Considerations from the Center For Personalized Cancer Therapy at UC San Diego Moores Cancer Center. Oncologist 2017, 22, 631-637. [CrossRef]

62. Shi, F.; Wang, X.; Teng, F.; Kong, L.; Yu, J. Abscopal effect of metastatic pancreatic cancer after local radiotherapy and granulocytemacrophage colony-stimulating factor therapy. Cancer Biol. Ther. 2017, 18, 137-141. [CrossRef]

63. Xie, G.; Di, G.; Zhang, L.; Chen, S.; Wu, D. A rapid and systemic complete response to stereotactic body radiation therapy and pembrolizumab in a patient with metastatic renal cell carcinoma. Cancer Biol. Ther. 2017, 18, 547-551. [CrossRef] [PubMed]

64. Britschgi, C.; Riesterer, O.; Burger, I.A.; Guckenberger, M.; Curioni-Fontecedro, A. Report of an abscopal effect induced by stereotactic body radiotherapy and nivolumab in a patient with metastatic non-small cell lung cancer. Radiat. Oncol. 2018, 13, 102. [CrossRef]

65. Gutkin, P.M.; Hiniker, S.M.; Swetter, S.M.; Reddy, S.A.; Knox, S.J. Complete Response of Metastatic Melanoma to Local Radiation and Immunotherapy: 6.5 Year Follow-Up. Cureus 2018, 10, e3723. [CrossRef] [PubMed]

66. Matsushita, Y.; Nakamura, K.; Furuse, H.; Ichinohe, K.; Miyake, H. Marked response to nivolumab combined with external radiation therapy for metastatic renal cell carcinoma: Report of two cases. Int. Cancer Conf. J. 2019, 8, 29-32. [CrossRef] [PubMed]

67. Rodríguez-Ruiz, M.E.; Perez-Gracia, J.L.; Rodríguez, I.; Alfaro, C.; Oñate, C.; Pérez, G.; Gil-Bazo, I.; Benito, A.; Inogés, S.; López-Diaz de Cerio, A.; et al. Combined immunotherapy encompassing intratumoral poly-ICLC, dendritic-cell vaccination and radiotherapy in advanced cancer patients. Ann. Oncol. 2018, 29, 1312-1319. [CrossRef] [PubMed]

68. Tsui, J.M.; Mihalcioiu, C.; Cury, F.L. Abscopal Effect in a Stage IV Melanoma Patient who Progressed on Pembrolizumab. Cureus 2018, 10, e2238. [CrossRef] [PubMed]

69. Van Gysen, K.; Kneebone, A.; Eade, T.; Guminski, A.; Hruby, G. Advanced Renal Cell Cancer and Low-Dose Palliative Radiation Treatment: A Case of a Substantial and Sustained Treatment Response. Case Rep. Oncol. 2018, 11, 756-762. [CrossRef]

70. Wight, J.C.; Hawkes, E.A.; Berlangieri, S.U.; Khor, R.; Grigg, A.P. An abscopal effect may augment PD-1 inhibition in refractory classical Hodgkin lymphoma. Leuk. Lymphoma 2018, 59, 2749-2751. [CrossRef]

71. Xu, M.J.; Wu, S.; Daud, A.I.; Yu, S.S.; Yom, S.S. In-field and abscopal response after short-course radiation therapy in patients with metastatic Merkel cell carcinoma progressing on PD-1 checkpoint blockade: A case series. J. Immunother. Cancer 2018,6 , 43. [CrossRef]

72. Zhao, X.; Kang, J.; Zhao, R. Abscopal effect of radiation on lymph node metastasis in esophageal carcinoma: A case report and literature review. Oncol. Lett. 2018, 16, 3555-3560. [CrossRef] [PubMed]

73. Abbas, W.; Goel, V.; Verma, A.; Gupta, V.G.; Rao, R.R. Harnessing the Immunomodulatory Effects of Radiation in Urinary Bladder Cancer. Cureus 2019, 11, e4108. [CrossRef]

74. Bitran, J. The Abscopal Effect Exists in Non-small Cell Lung Cancer: A Case Report and Review of the Literature. Cureus 2019, 11, e4118. [CrossRef]

75. Choi, J.S.; Sansoni, E.R.; Lovin, B.D.; Lindquist, N.R.; Phan, J.; Mayo, L.L.; Ferrarotto, R.; Su, S.Y. Abscopal Effect Following Immunotherapy and Combined Stereotactic Body Radiation Therapy in Recurrent Metastatic Head and Neck Squamous Cell Carcinoma: A Report of Two Cases and Literature Review. Ann. Otol. Rhinol. Laryngol. 2020, 129, 517-522. [CrossRef]

76. D'Andrea, M.A.; Reddy, G.K. Extracranial systemic antitumor response through the abscopal effect induced by brain radiation in a patient with metastatic melanoma. Radiat. Oncol. J. 2019, 37, 302-308. [CrossRef] [PubMed]

77. Garelli, E.; Rittmeyer, A.; Putora, P.M.; Glatzer, M.; Dressel, R.; Andreas, S. Abscopal effect in lung cancer: Three case reports and a concise review. Immunotherapy 2019, 11, 1445-1461. [CrossRef]

78. Gounder, M.M.; Zhu, G.; Roshal, L.; Lis, E.; Daigle, S.R.; Blakemore, S.J.; Michaud, N.R.; Hameed, M.; Hollmann, T.J. Immunologic Correlates of the Abscopal Effect in a SMARCB1/INI1-negative Poorly Differentiated Chordoma after EZH2 Inhibition and Radiotherapy. Clin. Cancer Res. 2019, 25, 2064-2071. [CrossRef] [PubMed]

79. Grimaux, X.; Delva, R.; Jadaud, E.; Croue, A. Nivolumab-induced bullous pemphigoid after radiotherapy and abscopal effect. Australas. J. Dermatol. 2019, 60, e235-e236. [CrossRef]

80. Ishiyama, Y.; Takagi, T.; Yoshida, K.; Iizuka, J.; Kakuta, Y.; Okumi, M.; Ishida, H.; Tanabe, K. Possible abscopal effect in urothelial carcinoma of the upper urinary tract after treatment with immune checkpoint inhibitors. IJU Case Rep. 2020, 3, 25-27. [CrossRef] [PubMed]

81. Lin, X.; Lu, T.; Xie, Z.; Qin, Y.; Liu, M.; Xie, X.; Li, S.; Zhou, C. Extracranial abscopal effect induced by combining immunotherapy with brain radiotherapy in a patient with lung adenocarcinoma: A case report and literature review. Thorac. Cancer 2019, 10, 1272-1275. [CrossRef]

82. Liu, X.; Yao, J.; Song, L.; Zhang, S.; Huang, T.; Li, Y. Local and abscopal responses in advanced intrahepatic cholangiocarcinoma with low TMB, MSS, pMMR and negative PD-L1 expression following combined therapy of SBRT with PD-1 blockade. J. Immunother. Cancer 2019, 7, 204. [CrossRef] [PubMed]

83. Moran, A.; Azghadi, S.; Maverakis, E.M.; Christensen, S.; Dyer, B.A. Combined Immune Checkpoint Blockade and Stereotactic Ablative Radiotherapy Can Stimulate Response to Immunotherapy in Metastatic Melanoma: A Case Report. Cureus 2019, 11, e4038. [CrossRef] [PubMed] 
84. Qin, Q.; Nan, X.; Miller, T.; Fisher, R.; Teh, B.; Pandita, S.; Farach, A.M.; Pingali, S.R.; Pandita, R.K.; Butler, E.B.; et al. Complete Local and Abscopal Responses from a Combination of Radiation and Nivolumab in Refractory Hodgkin's Lymphoma. Radiat. Res. 2018, 190, 322-329. [CrossRef]

85. Shinde, A.; Novak, J.; Freeman, M.L.; Glaser, S.; Amini, A. Induction of the Abscopal Effect with Immunotherapy and Palliative Radiation in Metastatic Head and Neck Squamous Cell Carcinoma: A Case Report and Review of the Literature. Cureus 2019, 11, e4201. [CrossRef]

86. Suzuki, G.; Masui, K.; Yamazaki, H.; Takenaka, T.; Asai, S.; Taniguchi, H.; Nakamura, T.; Ukimura, O.; Yamada, K. Abscopal effect of high-dose-rate brachytherapy on pelvic bone metastases from renal cell carcinoma: A case report. J. Contemp. Brachytherapy 2019, 11, 458-461. [CrossRef]

87. Trommer, M.; Yeo, S.Y.; Persigehl, T.; Bunck, A.; Grüll, H.; Schlaak, M.; Theurich, S.; von Bergwelt-Baildon, M.; Morgenthaler, J.; Herter, J.M.; et al. Abscopal Effects in Radio-Immunotherapy-Response Analysis of Metastatic Cancer Patients with Progressive Disease under Anti-PD-1 Immune Checkpoint Inhibition. Front. Pharmacol. 2019, 10, 511. [CrossRef]

88. Yaguchi, D.; Ichikawa, M.; Ito, M.; Okamoto, S.; Kimura, H.; Watanabe, K. Dramatic response to nivolumab after local radiotherapy in pulmonary pleomorphic carcinoma with rapid progressive post-surgical recurrence. Thorac. Cancer 2019, 10, 1263-1266. [CrossRef]

89. Forner, D.; Horwich, P.; Trites, J.R.; Hollenhorst, H.; Bullock, M.; Lamond, N.W.D. The abscopal effect in head-and-neck squamous cell carcinoma treated with radiotherapy and nivolumab: A case report and literature review. Curr. Oncol. 2020, 27, 330-335. [CrossRef] [PubMed]

90. Hori, K.; Hirohashi, Y.; Aoyagi, T.; Taniguchi, N.; Murakumo, M.; Miyata, H.; Torigoe, T.; Abe, T.; Shinohara, N.; Morita, K. Abscopal effect following nivolumab induction in a patient with metastatic renal cell carcinoma-unique pathological features of the primary specimen: A case report. Exp. Ther. Med. 2020, 19, 1903-1907. [CrossRef]

91. Igarashi, H.; Fukuda, M.; Konno, Y.; Takano, H. Abscopal effect of radiation therapy after nivolumab monotherapy in a patient with oral mucosal melanoma: A case report. Oral Oncol. 2020, 108, 104919. [CrossRef]

92. Kuhara, Y.; Ninomiya, M.; Hirahara, S.; Doi, H.; Kenji, S.; Toyota, K.; Yano, R.; Kobayashi, H.; Hashimoto, Y.; Yokoyama, Y.; et al. A long-term survival case of unresectable gastric cancer with multidisciplinary therapy including immunotherapy and abscopal effect. Int. Cancer Conf. J. 2020, 9, 193-198. [CrossRef]

93. Levitin, M.; Ofori, J.; Shin, W.J.; Huang, J.; Daly, M.; Cao, D.; Pachynski, R. Radiation and Checkpoint Inhibitor Immunotherapy Lead to Long Term Disease Control in a Metastatic RCC patient with Brain Metastases. Front. Oncol. 2020, 10, 566070. [CrossRef]

94. Nakajima, N.; Kano, T.; Oda, K.; Uchida, T.; Otaki, T.; Nagao, K.; Shimizu, Y.; Kawakami, M.; Kim, H.; Nitta, M.; et al. Possible abscopal effect after discontinuation of nivolumab in metastatic renal cell carcinoma. IJU Case Rep. 2020, 3, 215-218. [CrossRef] [PubMed]

95. Sohal, R.J.; Sohal, S.; Wazir, A.; Benjamin, S. Mucosal Melanoma: A Rare Entity and Review of the Literature. Cureus 2020, 12, e9483. [CrossRef] [PubMed]

96. Wang, W.; Huang, C.; Wu, S.; Liu, Z.; Liu, L.; Li, L.; Li, S. Abscopal effect induced by modulated radiation therapy and pembrolizumab in a patient with pancreatic metastatic lung squamous cell carcinoma. Thorac. Cancer 2020, 11, 2014-2017. [CrossRef] [PubMed]

97. Watanabe, T.; Firat, E.; Scholber, J.; Gaedicke, S.; Heinrich, C.; Luo, R.; Ehrat, N.; Multhoff, G.; Schmitt-Graeff, A.; Grosu, A.-L.; et al. Deep abscopal response to radiotherapy and anti-PD-1 in an oligometastatic melanoma patient with unfavorable pretreatment immune signature. Cancer Immunol. Immunother. 2020, 69, 1823-1832. [CrossRef]

98. Hotta, T.; Okuno, T.; Nakao, M.; Amano, Y.; Isobe, T.; Tsubata, Y. Reproducible abscopal effect in a patient with lung cancer who underwent whole-brain irradiation and atezolizumab administration. Thorac. Cancer 2021, 12, 985-988. [CrossRef]

99. Mampuya, W.A.; Bouchaab, H.; Schaefer, N.; Kinj, R.; La Rosa, S.; Letovanec, I.; Ozsahin, M.; Bourhis, J.; Coukos, G.; Peters, S.; et al. Abscopal effect in a patient with malignant pleural mesothelioma treated with palliative radiotherapy and pembrolizumab. Clin. Transl. Radiat. Oncol. 2021, 27, 85-88. [CrossRef] [PubMed]

100. Wong, A.; Vellayappan, B.; Cheng, L.; Zhao, J.J.; Muthu, V.; Asokumaran, Y.; Low, J.-L.; Lee, M.; Huang, Y.-Q.; Kumarakulasinghe, N.B.; et al. Atypical Response Patterns in Renal Cell Carcinoma Treated with Immune Checkpoint Inhibitors-Navigating the Radiologic Potpourri. Cancers 2021, 13, 1689. [CrossRef]

101. Azzam, E.I.; Jay-Gerin, J.-P.; Pain, D. Ionizing radiation-induced metabolic oxidative stress and prolonged cell injury. Cancer Lett. 2012, 327, 48-60. [CrossRef]

102. Srinivas, U.S.; Tan, B.W.Q.; Vellayappan, B.A.; Jeyasekharan, A.D. ROS and the DNA damage response in cancer. Redox Biol. 2019, 25, 101084. [CrossRef]

103. Garibaldi, C.; Jereczek-Fossa, B.A.; Marvaso, G.; Dicuonzo, S.; Rojas, D.P.; Cattani, F.; Starzyńska, A.; Ciardo, D.; Surgo, A.; Leonardi, M.C.; et al. Recent advances in radiation oncology. Ecancermedicalscience 2017, 11, 785. [CrossRef]

104. Golden, E.B.; Apetoh, L. Radiotherapy and immunogenic cell death. Semin. Radiat. Oncol. 2015, 25, 11-17. [CrossRef]

105. Wani, S.Q.; Dar, I.A.; Khan, T.; Lone, M.M.; Afroz, F. Radiation Therapy and its Effects beyond the Primary Target: An Abscopal Effect. Cureus 2019, 11, e4100. [CrossRef] [PubMed]

106. Demaria, S.; Ng, B.; Devitt, M.L.; Babb, J.S.; Kawashima, N.; Liebes, L.; Formenti, S.C. Ionizing radiation inhibition of distant untreated tumors (abscopal effect) is immune mediated. Int. J. Radiat. Oncol. Biol. Phys. 2004, 58, 862-870. [CrossRef] 
107. Formenti, S.C.; Demaria, S. Radiation therapy to convert the tumor into an in situ vaccine. Int. J. Radiat. Oncol. Biol. Phys. 2012, 84, 879-880. [CrossRef] [PubMed]

108. Barker, H.E.; Paget, J.T.E.; Khan, A.A.; Harrington, K.J. The tumour microenvironment after radiotherapy: Mechanisms of resistance and recurrence. Nat. Rev. Cancer 2015, 15, 409-425. [CrossRef] [PubMed]

109. Grass, G.D.; Krishna, N.; Kim, S. The immune mechanisms of abscopal effect in radiation therapy. Curr. Probl. Cancer 2016, 40, 10-24. [CrossRef]

110. Gupta, A.; Probst, H.C.; van Vuong Landshammer, A.; Muth, S.; Yagita, H.; Schwendener, R.; Pruschy, M.; Knuth, A.; van den Broek, M. Radiotherapy promotes tumor-specific effector CD8+ T cells via dendritic cell activation. J. Immunol. 2012, 189, 558-566. [CrossRef]

111. Kaur, P.; Asea, A. Radiation-induced effects and the immune system in cancer. Front. Oncol. 2012, 2, 191. [CrossRef] [PubMed]

112. Rodriguez-Ruiz, M.E.; Rodriguez, I.; Leaman, O.; López-Campos, F.; Montero, A.; Conde, A.J.; Aristu, J.J.; Lara, P.; Calvo, F.M.; Melero, I. Immune mechanisms mediating abscopal effects in radioimmunotherapy. Pharmacol. Ther. 2019, 196, 195-203. [CrossRef]

113. Lanneau, D.; de Thonel, A.; Maurel, S.; Didelot, C.; Garrido, C. Apoptosis versus cell differentiation: Role of heat shock proteins HSP90, HSP70 and HSP27. Prion 2007, 1, 53-60. [CrossRef] [PubMed]

114. Chen, T.; Cao, X. Stress for maintaining memory: HSP70 as a mobile messenger for innate and adaptive immunity. Eur. J. Immunol. 2010, 40, 1541-1544. [CrossRef] [PubMed]

115. Gameiro, S.R.; Jammeh, M.L.; Wattenberg, M.M.; Tsang, K.Y.; Ferrone, S.; Hodge, J.W. Radiation-induced immunogenic modulation of tumor enhances antigen processing and calreticulin exposure, resulting in enhanced T-cell killing. Oncotarget 2014, 5, 403-416. [CrossRef]

116. Di Virgilio, F. Liaisons dangereuses: P2X(7) and the inflammasome. Trends Pharmacol. Sci. 2007, 28, 465-472. [CrossRef] [PubMed]

117. Martinon, F.; Mayor, A.; Tschopp, J. The inflammasomes: Guardians of the body. Annu. Rev. Immunol. 2009, 27, 229-265. [CrossRef]

118. Ghiringhelli, F.; Apetoh, L.; Tesniere, A.; Aymeric, L.; Ma, Y.; Ortiz, C.; Vermaelen, K.; Panaretakis, T.; Mignot, G.; Ullrich, E.; et al. Activation of the NLRP3 inflammasome in dendritic cells induces IL-1beta-dependent adaptive immunity against tumors. Nat. Med. 2009, 15, 1170-1178. [CrossRef]

119. Sato, H.; Okonogi, N.; Nakano, T. Rationale of combination of anti-PD-1/PD-L1 antibody therapy and radiotherapy for cancer treatment. Int. J. Clin. Oncol. 2020, 25, 801-809. [CrossRef]

120. Sun, L.; Wu, J.; Du, F.; Chen, X.; Chen, Z.J. Cyclic GMP-AMP synthase is a cytosolic DNA sensor that activates the type I interferon pathway. Science 2013, 339, 786-791. [CrossRef]

121. Ablasser, A.; Goldeck, M.; Cavlar, T.; Deimling, T.; Witte, G.; Röhl, I.; Hopfner, K.-P.; Ludwig, J.; Hornung, V. cGAS produces a 2'-5'-linked cyclic dinucleotide second messenger that activates STING. Nature 2013, 498, 380-384. [CrossRef]

122. Ishikawa, H.; Ma, Z.; Barber, G.N. STING regulates intracellular DNA-mediated, type I interferon-dependent innate immunity. Nature 2009, 461, 788-792. [CrossRef]

123. Guo, Y.-R.; Cao, Q.-D.; Hong, Z.-S.; Tan, Y.-Y.; Chen, S.-D.; Jin, H.-J.; Tan, K.-S.; Wang, D.-Y.; Yan, Y. The origin, transmission and clinical therapies on coronavirus disease 2019 (COVID-19) outbreak-An update on the status. Mil. Med. Res. $2020,7,11$. [CrossRef]

124. Deng, L.; Liang, H.; Xu, M.; Yang, X.; Burnette, B.; Arina, A.; Li, X.-D.; Mauceri, H.; Beckett, M.; Darga, T.; et al. STING-Dependent Cytosolic DNA Sensing Promotes Radiation-Induced Type I Interferon-Dependent Antitumor Immunity in Immunogenic Tumors. Immunity 2014, 41, 843-852. [CrossRef] [PubMed]

125. Burnette, B.C.; Liang, H.; Lee, Y.; Chlewicki, L.; Khodarev, N.N.; Weichselbaum, R.R.; Fu, Y.-X.; Auh, S.L. The efficacy of radiotherapy relies upon induction of type i interferon-dependent innate and adaptive immunity. Cancer Res. 2011, 71, 2488-2496. [CrossRef]

126. Rodríguez-Ruiz, M.E.; Vanpouille-Box, C.; Melero, I.; Formenti, S.C.; Demaria, S. Immunological Mechanisms Responsible for Radiation-Induced Abscopal Effect. Trends Immunol. 2018, 39, 644-655. [CrossRef] [PubMed]

127. Lugade, A.A.; Sorensen, E.W.; Gerber, S.A.; Moran, J.P.; Frelinger, J.G.; Lord, E.M. Radiation-induced IFN-gamma production within the tumor microenvironment influences antitumor immunity. J. Immunol. 2008, 180, 3132-3139. [CrossRef] [PubMed]

128. Matsumura, S.; Wang, B.; Kawashima, N.; Braunstein, S.; Badura, M.; Cameron, T.O.; Babb, J.S.; Schneider, R.J.; Formenti, S.C.; Dustin, M.L.; et al. Radiation-induced CXCL16 release by breast cancer cells attracts effector T cells. J. Immunol. 2008, 181, 3099-3107. [CrossRef]

129. Matsumura, S.; Demaria, S. Up-regulation of the pro-inflammatory chemokine CXCL16 is a common response of tumor cells to ionizing radiation. Radiat. Res. 2010, 173, 418-425. [CrossRef]

130. Lim, J.Y.H.; Gerber, S.A.; Murphy, S.P.; Lord, E.M. Type I interferons induced by radiation therapy mediate recruitment and effector function of CD8(+) T cells. Cancer Immunol. Immunother. 2014, 63, 259-271. [CrossRef]

131. Hallahan, D.E.; Spriggs, D.R.; Beckett, M.A.; Kufe, D.W.; Weichselbaum, R.R. Increased tumor necrosis factor alpha mRNA after cellular exposure to ionizing radiation. Proc. Natl. Acad. Sci. USA 1989, 86, 10104-10107. [CrossRef]

132. Twyman-Saint Victor, C.; Rech, A.J.; Maity, A.; Rengan, R.; Pauken, K.E.; Stelekati, E.; Benci, J.L.; Xu, B.; Dada, H.; Odorizzi, P.M.; et al. Radiation and dual checkpoint blockade activate non-redundant immune mechanisms in cancer. Nature 2015, 520, 373-377. [CrossRef] [PubMed] 
133. Ben-Shoshan, J.; Maysel-Auslender, S.; Mor, A.; Keren, G.; George, J. Hypoxia controls CD4+CD25+ regulatory T-cell homeostasis via hypoxia-inducible factor-1alpha. Eur. J. Immunol. 2008, 38, 2412-2418. [CrossRef] [PubMed]

134. Yan, M.; Jene, N.; Byrne, D.; Millar, E.K.A.; O’Toole, S.A.; McNeil, C.M.; Bates, G.J.; Harris, A.L.; Banham, A.H.; Sutherland, R.L.; et al. Recruitment of regulatory $\mathrm{T}$ cells is correlated with hypoxia-induced CXCR4 expression, and is associated with poor prognosis in basal-like breast cancers. Breast Cancer Res. 2011, 13, R47. [CrossRef] [PubMed]

135. Sethumadhavan, S.; Silva, M.; Philbrook, P.; Nguyen, T.; Hatfield, S.M.; Ohta, A.; Sitkovsky, M.V. Hypoxia and hypoxia-inducible factor (HIF) downregulate antigen-presenting MHC class I molecules limiting tumor cell recognition by T cells. PLoS ONE 2017, 12, e0187314. [CrossRef] [PubMed]

136. Chen, M.; Qiao, G.; Hylander, B.L.; Mohammadpour, H.; Wang, X.-Y.; Subjeck, J.R.; Singh, A.K.; Repasky, E.A. Adrenergic stress constrains the development of anti-tumor immunity and abscopal responses following local radiation. Nat. Commun. 2020, 11, 1821. [CrossRef]

137. Donlon, N.E.; Power, R.; Hayes, C.; Reynolds, J.V.; Lysaght, J. Radiotherapy, immunotherapy, and the tumour microenvironment: Turning an immunosuppressive milieu into a therapeutic opportunity. Cancer Lett. 2021, 502, 84-96. [CrossRef]

138. Demaria, S.; Kawashima, N.; Yang, A.M.; Devitt, M.L.; Babb, J.S.; Allison, J.P.; Formenti, S.C. Immune-mediated inhibition of metastases after treatment with local radiation and CTLA-4 blockade in a mouse model of breast cancer. Clin. Cancer Res. 2005, $11,728-734$.

139. Dewan, M.Z.; Galloway, A.E.; Kawashima, N.; Dewyngaert, J.K.; Babb, J.S.; Formenti, S.C.; Demaria, S. Fractionated but not single-dose radiotherapy induces an immune-mediated abscopal effect when combined with anti-CTLA-4 antibody. Clin. Cancer Res. 2009, 15, 5379-5388. [CrossRef]

140. Rodriguez-Ruiz, M.E.; Rodriguez, I.; Barbes, B.; Mayorga, L.; Sanchez-Paulete, A.R.; Ponz-Sarvise, M.; Pérez-Gracia, J.L.; Melero, I. Brachytherapy attains abscopal effects when combined with immunostimulatory monoclonal antibodies. Brachytherapy 2017, 16, 1246-1251. [CrossRef]

141. Rekers, N.H.; Olivo Pimentel, V.; Yaromina, A.; Lieuwes, N.G.; Biemans, R.; Zegers, C.M.L.; Germeraad, W.T.V.; van Limbergen, E.J.; Neri, D.; Dubois, L.J.; et al. The immunocytokine L19-IL2: An interplay between radiotherapy and long-lasting systemic anti-tumour immune responses. Oncoimmunology 2018, 7, e1414119. [CrossRef]

142. Yasmin-Karim, S.; Bruck, P.T.; Moreau, M.; Kunjachan, S.; Chen, G.Z.; Kumar, R.; Grabow, S.; Dougan, S.K.; Ngwa, W. Radiation and Local Anti-CD40 Generate an Effective in situ Vaccine in Preclinical Models of Pancreatic Cancer. Front. Immunol. 2018, 9 , 2030. [CrossRef] [PubMed]

143. Kwon, Y.-S.; Lee, M.-G.; Baek, J.; Nam, K.-S.; Im Lee, J.; Kim, S.; Jang, H. Evaluation of Radiotherapy-Induced Systemic Antitumor Effects in Mice Bearing 4T1 Mouse Breast Cancer Cells. Cancer Biother. Radiopharm. 2020. [CrossRef] [PubMed]

144. Herrscher, H.; Sauer, B.; Truntzer, P.; Robert, C. Abscopal antitumor effect in a patient with melanoma and coronavirus disease 2019. Eur. J. Cancer 2021, 149, 91-93. [CrossRef] [PubMed]

145. Kucerova, P.; Cervinkova, M. Spontaneous regression of tumour and the role of microbial infection-Possibilities for cancer treatment. Anticancer Drugs 2016, 27, 269-277. [CrossRef] [PubMed]

146. Thomas, J.A.; Badini, M. The role of innate immunity in spontaneous regression of cancer. Indian J. Cancer 2011, 48, $246-251$. [CrossRef]

147. Sung, H.; Ferlay, J.; Siegel, R.L.; Laversanne, M.; Soerjomataram, I.; Jemal, A.; Bray, F. Global Cancer Statistics 2020: GLOBOCAN Estimates of Incidence and Mortality Worldwide for 36 Cancers in 185 Countries. CA Cancer J. Clin. 2021, 71, 209-249. [CrossRef] [PubMed]

148. Mullangi, S.; Lekkala, M.R. Adenocarcinoma; StatPearls: Treasure Island, FL, USA, 2021.

149. Varadhachary, G.R. Carcinoma of unknown primary origin. Gastrointest. Cancer Res. 2007, 1, $229-235$.

150. Dicken, B.J.; Bigam, D.L.; Cass, C.; Mackey, J.R.; Joy, A.A.; Hamilton, S.M. Gastric adenocarcinoma: Review and considerations for future directions. Ann. Surg. 2005, 241, 27-39. [CrossRef]

151. Baba, K.; Nomura, M.; Ohashi, S.; Hiratsuka, T.; Nakai, Y.; Saito, T.; Kondo, Y.; Fukuyama, K.; Kikuchi, O.; Yamada, A.; et al. Experimental model for the irradiation-mediated abscopal effect and factors influencing this effect. Am. J. Cancer Res. 2020, 10, $440-453$.

152. Shaheen, O.; Ghibour, A.; Alsaid, B. Esophageal Cancer Metastases to Unexpected Sites: A Systematic Review. Gastroenterol. Res. Pract. 2017, 2017, 1657310. [CrossRef]

153. Molina, J.R.; Yang, P.; Cassivi, S.D.; Schild, S.E.; Adjei, A.A. Non-small cell lung cancer: Epidemiology, risk factors, treatment, and survivorship. Mayo Clin. Proc. 2008, 83, 584-594. [CrossRef]

154. Zappa, C.; Mousa, S.A. Non-small cell lung cancer: Current treatment and future advances. Transl. Lung Cancer Res. 2016, 5, 288-300. [CrossRef] [PubMed]

155. Putora, P.M.; Fruh, M.; Kern, L. The place of radiotherapy in the palliative management of NSCLC. Breathe 2011, 8, 134-143. [CrossRef]

156. Lindberg, K.; Nyman, J.; Riesenfeld Källskog, V.; Hoyer, M.; Lund, J.Å.; Lax, I.; Wersäll, P.; Karlsson, K.; Friesland, S.; Lewensohn, R. Long-term results of a prospective phase II trial of medically inoperable stage I NSCLC treated with SBRT-The Nordic experience. Acta Oncol. 2015, 54, 1096-1104. [CrossRef] [PubMed] 
157. Postmus, P.E.; Kerr, K.M.; Oudkerk, M.; Senan, S.; Waller, D.A.; Vansteenkiste, J.; Escriu, C.; Peters, S. Early and locally advanced non-small-cell lung cancer (NSCLC): ESMO Clinical Practice Guidelines for diagnosis, treatment and follow-up. Ann. Oncol. 2017, 28, iv1-iv21. [CrossRef]

158. Fiorica, F.; Tebano, U.; Gabbani, M.; Perrone, M.; Missiroli, S.; Berretta, M.; Giuliani, J.; Bonetti, A.; Remo, A.; Pigozzi, E.; et al. Beyond Abscopal Effect: A Meta-Analysis of Immune Checkpoint Inhibitors and Radiotherapy in Advanced Non-Small Cell Lung Cancer. Cancers 2021, 13, 2352. [CrossRef] [PubMed]

159. Escudier, B.; Porta, C.; Schmidinger, M.; Rioux-Leclercq, N.; Bex, A.; Khoo, V.; Grunwald, V.; Gillessen, S.; Horwich, A. Renal cell carcinoma: ESMO Clinical Practice Guidelines for diagnosis, treatment and follow-up. Ann. Oncol. 2019, 30, 706-720. [CrossRef]

160. Ljungberg, B.; Albiges, L.; Bedke, J.; Bex, A.; Capitanio, U.; Giles, R.H.; Hora, M.; Klatte, T.; Lam, T.; Marconi, L.; et al. European Association of Urology Guidelines on Renal Cell Carcinoma Presented at the EAU Annual Congress Milan 2021; EAU Guidelines Office: Arnhem, The Netherlands, 2021; ISBN 978-94-92671-13-4.

161. Sullivan, R.J.; Atkins, M.B.; Kirkwood, J.M.; Agarwala, S.S.; Clark, J.I.; Ernstoff, M.S.; Fecher, L.; Gajewski, T.F.; Gastman, B.; Lawson, D.H.; et al. An update on the Society for Immunotherapy of Cancer consensus statement on tumor immunotherapy for the treatment of cutaneous melanoma: Version 2.0. J. Immunother. Cancer 2018, 6, 44. [CrossRef]

162. Hodi, F.S.; Chiarion-Sileni, V.; Gonzalez, R.; Grob, J.-J.; Rutkowski, P.; Cowey, C.L.; Lao, C.D.; Schadendorf, D.; Wagstaff, J.; Dummer, R.; et al. Nivolumab plus ipilimumab or nivolumab alone versus ipilimumab alone in advanced melanoma (CheckMate 067): 4-year outcomes of a multicentre, randomised, phase 3 trial. Lancet Oncol. 2018, 19, 1480-1492. [CrossRef]

163. Robert, C.; Ribas, A.; Schachter, J.; Arance, A.; Grob, J.-J.; Mortier, L.; Daud, A.; Carlino, M.S.; McNeil, C.M.; Lotem, M.; et al. Pembrolizumab versus ipilimumab in advanced melanoma (KEYNOTE-006): Post-hoc 5-year results from an open-label, multicentre, randomised, controlled, phase 3 study. Lancet Oncol. 2019, 20, 1239-1251. [CrossRef]

164. Park, S.S.; Dong, H.; Liu, X.; Harrington, S.M.; Krco, C.J.; Grams, M.P.; Mansfield, A.S.; Furutani, K.M.; Olivier, K.R.; Kwon, E.D. PD-1 Restrains Radiotherapy-Induced Abscopal Effect. Cancer Immunol. Res. 2015, 3, 610-619. [CrossRef] [PubMed]

165. Pfannenstiel, L.W.; McNeilly, C.; Xiang, C.; Kang, K.; Diaz-Montero, C.M.; Yu, J.S.; Gastman, B.R. Combination PD-1 blockade and irradiation of brain metastasis induces an effective abscopal effect in melanoma. Oncoimmunology 2019, 8, e1507669. [CrossRef]

166. Hiniker, S.M.; Reddy, S.A.; Maecker, H.T.; Subrahmanyam, P.B.; Rosenberg-Hasson, Y.; Swetter, S.M.; Saha, S.; Shura, L.; Knox, S.J A Prospective Clinical Trial Combining Radiation Therapy with Systemic Immunotherapy in Metastatic Melanoma. Int. J. Radiat. Oncol. Biol. Phys. 2016, 96, 578-588. [CrossRef] [PubMed]

167. Theurich, S.; Rothschild, S.I.; Hoffmann, M.; Fabri, M.; Sommer, A.; Garcia-Marquez, M.; Thelen, M.; Schill, C.; Merki, R.; Schmid, T.; et al. Local Tumor Treatment in Combination with Systemic Ipilimumab Immunotherapy Prolongs Overall Survival in Patients with Advanced Malignant Melanoma. Cancer Immunol. Res. 2016, 4, 744-754. [CrossRef]

168. Formenti, S.C.; Lee, P.; Adams, S.; Goldberg, J.D.; Li, X.; Xie, M.W.; Ratikan, J.A.; Felix, C.; Hwang, L.; Faull, K.F.; et al. Focal Irradiation and Systemic TGF $\beta$ Blockade in Metastatic Breast Cancer. Clin. Cancer Res. 2018, 24, 2493-2504. [CrossRef]

169. Zhang, L.; Tang, R.; Deng, J.-P.; Zhang, W.-W.; Lin, H.-X.; Wu, S.-G.; He, Z.-Y. The effect of postmastectomy radiotherapy in node-positive triple-negative breast cancer. BMC Cancer 2020, 20, 1146. [CrossRef]

170. Rodriguez-Ruiz, M.E.; Rodriguez, I.; Garasa, S.; Barbes, B.; Solorzano, J.L.; Perez-Gracia, J.L.; Labiano, S.; Sanmamed, M.F.; Azpilikueta, A.; Bolaños, E.; et al. Abscopal Effects of Radiotherapy Are Enhanced by Combined Immunostimulatory mAbs and Are Dependent on CD8 T Cells and Crosspriming. Cancer Res. 2016, 76, 5994-6005. [CrossRef] [PubMed]

171. Krombach, J.; Hennel, R.; Brix, N.; Orth, M.; Schoetz, U.; Ernst, A.; Schuster, J.; Zuchtriegel, G.; Reichel, C.A.; Bierschenk, S.; et al. Priming anti-tumor immunity by radiotherapy: Dying tumor cell-derived DAMPs trigger endothelial cell activation and recruitment of myeloid cells. Oncoimmunology 2019, 8, e1523097. [CrossRef]

172. Oei, A.L.; Korangath, P.; Mulka, K.; Helenius, M.; Coulter, J.B.; Stewart, J.; Velarde, E.; Crezee, J.; Simons, B.; Stalpers, L.J.A.; et al. Enhancing the abscopal effect of radiation and immune checkpoint inhibitor therapies with magnetic nanoparticle hyperthermia in a model of metastatic breast cancer. Int. J. Hyperth. 2019, 36, 47-63. [CrossRef]

173. Ferlay, J.; Ervik MLam, F.; Colombet, M.; Mery, L.; Piñeros, M.; Znaor, A.; Soerjomataram, I.; Bray, F. Global Cancer Observatory: Cancer Today. Available online: https:/ / gco.iarc.fr/today (accessed on 4 February 2021).

174. Kirby, M.; Hirst, C.; Crawford, E.D. Characterising the castration-resistant prostate cancer population: A systematic review. Int. J. Clin. Pract. 2011, 65, 1180-1192. [CrossRef]

175. Hotte, S.J.; Saad, F. Current management of castrate-resistant prostate cancer. Curr. Oncol. 2010, 17 (Suppl. 2), S72-S79. [CrossRef] [PubMed]

176. Rose, J.N.; Crook, J.M. The role of radiation therapy in the treatment of metastatic castrate-resistant prostate cancer. Ther. Adv. Urol. 2015, 7, 135-145. [CrossRef]

177. Slovin, S.F.; Higano, C.S.; Hamid, O.; Tejwani, S.; Harzstark, A.; Alumkal, J.J.; Scher, H.I.; Chin, K.; Gagnier, P.; McHenry, M.B.; et al. Ipilimumab alone or in combination with radiotherapy in metastatic castration-resistant prostate cancer: Results from an openlabel, multicenter phase I/II study. Ann. Oncol. 2013, 24, 1813-1821. [CrossRef] [PubMed]

178. Kwon, E.D.; Drake, C.G.; Scher, H.I.; Fizazi, K.; Bossi, A.; van den Eertwegh, A.J.M.; Krainer, M.; Houede, N.; Santos, R.; Mahammedi, H.; et al. Ipilimumab versus placebo after radiotherapy in patients with metastatic castration-resistant prostate cancer that had progressed after docetaxel chemotherapy (CA184-043): A multicentre, randomised, double-blind, phase 3 trial. Lancet Oncol. 2014, 15, 700-712. [CrossRef] 
179. Xu, J.; Escamilla, J.; Mok, S.; David, J.; Priceman, S.; West, B.; Bollag, G.; McBride, W.; Wu, L. CSF1R signaling blockade stanches tumor-infiltrating myeloid cells and improves the efficacy of radiotherapy in prostate cancer. Cancer Res. 2013, 73, $2782-2794$. [CrossRef] [PubMed]

180. Dudzinski, S.O.; Cameron, B.D.; Wang, J.; Rathmell, J.C.; Giorgio, T.D.; Kirschner, A.N. Combination immunotherapy and radiotherapy causes an abscopal treatment response in a mouse model of castration resistant prostate cancer. J. Immunother. Cancer 2019, 7, 218. [CrossRef]

181. Poleszczuk, J.T.; Luddy, K.A.; Prokopiou, S.; Robertson-Tessi, M.; Moros, E.G.; Fishman, M.; Djeu, J.Y.; Finkelstein, S.E.; Enderling, H. Abscopal Benefits of Localized Radiotherapy Depend on Activated T-cell Trafficking and Distribution between Metastatic Lesions. Cancer Res. 2016, 76, 1009-1018. [CrossRef]

182. Demaria, S.; Formenti, S.C. Can abscopal effects of local radiotherapy be predicted by modeling T cell trafficking? J. Immunother. Cancer 2016, 4, 29. [CrossRef]

183. Camphausen, K.; Moses, M.A.; Ménard, C.; Sproull, M.; Beecken, W.-D.; Folkman, J.; O’Reilly, M.S. Radiation abscopal antitumor effect is mediated through p53. Cancer Res. 2003, 63, 1990-1993.

184. Strigari, L.; Mancuso, M.; Ubertini, V.; Soriani, A.; Giardullo, P.; Benassi, M.; D’Alessio, D.; Leonardi, S.; Soddu, S.; Bossi, G. Abscopal effect of radiation therapy: Interplay between radiation dose and p53 status. Int. J. Radiat. Biol. 2014, 90, 248-255. [CrossRef]

185. Bayer, C.; Liebhardt, M.E.; Schmid, T.E.; Trajkovic-Arsic, M.; Hube, K.; Specht, H.M.; Schilling, D.; Gehrmann, M.; Stangl, S.; Siveke, J.T.; et al. Validation of heat shock protein 70 as a tumor-specific biomarker for monitoring the outcome of radiation therapy in tumor mouse models. Int. J. Radiat. Oncol. Biol. Phys. 2014, 88, 694-700. [CrossRef]

186. Siva, S.; Lobachevsky, P.; MacManus, M.P.; Kron, T.; Möller, A.; Lobb, R.J.; Ventura, J.; Best, N.; Smith, J.; Ball, D.; et al. Radiotherapy for Non-Small Cell Lung Cancer Induces DNA Damage Response in Both Irradiated and Out-of-field Normal Tissues. Clin. Cancer Res. 2016, 22, 4817-4826. [CrossRef] [PubMed]

187. Blattner, C.; Fleming, V.; Weber, R.; Himmelhan, B.; Altevogt, P.; Gebhardt, C.; Schulze, T.J.; Razon, H.; Hawila, E.; Wildbaum, G.; et al. CCR5+ Myeloid-Derived Suppressor Cells Are Enriched and Activated in Melanoma Lesions. Cancer Res. 2018, 78, 157-167. [CrossRef] [PubMed]

188. Chen, D.; Verma, V.; Patel, R.R.; Barsoumian, H.B.; Cortez, M.A.; Welsh, J.W. Absolute Lymphocyte Count Predicts Abscopal Responses and Outcomes in Patients Receiving Combined Immunotherapy and Radiation Therapy: Analysis of 3 Phase $1 / 2$ Trials. Int. J. Radiat. Oncol. Biol. Phys. 2020, 108, 196-203. [CrossRef]

189. Golden, E.B.; Chhabra, A.; Chachoua, A.; Adams, S.; Donach, M.; Fenton-Kerimian, M.; Friedman, K.; Ponzo, F.; Babb, J.S.; Goldberg, J.; et al. Local radiotherapy and granulocyte-macrophage colony-stimulating factor to generate abscopal responses in patients with metastatic solid tumours: A proof-of-principle trial. Lancet Oncol. 2015, 16, 795-803. [CrossRef]

190. Vousden, K.H.; Lane, D.P. p53 in health and disease. Nat. Rev. Mol. Cell Biol. 2007, 8, 275-283. [CrossRef]

191. Fucikova, J.; Spisek, R.; Kroemer, G.; Galluzzi, L. Calreticulin and cancer. Cell Res. 2021, 31, 5-16. [CrossRef]

192. Ngwa, W.; Irabor, O.C.; Schoenfeld, J.D.; Hesser, J.; Demaria, S.; Formenti, S.C. Using immunotherapy to boost the abscopal effect. Nat. Rev. Cancer 2018, 18, 313-322. [CrossRef] [PubMed]

193. Kroemer, G.; Zitvogel, L. Subversion of calreticulin exposure as a strategy of immune escape. Cancer Cell 2021, $39,449-451$. [CrossRef]

194. Obeid, M.; Tesniere, A.; Ghiringhelli, F.; Fimia, G.M.; Apetoh, L.; Perfettini, J.-L.; Castedo, M.; Mignot, G.; Panaretakis, T.; Casares, N.; et al. Calreticulin exposure dictates the immunogenicity of cancer cell death. Nat. Med. 2007, 13, 54-61. [CrossRef]

195. Obeid, M.; Tesniere, A.; Panaretakis, T.; Tufi, R.; Joza, N.; van Endert, P.; Ghiringhelli, F.; Apetoh, L.; Chaput, N.; Flament, C.; et al. Ecto-calreticulin in immunogenic chemotherapy. Immunol. Rev. 2007, 220, 22-34. [CrossRef] [PubMed]

196. Gehrmann, M.; Specht, H.M.; Bayer, C.; Brandstetter, M.; Chizzali, B.; Duma, M.; Breuninger, S.; Hube, K.; Lehnerer, S.; van Phi, V.; et al. Hsp70-A biomarker for tumor detection and monitoring of outcome of radiation therapy in patients with squamous cell carcinoma of the head and neck. Radiat. Oncol. 2014, 9, 131. [CrossRef]

197. Juhasz, K.; Lipp, A.-M.; Nimmervoll, B.; Sonnleitner, A.; Hesse, J.; Haselgruebler, T.; Balogi, Z. The complex function of hsp70 in metastatic cancer. Cancers 2013, 6, 42-66. [CrossRef]

198. Abe, M.; Manola, J.B.; Oh, W.K.; Parslow, D.L.; George, D.J.; Austin, C.L.; Kantoff, P.W. Plasma levels of heat shock protein 70 in patients with prostate cancer: A potential biomarker for prostate cancer. Clin. Prostate Cancer 2004, 3, 49-53. [CrossRef] [PubMed]

199. Fujita, Y.; Nakanishi, T.; Miyamoto, Y.; Hiramatsu, M.; Mabuchi, H.; Miyamoto, A.; Shimizu, A.; Takubo, T.; Tanigawa, N Proteomics-based identification of autoantibody against heat shock protein 70 as a diagnostic marker in esophageal squamous cell carcinoma. Cancer Lett. 2008, 263, 280-290. [CrossRef] [PubMed]

200. Chuma, M.; Sakamoto, M.; Yamazaki, K.; Ohta, T.; Ohki, M.; Asaka, M.; Hirohashi, S. Expression profiling in multistage hepatocarcinogenesis: Identification of HSP70 as a molecular marker of early hepatocellular carcinoma. Hepatology 2003, 37, 198-207. [CrossRef] [PubMed]

201. Davidson, B.; Valborg Reinertsen, K.; Trinh, D.; Reed, W.; Bøhler, P.J. BAG-1/SODD, HSP70, and HSP90 are potential prognostic markers of poor survival in node-negative breast carcinoma. Hum. Pathol. 2016, 54, 64-73. [CrossRef] [PubMed]

202. Multhoff, G.; Pockley, A.G.; Schmid, T.E.; Schilling, D. The role of heat shock protein 70 (Hsp70) in radiation-induced immunomodulation. Cancer Lett. 2015, 368, 179-184. [CrossRef] 
203. Vega, V.L.; Rodríguez-Silva, M.; Frey, T.; Gehrmann, M.; Diaz, J.C.; Steinem, C.; Multhoff, G.; Arispe, N.; de Maio, A. Hsp70 translocates into the plasma membrane after stress and is released into the extracellular environment in a membrane-associated form that activates macrophages. J. Immunol. 2008, 180, 4299-4307. [CrossRef]

204. Multhoff, G. Activation of natural killer cells by heat shock protein 70. Int. J. Hyperth. 2002, 18, 576-585. [CrossRef]

205. Srivastava, P.K.; Menoret, A.; Basu, S.; Binder, R.J.; McQuade, K.L. Heat shock proteins come of age: Primitive functions acquire new roles in an adaptive world. Immunity 1998, 8, 657-665. [CrossRef]

206. Redon, C.E.; Dickey, J.S.; Bonner, W.M.; Sedelnikova, O.A. $\gamma$-H2AX as a biomarker of DNA damage induced by ionizing radiation in human peripheral blood lymphocytes and artificial skin. Adv. Space Res. 2009, 43, 1171-1178. [CrossRef] [PubMed]

207. Herbst, R.S.; Soria, J.-C.; Kowanetz, M.; Fine, G.D.; Hamid, O.; Gordon, M.S.; Sosman, J.A.; McDermott, D.F.; Powderly, J.D.; Gettinger, S.N.; et al. Predictive correlates of response to the anti-PD-L1 antibody MPDL3280A in cancer patients. Nature 2014, 515, 563-567. [CrossRef]

208. Carbognin, L.; Pilotto, S.; Milella, M.; Vaccaro, V.; Brunelli, M.; Caliò, A.; Cuppone, F.; Sperduti, I.; Giannarelli, D.; Chilosi, M.; et al. Differential Activity of Nivolumab, Pembrolizumab and MPDL3280A according to the Tumor Expression of Programmed Death-Ligand-1 (PD-L1): Sensitivity Analysis of Trials in Melanoma, Lung and Genitourinary Cancers. PLoS ONE 2015, 10, e0130142. [CrossRef] [PubMed]

209. Shimizu, A.; Kaira, K.; Okubo, Y.; Utsumi, D.; Yasuda, M.; Asao, T.; Nishiyama, M.; Takahashi, K.; Ishikawa, O. Positive PD-L1 Expression Predicts Worse Outcome in Cutaneous Angiosarcoma. J. Glob. Oncol. 2017, 3, 360-369. [CrossRef]

210. Lyu, X.; Zhang, M.; Li, G.; Jiang, Y.; Qiao, Q. PD-1 and PD-L1 Expression Predicts Radiosensitivity and Clinical Outcomes in Head and Neck Cancer and is Associated with HPV Infection. J. Cancer 2019, 10, 937-948. [CrossRef] [PubMed]

211. Valentinuzzi, D.; Simončič, U.; Uršič, K.; Vrankar, M.; Turk, M.; Jeraj, R. Predicting tumour response to anti-PD-1 immunotherapy with computational modelling. Phys. Med. Biol. 2019, 64, 25017. [CrossRef]

212. Davis, A.A.; Patel, V.G. The role of PD-L1 expression as a predictive biomarker: An analysis of all US Food and Drug Administration (FDA) approvals of immune checkpoint inhibitors. J. Immunother. Cancer 2019, 7, 278. [CrossRef]

213. Nishino, M.; Ramaiya, N.H.; Hatabu, H.; Hodi, F.S. Monitoring immune-checkpoint blockade: Response evaluation and biomarker development. Nat. Rev. Clin. Oncol. 2017, 14, 655-668. [CrossRef]

214. Hong, L.; Negrao, M.V.; Dibaj, S.S.; Chen, R.; Reuben, A.; Bohac, J.M.; Liu, X.; Skoulidis, F.; Gay, C.M.; Cascone, T.; et al. Programmed Death-Ligand 1 Heterogeneity and Its Impact on Benefit from Immune Checkpoint Inhibitors in NSCLC. J. Thorac. Oncol. 2020, 15, 1449-1459. [CrossRef]

215. Fu, J.; Wang, W.; Wang, Y.; Liu, C.; Wang, P. The role of squamous cell carcinoma antigen (SCC Ag) in outcome prediction after concurrent chemoradiotherapy and treatment decisions for patients with cervical cancer. Radiat. Oncol. 2019, 14, 146. [CrossRef]

216. Henze, G.; Dummer, R.; Joller-Jemelka, H.I.; Böni, R.; Burg, G. Serum S100—A marker for disease monitoring in metastatic melanoma. Dermatology 1997, 194, 208-212. [CrossRef] [PubMed]

217. Hauschild, A.; Engel, G.; Brenner, W.; Gläser, R.; Mönig, H.; Henze, E.; Christophers, E. Predictive value of serum S100B for monitoring patients with metastatic melanoma during chemotherapy and/or immunotherapy. Br. J. Dermatol. 1999, 140, 1065-1071. [CrossRef] [PubMed]

218. Park, Y.-A.; Sohn, S.-K.; Seong, J.; Baik, S.-H.; Lee, K.-Y.; Kim, N.-K.; Cho, C.-W. Serum CEA as a predictor for the response to preoperative chemoradiation in rectal cancer. J. Surg. Oncol. 2006, 93, 145-150. [CrossRef] [PubMed]

219. Saito, G.; Sadahiro, S.; Ogimi, T.; Miyakita, H.; Okada, K.; Tanaka, A.; Suzuki, T. Relations of Changes in Serum Carcinoembryonic Antigen Levels before and after Neoadjuvant Chemoradiotherapy and after Surgery to Histologic Response and Outcomes in Patients with Locally Advanced Rectal Cancer. Oncology 2018, 94, 167-175. [CrossRef] [PubMed]

220. Luo, H.; Shen, K.; Li, B.; Li, R.; Wang, Z.; Xie, Z. Clinical significance and diagnostic value of serum NSE, CEA, CA19-9, CA125 and CA242 levels in colorectal cancer. Oncol. Lett. 2020, 20, 742-750. [CrossRef]

221. Grunnet, M.; Sorensen, J.B. Carcinoembryonic antigen (CEA) as tumor marker in lung cancer. Lung Cancer 2012, 76, 138-143. [CrossRef] [PubMed]

222. Park, B.-W.; Oh, J.-W.; Kim, J.-H.; Park, S.H.; Kim, K.-S.; Kim, J.H.; Lee, K.S. Preoperative CA 15-3 and CEA serum levels as predictor for breast cancer outcomes. Ann. Oncol. 2008, 19, 675-681. [CrossRef]

223. Lee, J.S.; Park, S.; Park, J.M.; Cho, J.H.; Kim, S.I.; Park, B.-W. Elevated levels of preoperative CA 15-3 and CEA serum levels have independently poor prognostic significance in breast cancer. Ann. Oncol. 2013, 24, 1225-1231. [CrossRef] [PubMed]

224. Lee, T.; Teng, T.Z.J.; Shelat, V.G. Carbohydrate antigen 19-9-Tumor marker: Past, present, and future. World J. Gastrointest. Surg. 2020, 12, 468-490. [CrossRef]

225. Dawson, S.-J.; Tsui, D.W.Y.; Murtaza, M.; Biggs, H.; Rueda, O.M.; Chin, S.-F.; Dunning, M.J.; Gale, D.; Forshew, T.; Mahler-Araujo, B.; et al. Analysis of circulating tumor DNA to monitor metastatic breast cancer. N. Engl. J. Med. 2013, 368, 1199-1209. [CrossRef] [PubMed]

226. Murtaza, M.; Dawson, S.-J.; Tsui, D.W.Y.; Gale, D.; Forshew, T.; Piskorz, A.M.; Parkinson, C.; Chin, S.-F.; Kingsbury, Z.; Wong, A.S.C.; et al. Non-invasive analysis of acquired resistance to cancer therapy by sequencing of plasma DNA. Nature 2013, 497, 108-112. [CrossRef] [PubMed]

227. Yong, E. Cancer biomarkers: Written in blood. Nature 2014, 511, 524-526. [CrossRef] [PubMed]

228. Lee, M.; Samstein, R.M.; Valero, C.; Chan, T.A.; Morris, L.G.T. Tumor mutational burden as a predictive biomarker for checkpoint inhibitor immunotherapy. Hum. Vaccin. Immunother. 2020, 16, 112-115. [CrossRef] 
229. Turajlic, S.; Litchfield, K.; Xu, H.; Rosenthal, R.; McGranahan, N.; Reading, J.L.; Wong, Y.N.S.; Rowan, A.; Kanu, N.; Al Bakir, M.; et al. Insertion-and-deletion-derived tumour-specific neoantigens and the immunogenic phenotype: A pan-cancer analysis. Lancet Oncol. 2017, 18, 1009-1021. [CrossRef]

230. Chan, T.A.; Yarchoan, M.; Jaffee, E.; Swanton, C.; Quezada, S.A.; Stenzinger, A.; Peters, S. Development of tumor mutation burden as an immunotherapy biomarker: Utility for the oncology clinic. Ann. Oncol. 2019, 30, 44-56. [CrossRef]

231. Gandara, D.R.; Paul, S.M.; Kowanetz, M.; Schleifman, E.; Zou, W.; Li, Y.; Rittmeyer, A.; Fehrenbacher, L.; Otto, G.; Malboeuf, C.; et al. Blood-based tumor mutational burden as a predictor of clinical benefit in non-small-cell lung cancer patients treated with atezolizumab. Nat. Med. 2018, 24, 1441-1448. [CrossRef] [PubMed]

232. Guibert, N.; Mazieres, J.; Delaunay, M.; Casanova, A.; Farella, M.; Keller, L.; Favre, G.; Pradines, A. Monitoring of KRAS-mutated ctDNA to discriminate pseudo-progression from true progression during anti-PD-1 treatment of lung adenocarcinoma. Oncotarget 2017, 8, 38056-38060. [CrossRef]

233. Chaudhuri, A.A.; Binkley, M.S.; Osmundson, E.C.; Alizadeh, A.A.; Diehn, M. Predicting Radiotherapy Responses and Treatment Outcomes through Analysis of Circulating Tumor DNA. Semin. Radiat. Oncol. 2015, 25, 305-312. [CrossRef]

234. McGranahan, N.; Furness, A.J.S.; Rosenthal, R.; Ramskov, S.; Lyngaa, R.; Saini, S.K.; Jamal-Hanjani, M.; Wilson, G.A.; Birkbak, N.J.; Hiley, C.T.; et al. Clonal neoantigens elicit $\mathrm{T}$ cell immunoreactivity and sensitivity to immune checkpoint blockade. Science 2016, 351, 1463-1469. [CrossRef]

235. Yi, M.; Qin, S.; Zhao, W.; Yu, S.; Chu, Q.; Wu, K. The role of neoantigen in immune checkpoint blockade therapy. Exp. Hematol. Oncol. 2018, 7, 28. [CrossRef] [PubMed]

236. Rizvi, N.A.; Hellmann, M.D.; Snyder, A.; Kvistborg, P.; Makarov, V.; Havel, J.J.; Lee, W.; Yuan, J.; Wong, P.; Ho, T.S.; et al. Cancer immunology. Mutational landscape determines sensitivity to PD-1 blockade in non-small cell lung cancer. Science 2015, 348, 124-128. [CrossRef] [PubMed]

237. Mahanty, S.; Prigent, A.; Garraud, O. Immunogenicity of infectious pathogens and vaccine antigens. BMC Immunol. 2015, 16, 31. [CrossRef] [PubMed]

238. Wang, S.; He, Z.; Wang, X.; Li, H.; Liu, X.-S. Antigen presentation and tumor immunogenicity in cancer immunotherapy response prediction. Elife 2019, 8, e49020. [CrossRef] [PubMed]

239. Ku, G.Y.; Yuan, J.; Page, D.B.; Schroeder, S.E.A.; Panageas, K.S.; Carvajal, R.D.; Chapman, P.B.; Schwartz, G.K.; Allison, J.P.; Wolchok, J.D. Single-institution experience with ipilimumab in advanced melanoma patients in the compassionate use setting: Lymphocyte count after 2 doses correlates with survival. Cancer 2010, 116, 1767-1775. [CrossRef] [PubMed]

240. Delyon, J.; Mateus, C.; Lefeuvre, D.; Lanoy, E.; Zitvogel, L.; Chaput, N.; Roy, S.; Eggermont, A.M.M.; Routier, E.; Robert, C. Experience in daily practice with ipilimumab for the treatment of patients with metastatic melanoma: An early increase in lymphocyte and eosinophil counts is associated with improved survival. Ann. Oncol. 2013, 24, 1697-1703. [CrossRef]

241. Bai, R.; Lv, Z.; Xu, D.; Cui, J. Predictive biomarkers for cancer immunotherapy with immune checkpoint inhibitors. Biomark. Res. 2020, 8, 34. [CrossRef]

242. Kovacs, C. Cytokine profiles in patients receiving wide-field + prostate boost radiotherapy (xRT) for adenocarcinoma of the prostate. Cytokine 2003, 23, 151-163. [CrossRef]

243. Johnke, R.M.; Edwards, J.M.; Evans, M.J.; Nangami, G.N.; Bakken, N.T.G.; Kilburn, J.M.; Lee, T.-K.; Allison, R.R.; Karlsson, U.L.; Arastu, H.H. Circulating cytokine levels in prostate cancer patients undergoing radiation therapy: Influence of neoadjuvant total androgen suppression. In Vivo 2009, 23, 827-833.

244. Dirksen, S.R.; Kirschner, K.F.; Belyea, M.J. Association of symptoms and cytokines in prostate cancer patients receiving radiation treatment. Biol. Res. Nurs. 2014, 16, 250-257. [CrossRef]

245. Bedini, N.; Cicchetti, A.; Palorini, F.; Magnani, T.; Zuco, V.; Pennati, M.; Campi, E.; Allavena, P.; Pesce, S.; Villa, S.; et al. Evaluation of Mediators Associated with the Inflammatory Response in Prostate Cancer Patients Undergoing Radiotherapy. Dis. Markers 2018, 2018, 9128128. [CrossRef]

246. Salgado, R.; Junius, S.; Benoy, I.; van Dam, P.; Vermeulen, P.; van Marck, E.; Huget, P.; Dirix, L.Y. Circulating interleukin-6 predicts survival in patients with metastatic breast cancer. Int. J. Cancer 2003, 103, 642-646. [CrossRef]

247. Benoy, I.H.; Salgado, R.; van Dam, P.; Geboers, K.; van Marck, E.; Scharpé, S.; Vermeulen, P.B.; Dirix, L.Y. Increased serum interleukin-8 in patients with early and metastatic breast cancer correlates with early dissemination and survival. Clin. Cancer Res. 2004, 10, 7157-7162. [CrossRef]

248. Kawaguchi, K.; Sakurai, M.; Yamamoto, Y.; Suzuki, E.; Tsuda, M.; Kataoka, T.R.; Hirata, M.; Nishie, M.; Nojiri, T.; Kumazoe, M.; et al. Alteration of specific cytokine expression patterns in patients with breast cancer. Sci. Rep. 2019, 9, 2924. [CrossRef]

249. Eide, H.A.; Knudtsen, I.S.; Sandhu, V.; Løndalen, A.M.; Halvorsen, A.R.; Abravan, A.; Kure, E.H.; Bogsrud, T.V.; Brustugun, O.T.; Kyte, J.A.; et al. Serum cytokine profiles and metabolic tumor burden in patients with non-small cell lung cancer undergoing palliative thoracic radiation therapy. Adv. Radiat. Oncol. 2018, 3, 130-138. [CrossRef]

250. Cha, H.; Lee, E.J.; Seong, J. Multi-analyte analysis of cytokines that predict outcomes in patients with hepatocellular carcinoma treated with radiotherapy. World J. Gastroenterol. 2017, 23, 2077-2085. [CrossRef]

251. Shevtsov, M.; Sato, H.; Multhoff, G.; Shibata, A. Novel Approaches to Improve the Efficacy of Immuno-Radiotherapy. Front. Oncol. 2019, 9, 156. [CrossRef] [PubMed]

252. Kachikwu, E.L.; Iwamoto, K.S.; Liao, Y.-P.; DeMarco, J.J.; Agazaryan, N.; Economou, J.S.; McBride, W.H.; Schaue, D. Radiation enhances regulatory T cell representation. Int. J. Radiat. Oncol. Biol. Phys. 2011, 81, 1128-1135. [CrossRef] 
253. De Leve, S.; Wirsdörfer, F.; Jendrossek, V. Targeting the Immunomodulatory CD73/Adenosine System to Improve the Therapeutic Gain of Radiotherapy. Front. Immunol. 2019, 10, 698. [CrossRef] [PubMed]

254. Schalper, K.A.; Carleton, M.; Zhou, M.; Chen, T.; Feng, Y.; Huang, S.-P.; Walsh, A.M.; Baxi, V.; Pandya, D.; Baradet, T.; et al. Elevated serum interleukin- 8 is associated with enhanced intratumor neutrophils and reduced clinical benefit of immunecheckpoint inhibitors. Nat. Med. 2020, 26, 688-692. [CrossRef] [PubMed]

255. Yuen, K.C.; Liu, L.-F.; Gupta, V.; Madireddi, S.; Keerthivasan, S.; Li, C.; Rishipathak, D.; Williams, P.; Kadel, E.E.; Koeppen, H.; et al. High systemic and tumor-associated IL-8 correlates with reduced clinical benefit of PD-L1 blockade. Nat. Med. 2020, 26, 693-698. [CrossRef]

256. Kalluri, R.; LeBleu, V.S. The biology, function, and biomedical applications of exosomes. Science 2020, 367, 6478. [CrossRef]

257. Shan, Z.; Wang, H.; Zhang, Y.; Min, W. The Role of Tumor-Derived Exosomes in the Abscopal Effect and Immunotherapy. Life 2021, 11, 381. [CrossRef]

258. Zhou, B.; Xu, K.; Zheng, X.; Chen, T.; Wang, J.; Song, Y.; Shao, Y.; Zheng, S. Application of exosomes as liquid biopsy in clinical diagnosis. Signal Transduct. Target. Ther. 2020, 5, 144. [CrossRef] [PubMed]

259. Greening, D.W.; Gopal, S.K.; Xu, R.; Simpson, R.J.; Chen, W. Exosomes and their roles in immune regulation and cancer. Semin. Cell Dev. Biol. 2015, 40, 72-81. [CrossRef]

260. Tuncay Cagatay, S.; Mayah, A.; Mancuso, M.; Giardullo, P.; Pazzaglia, S.; Saran, A.; Daniel, A.; Traynor, D.; Meade, A.D.; Lyng, F.; et al. Phenotypic and Functional Characteristics of Exosomes Derived from Irradiated Mouse Organs and Their Role in the Mechanisms Driving Non-Targeted Effects. Int. J. Mol. Sci. 2020, 21, 8389. [CrossRef] [PubMed]

261. Yin, T.; Xin, H.; Yu, J.; Teng, F. The role of exosomes in tumour immunity under radiotherapy: Eliciting abscopal effects? Biomark. Res. 2021, 9, 22. [CrossRef]

262. Todryk, S.; Melcher, A.A.; Hardwick, N.; Linardakis, E.; Bateman, A.; Colombo, M.P.; Stoppacciaro, A.; Vile, R.G. Heat shock protein 70 induced during tumor cell killing induces Th1 cytokines and targets immature dendritic cell precursors to enhance antigen uptake. J. Immunol. 1999, 163, 1398-1408.

263. Gastpar, R.; Gehrmann, M.; Bausero, M.A.; Asea, A.; Gross, C.; Schroeder, J.A.; Multhoff, G. Heat shock protein 70 surface-positive tumor exosomes stimulate migratory and cytolytic activity of natural killer cells. Cancer Res. 2005, 65, 5238-5247. [CrossRef] [PubMed]

264. Chen, G.; Huang, A.C.; Zhang, W.; Zhang, G.; Wu, M.; Xu, W.; Yu, Z.; Yang, J.; Wang, B.; Sun, H.; et al. Exosomal PD-L1 contributes to immunosuppression and is associated with anti-PD-1 response. Nature 2018, 560, 382-386. [CrossRef]

265. Del Re, M.; Marconcini, R.; Pasquini, G.; Rofi, E.; Vivaldi, C.; Bloise, F.; Restante, G.; Arrigoni, E.; Caparello, C.; Bianco, M.G.; et al. PD-L1 mRNA expression in plasma-derived exosomes is associated with response to anti-PD-1 antibodies in melanoma and NSCLC. Br. J. Cancer 2018, 118, 820-824. [CrossRef]

266. Kang, J.; Demaria, S.; Formenti, S. Current clinical trials testing the combination of immunotherapy with radiotherapy. J. Immunother. Cancer 2016, 4, 51. [CrossRef]

267. Postow, M.A.; Knox, S.J.; Goldman, D.A.; Elhanati, Y.; Mavinkurve, V.; Wong, P.; Halpenny, D.; Reddy, S.K.; Vado, K.; McCabe, D.; et al. A Prospective, Phase 1 Trial of Nivolumab, Ipilimumab, and Radiotherapy in Patients with Advanced Melanoma. Clin. Cancer Res. 2020, 26, 3193-3201. [CrossRef]

268. Sundahl, N.; Seremet, T.; van Dorpe, J.; Neyns, B.; Ferdinande, L.; Meireson, A.; Brochez, L.; Kruse, V.; Ost, P. Phase 2 Trial of Nivolumab Combined with Stereotactic Body Radiation Therapy in Patients with Metastatic or Locally Advanced Inoperable Melanoma. Int. J. Radiat. Oncol. Biol. Phys. 2019, 104, 828-835. [CrossRef]

269. McBride, S.; Sherman, E.; Tsai, C.J.; Baxi, S.; Aghalar, J.; Eng, J.; Zhi, W.I.; McFarland, D.; Michel, L.S.; Young, R.; et al. Randomized Phase II Trial of Nivolumab with Stereotactic Body Radiotherapy Versus Nivolumab Alone in Metastatic Head and Neck Squamous Cell Carcinoma. J. Clin. Oncol. 2021, 39, 30-37. [CrossRef]

270. University College, London, Merck Sharp \& Dohme Corp. A Trial Assessing the Effect of Pembrolizumab Combined with Radiotherapy in Patients with Relapsed, Refractory, Specified Stages of Cutaneous T-Cell Lymphoma (CTCL) Mycosis Fungoides (MF)/Sezary Syndrome (SS): NCT03385226, UCL/17/0053. Available online: https:/ / clinicaltrials.gov/show/NCT03385226 (accessed on 13 May 2021).

271. Emory University I Merck Sharp \& Dohme Corp. Pembrolizumab and Stereotactic Radiosurgery for Melanoma or Non-Small Cell Lung Cancer Brain Metastases: NCT02858869, IRB00086461 | NCI-2016-00718 | RAD3179-16. Available online: https:/ / clinicaltrials.gov/show/NCT02858869 (accessed on 13 May 2021).

272. City of Hope Medical Center I National Cancer Institute (NCI). Pembrolizumab and Palliative Radiation Therapy in Treating Patients with Metastatic Esophagus, Stomach, or Gastroesophageal Junction Cancer: NCT02830594, 16099 I NCI-2016-00686. Available online: https: / / clinicaltrials.gov/show / NCT02830594 (accessed on 13 May 2021).

273. University of Erlangen-Nürnberg Medical School. Investigation of the Timely-Coordinated Therapy of Patients with Metastatic Cancer by Radiotherapy Together with Immune Checkpoint Inhibition: NCT03453892, ST-ICI. Available online: https:// clinicaltrials.gov/show / NCT03453892 (accessed on 13 May 2021).

274. University Health Network, Toronto. Immunotherapy and Palliative Radiotherapy Combined in Patients with Advanced Malignancy: NCT03042156, 16-6189. Available online: https:/ / clinicaltrials.gov/show / NCT03042156 (accessed on 13 May 2021).

275. Giuliani, J.; Fiorica, F. Cost-effectiveness of immune checkpoint inhibitors and radiotherapy in advanced non-small cell lung cancer. J. Oncol. Pharm. Pract. 2021, 10781552211038925. [CrossRef] 
276. Golubnitschaja, O.; Topolcan, O.; Kucera, R.; Costigliola, V. 10th Anniversary of the European Association for Predictive, Preventive and Personalised (3P) Medicine-EPMA World Congress Supplement 2020. EPMA J. 2020, 5, 6. [CrossRef] [PubMed]

277. Goldstein, E.; Yeghiazaryan, K.; Ahmad, A.; Giordano, F.A.; Fröhlich, H.; Golubnitschaja, O. Optimal multiparametric set-up modelled for best survival outcomes in palliative treatment of liver malignancies: Unsupervised machine learning and 3 PM recommendations. EPMA J. 2020, 11, 505-515. [CrossRef] [PubMed]

278. Kucera, R.; Pecen, L.; Topolcan, O.; Dahal, A.R.; Costigliola, V.; Giordano, F.A.; Golubnitschaja, O. Prostate cancer management: Long-term beliefs, epidemic developments in the early twenty-first century and 3PM dimensional solutions. EPMA J. 2020, 11, 399-418. [CrossRef]

279. Liskova, A.; Samec, M.; Koklesova, L.; Giordano, F.A.; Kubatka, P.; Golubnitschaja, O. Liquid Biopsy is Instrumental for 3PM Dimensional Solutions in Cancer Management. J. Clin. Med. 2020, 9, 2749. [CrossRef] [PubMed]

280. Gerner, C.; Costigliola, V.; Golubnitschaja, O. Multiomic patterns in body fluids: Technological challenge with a great potential to implement the advanced paradigm of 3P medicine. Mass Spectrom. Rev. 2020, 39, 442-451. [CrossRef] [PubMed] 